\title{
Copper-Catalyzed Addition of H-P(O) Bonds to Arynes
}

\author{
Qian Chen,* Xinxing Yan, Chunxiao Wen, Jiekun Zeng, Yulin Huang, Xingguo Liu, \\ and Kun Zhang
}

School of Chemical Engineering and Light Industry, Guangdong University of Technology, Guangzhou, Guangdong 510006, China

*E-mail: qianchen@gdut.edu.cn

\section{SUPPORTING INFORMATION}

\section{Content:}

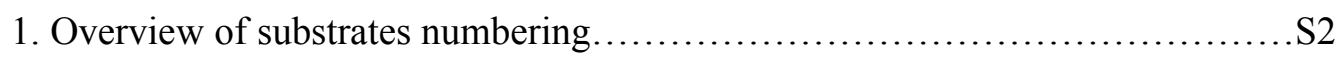

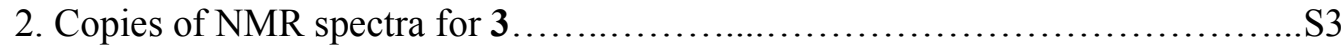




\section{Overview of substrates numbering}

\section{Aryne precursors:}

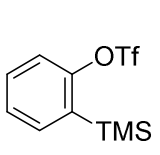

$1 \mathbf{a}$

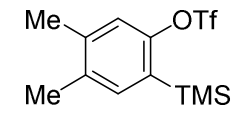

$1 \mathrm{~b}$
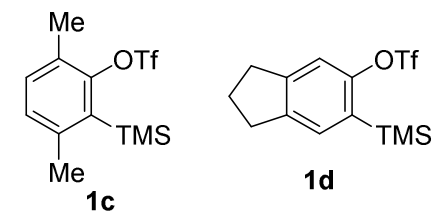

1d

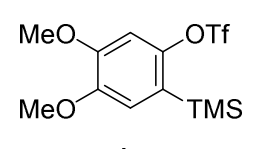

1e

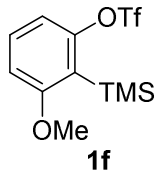

$\overbrace{1 \mathrm{TMS}}^{\mathrm{OTf}}$

Secondary phosphine oxides:

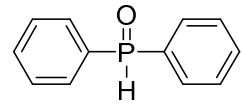

$2 a$
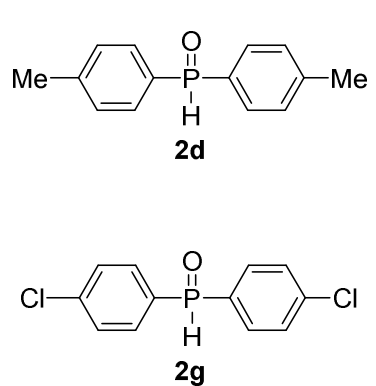

$2 \mathrm{~g}$

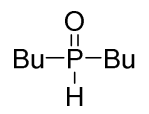

2j

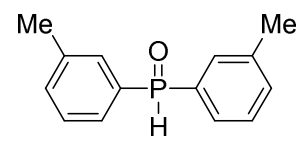

2b
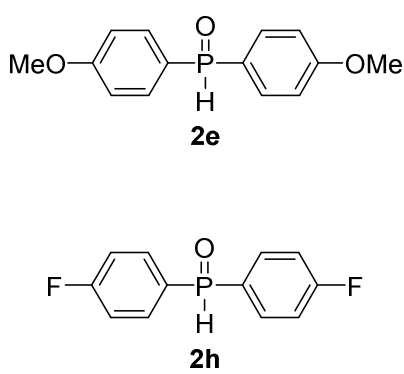

2h

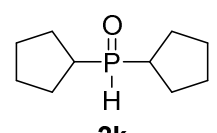

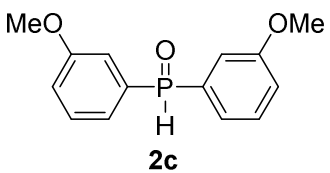
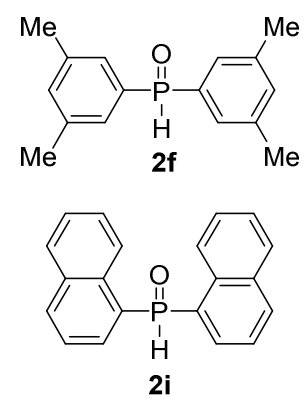


\section{Copies of NMR spectra for 3}

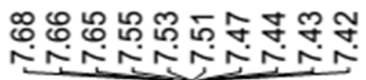
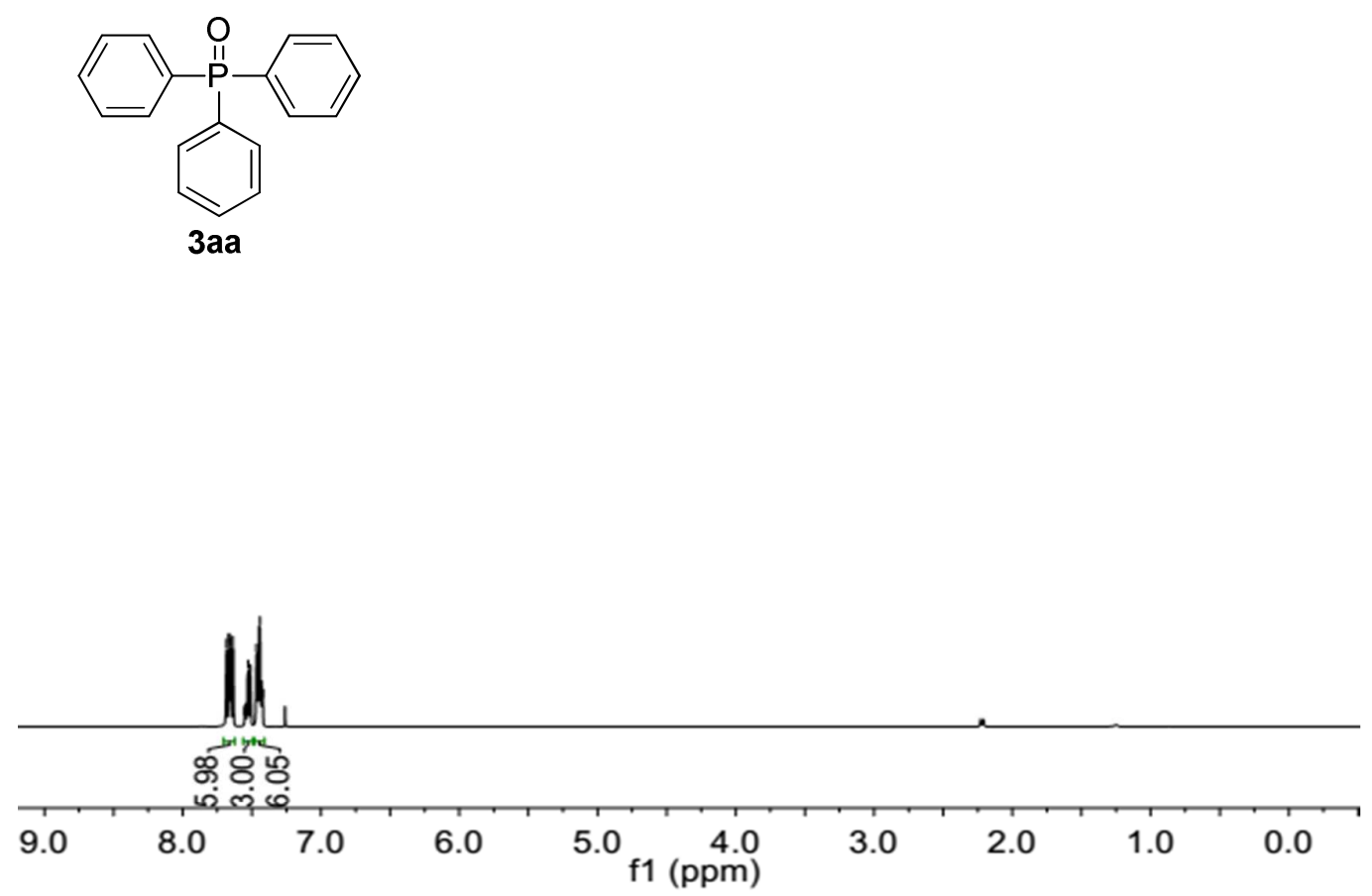

융요잉

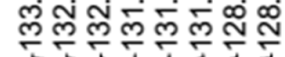

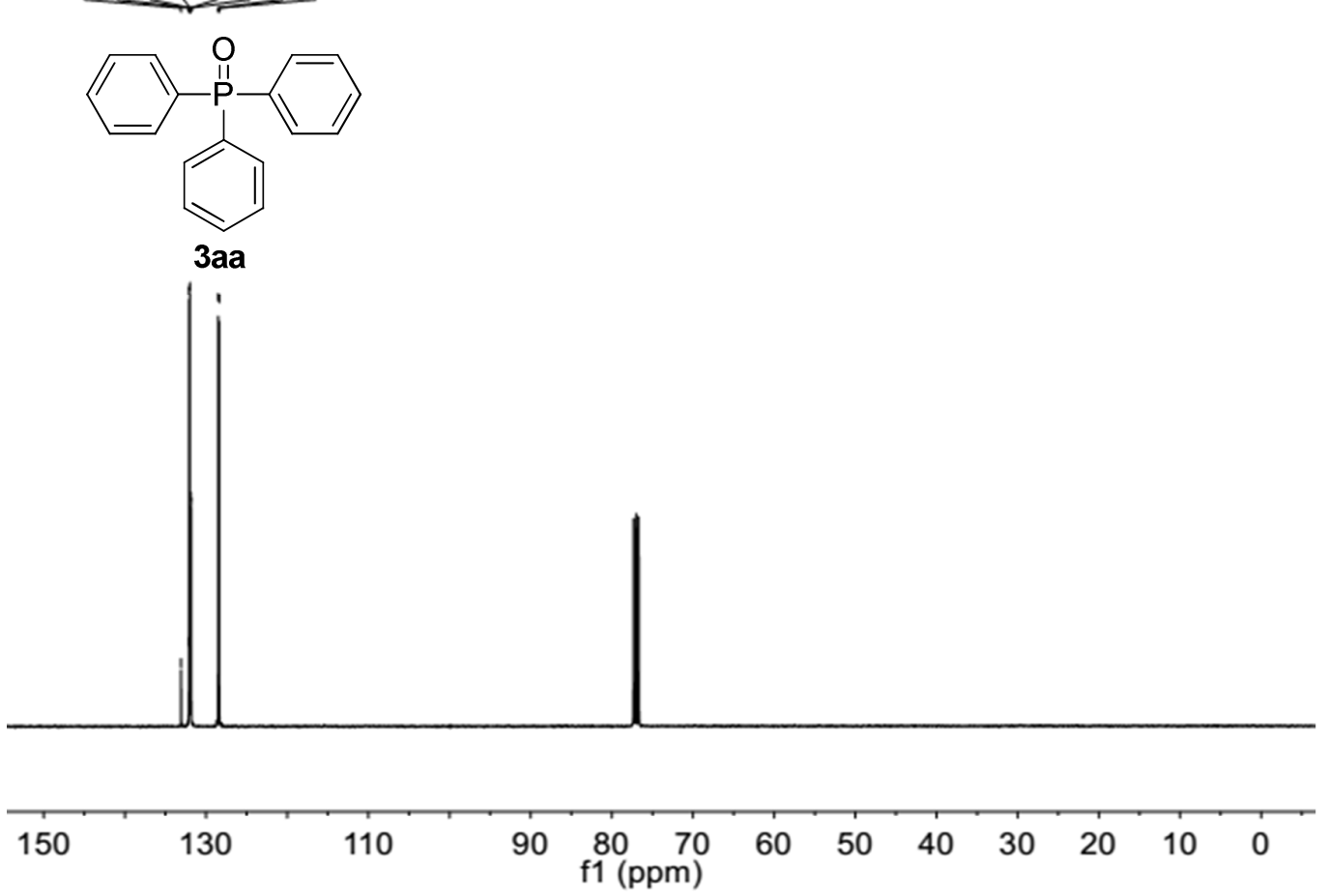




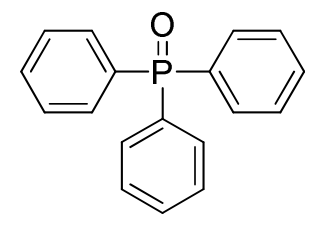

3aa

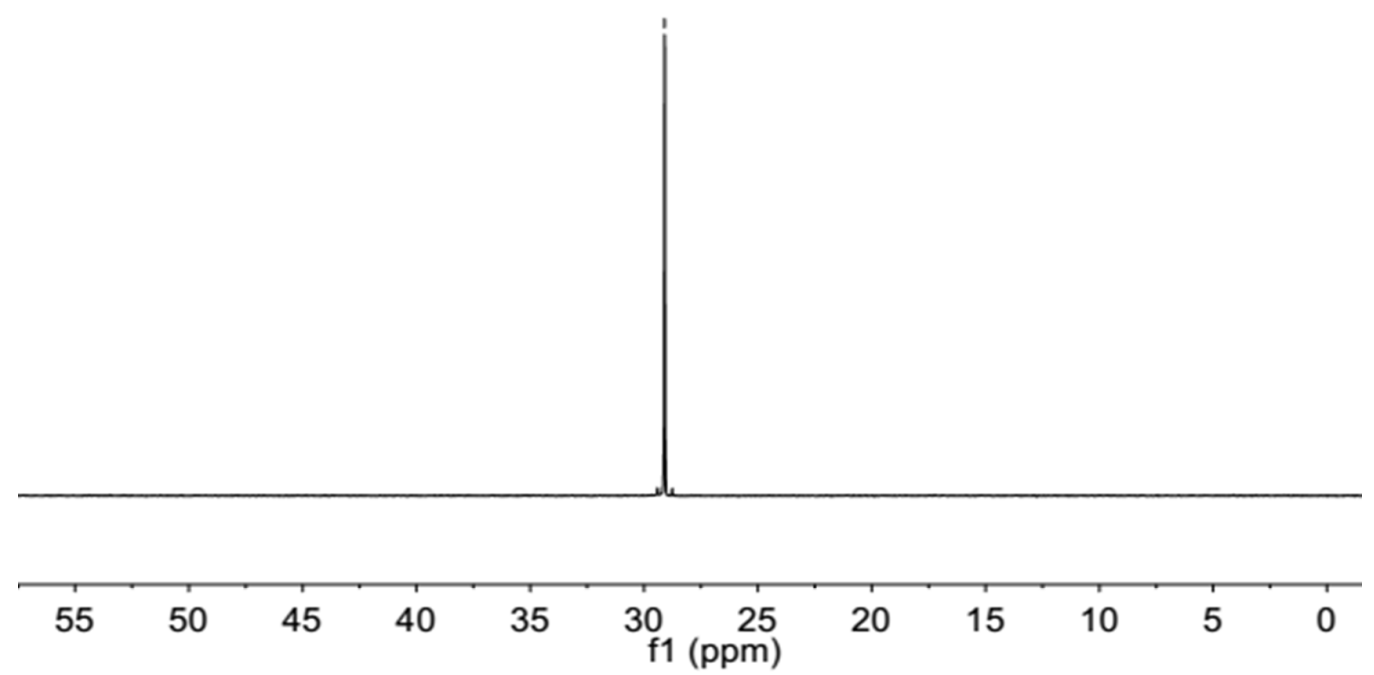

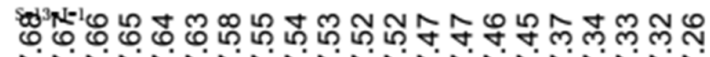

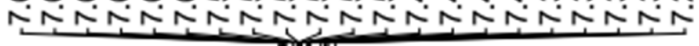<smiles>Cc1cccc(P(=O)(c2ccccc2)c2cccc(C)c2)c1</smiles>

$3 a b$

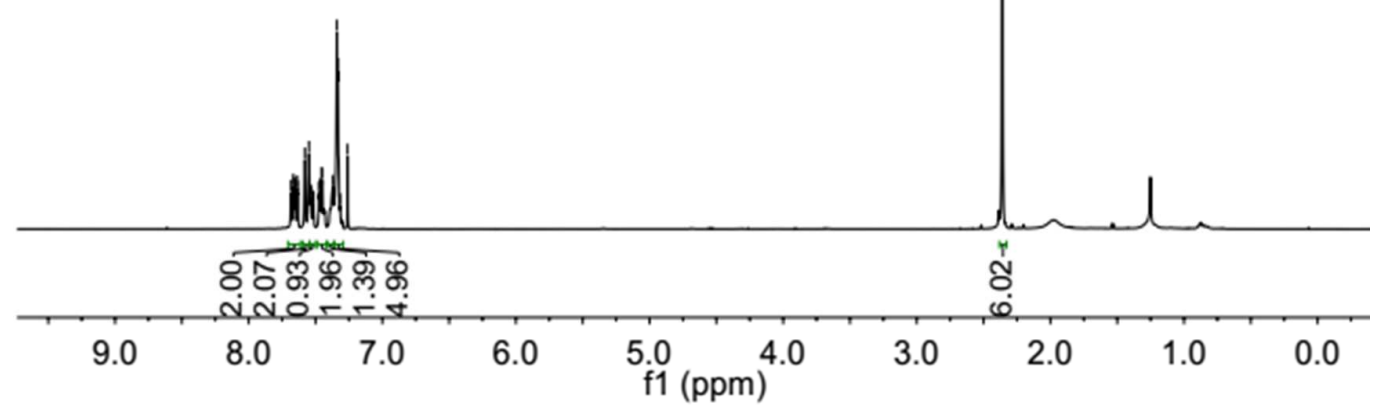



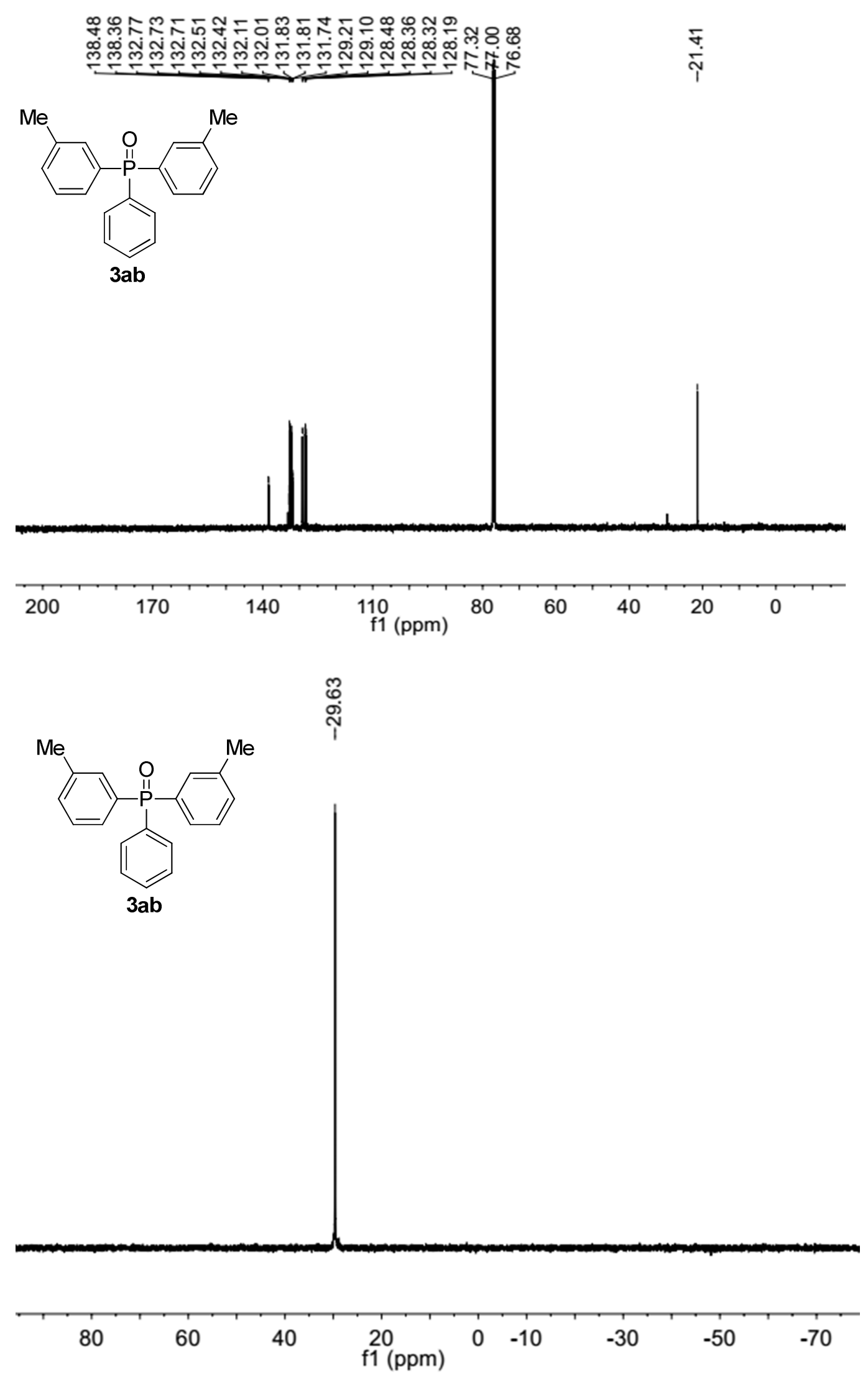


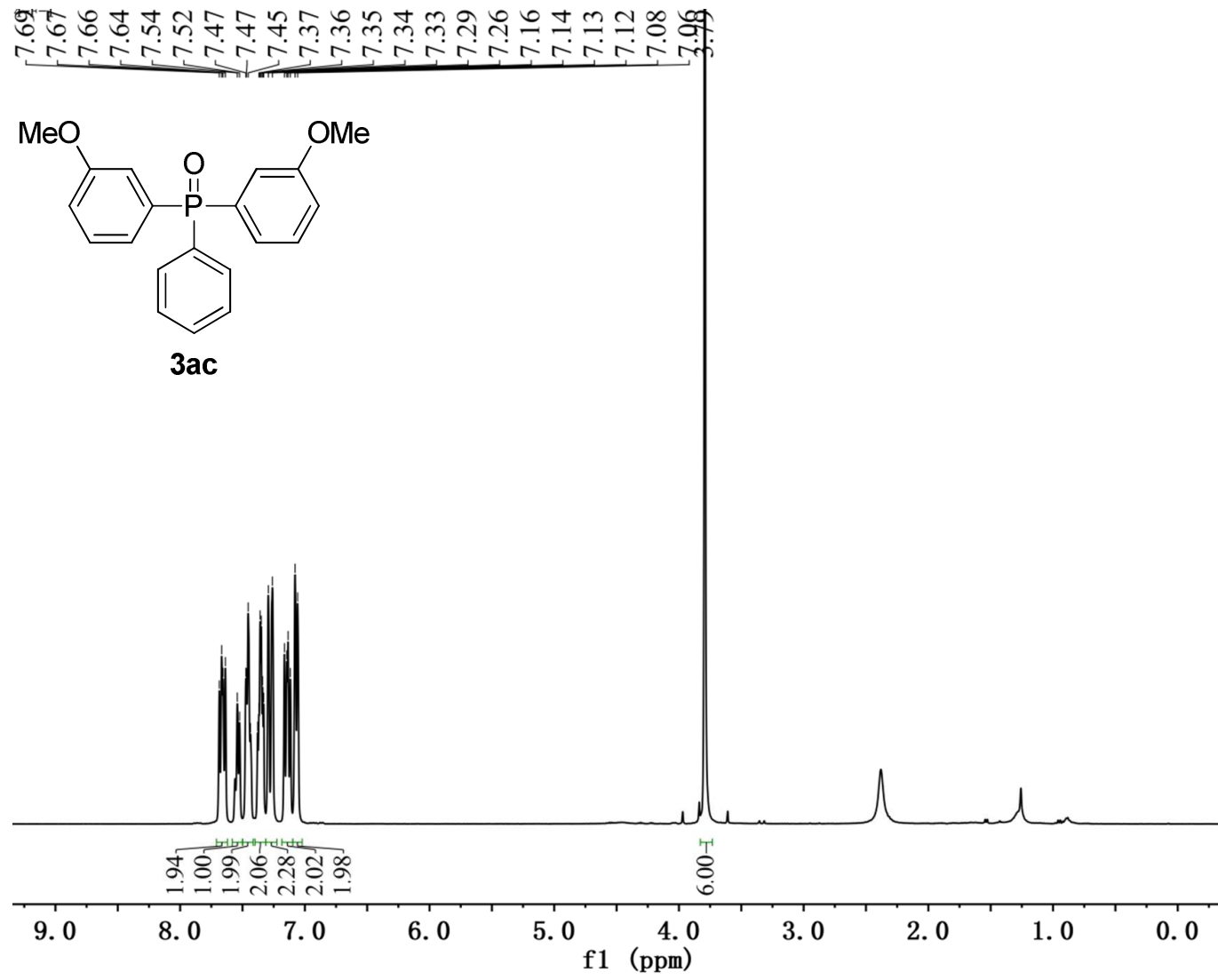

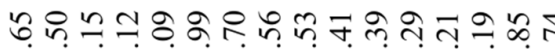

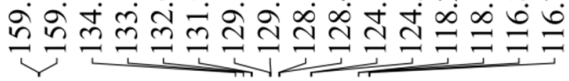<smiles>COc1cccc(P(=O)(c2ccccc2)c2cccc(OC)c2)c1</smiles>
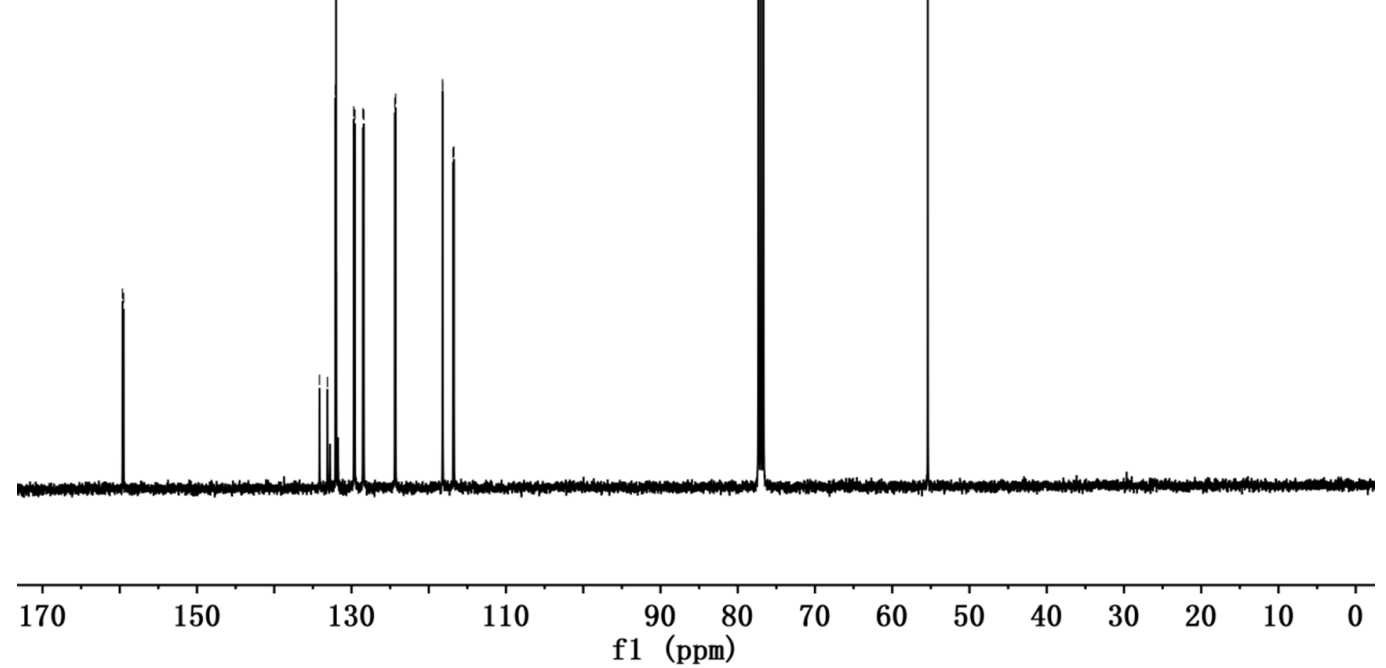


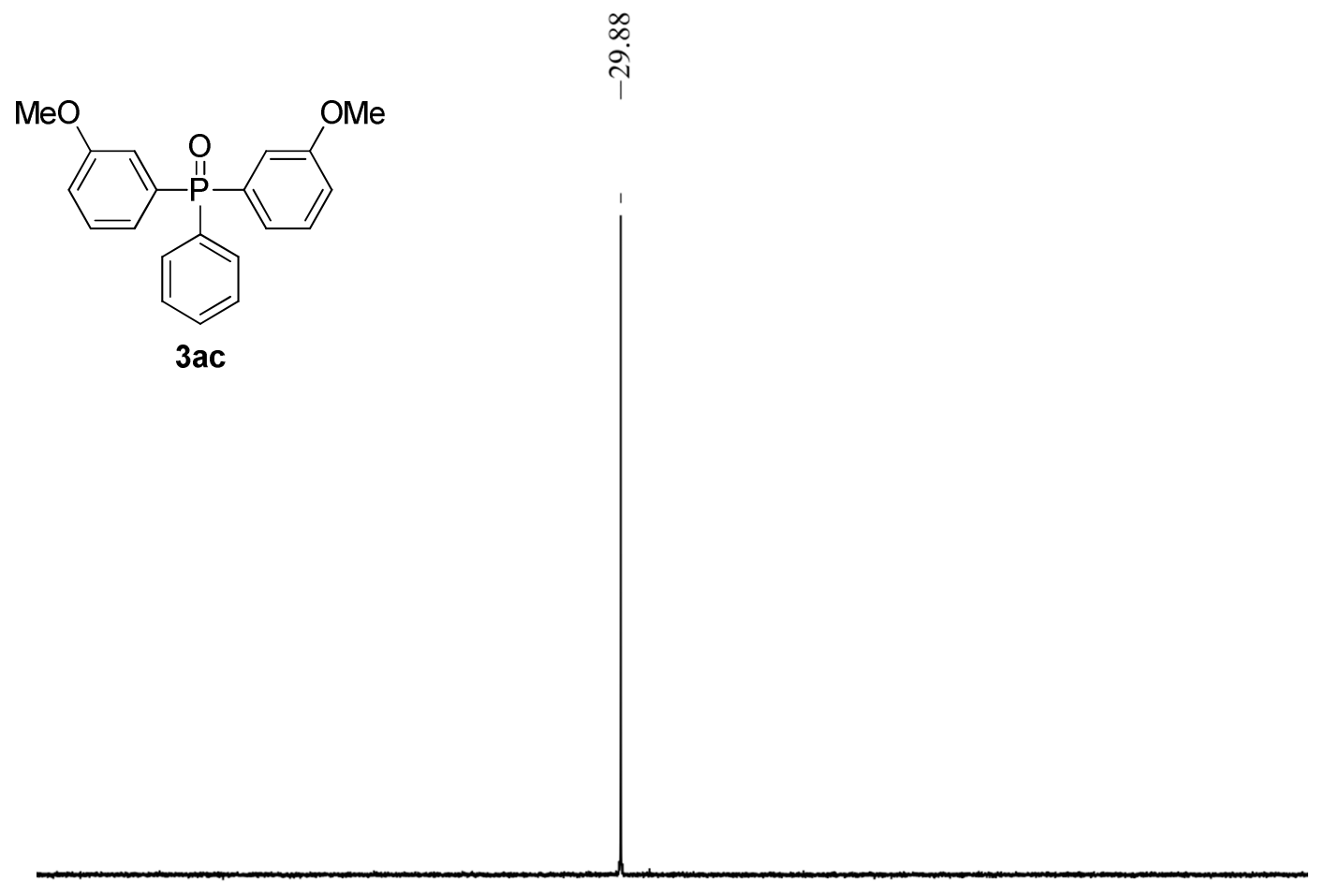

\begin{tabular}{|c|c|c|c|c|c|c|c|c|c|c|}
\hline 120 & 100 & 80 & 60 & 40 & $\begin{array}{c}20 \\
(\mathrm{ppm})\end{array}$ & 0 & -20 & -40 & -60 & -80 \\
\hline
\end{tabular}

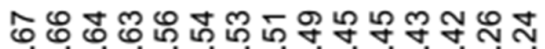

NNNNNNNNNNN

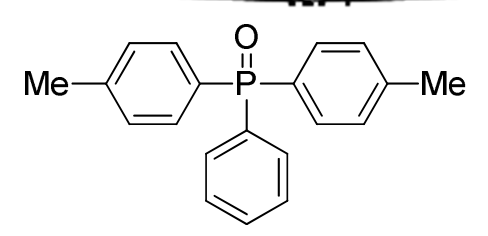

穴

3ad

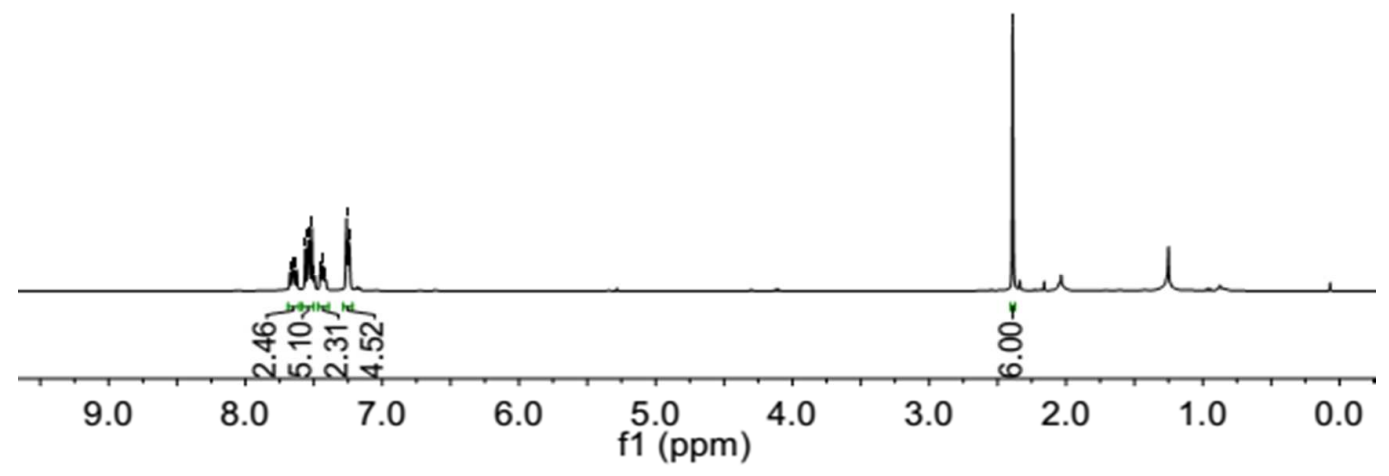



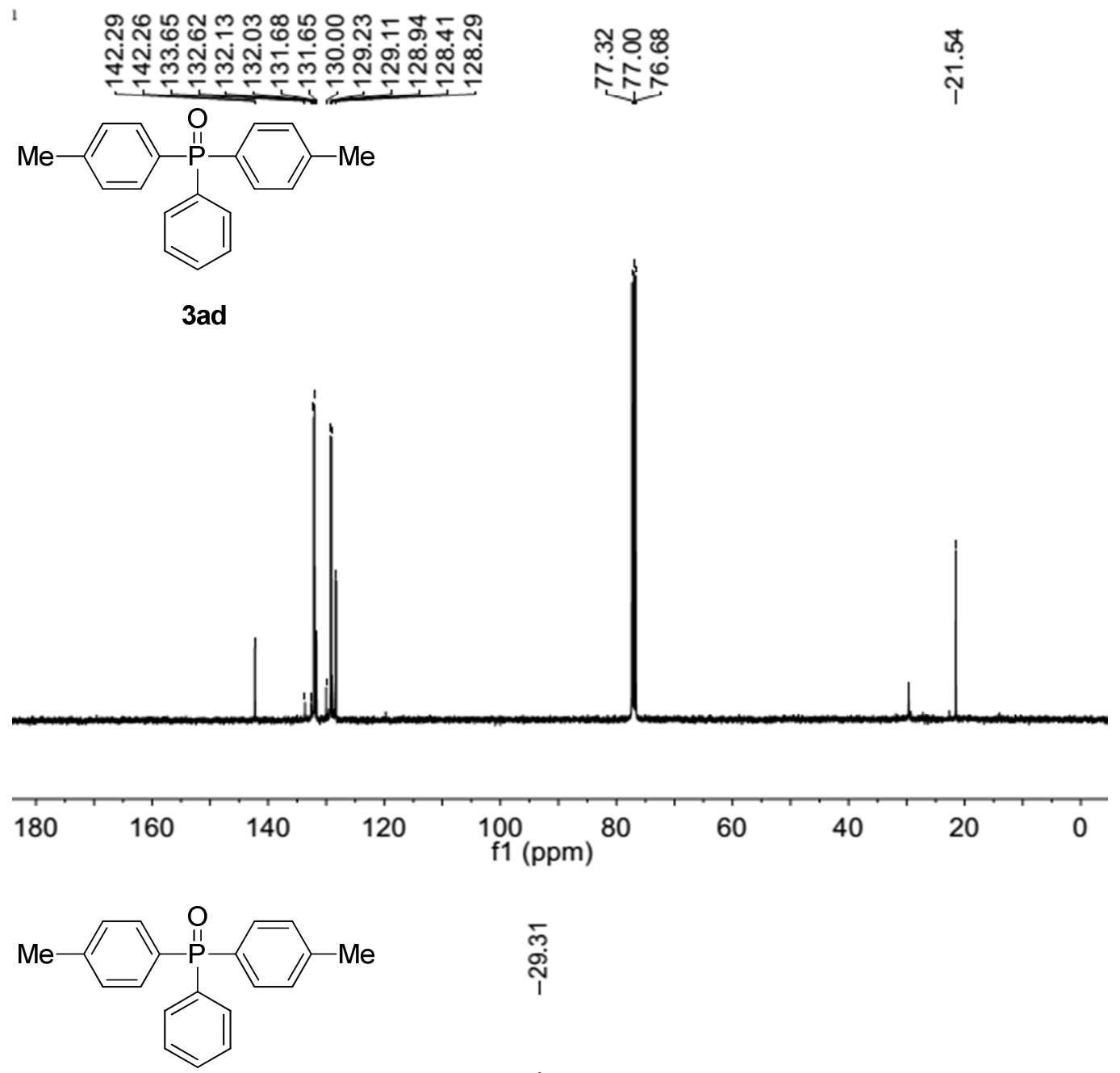

กั

3ad

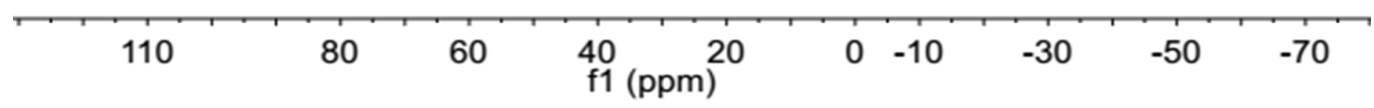




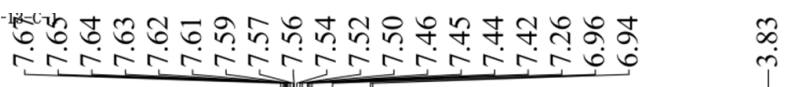<smiles>COc1ccc(P(=O)(c2ccccc2)c2ccc(OC)cc2)cc1</smiles>

3ae

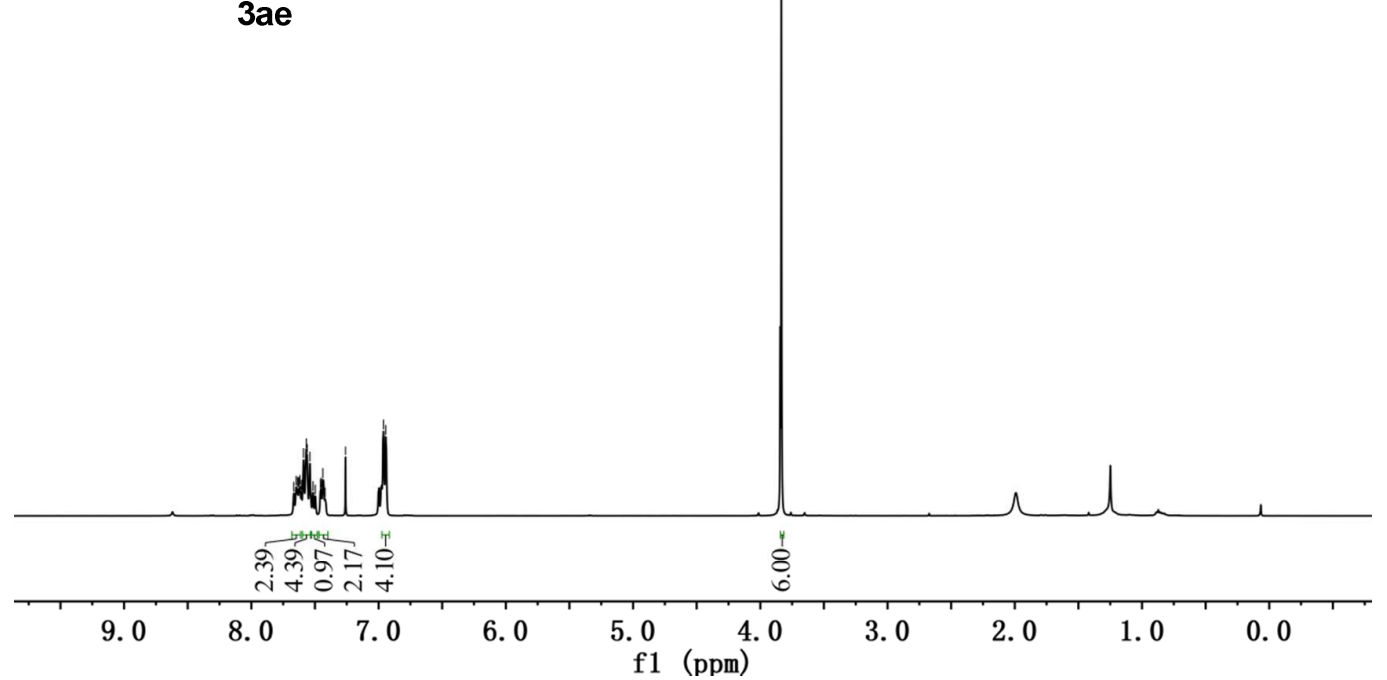

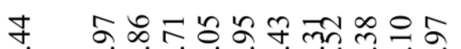

狩

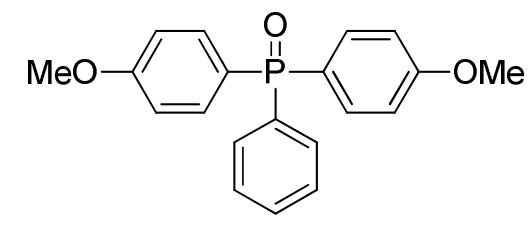

3ae
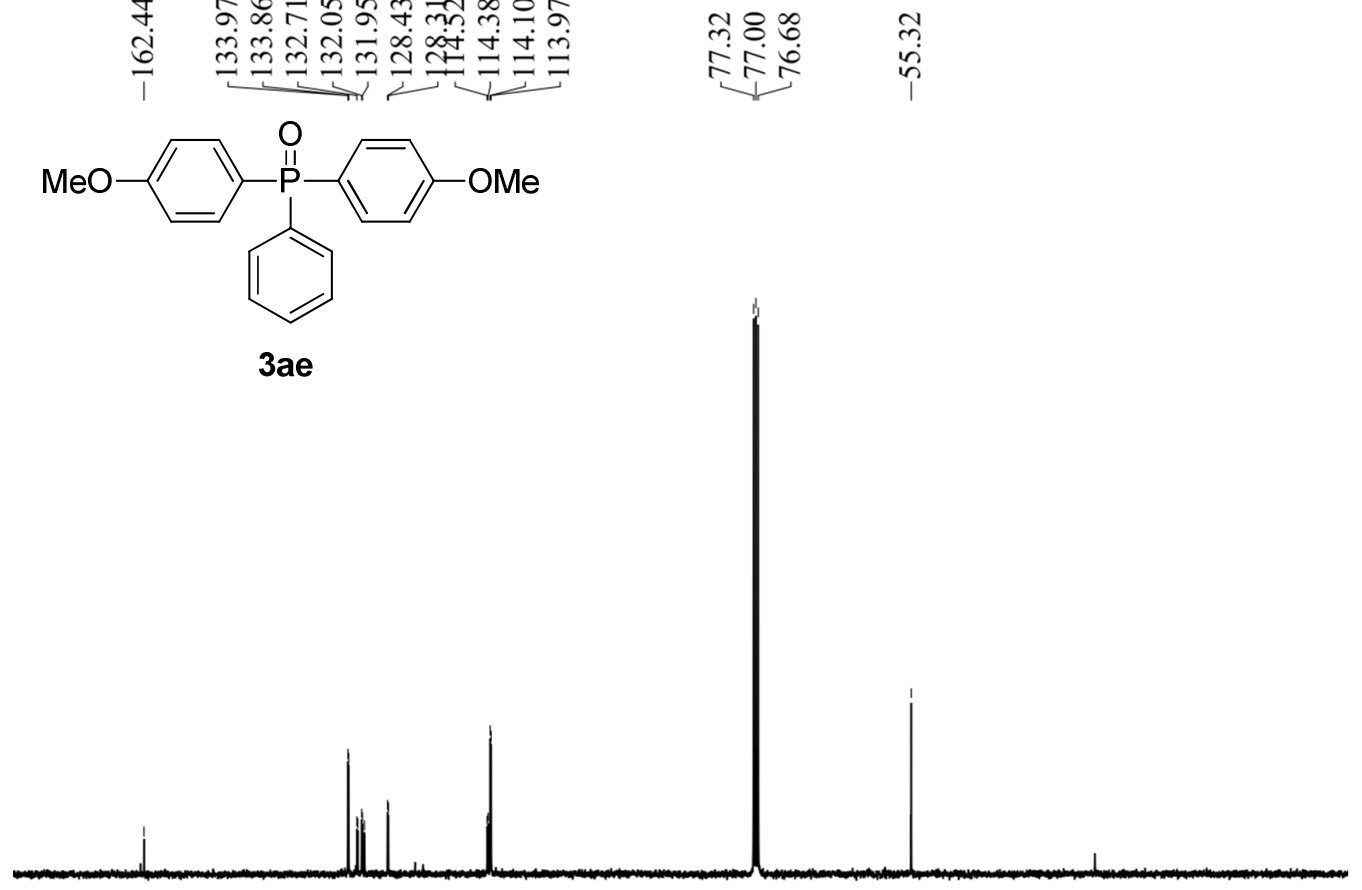

170

150

130

110

$\begin{array}{llllllllll}90 & 80 & 70 & 60 & 50 & 40 & 30 & 20 & 10 & 0\end{array}$ 


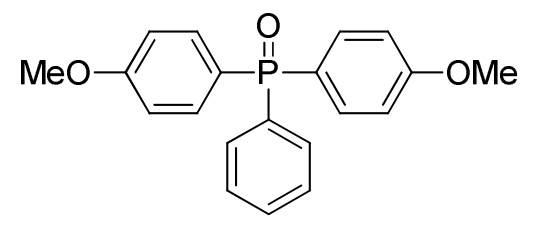

3ae

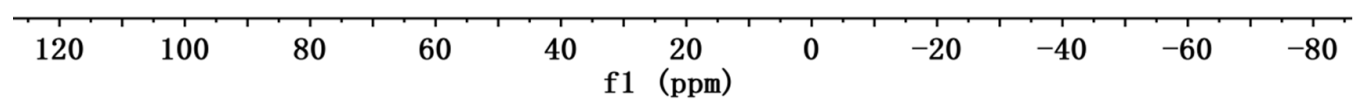

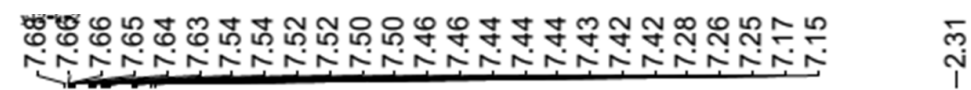
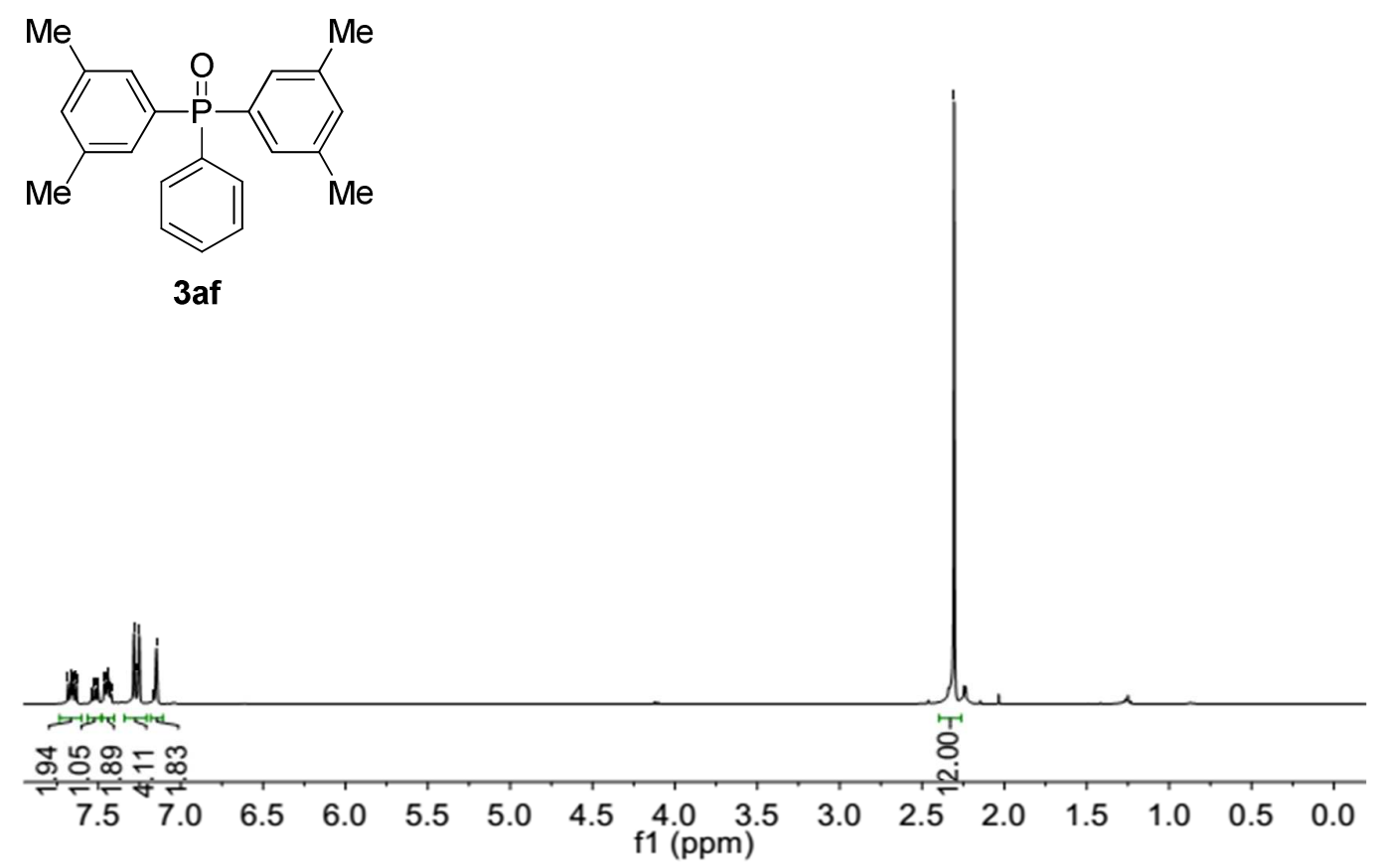

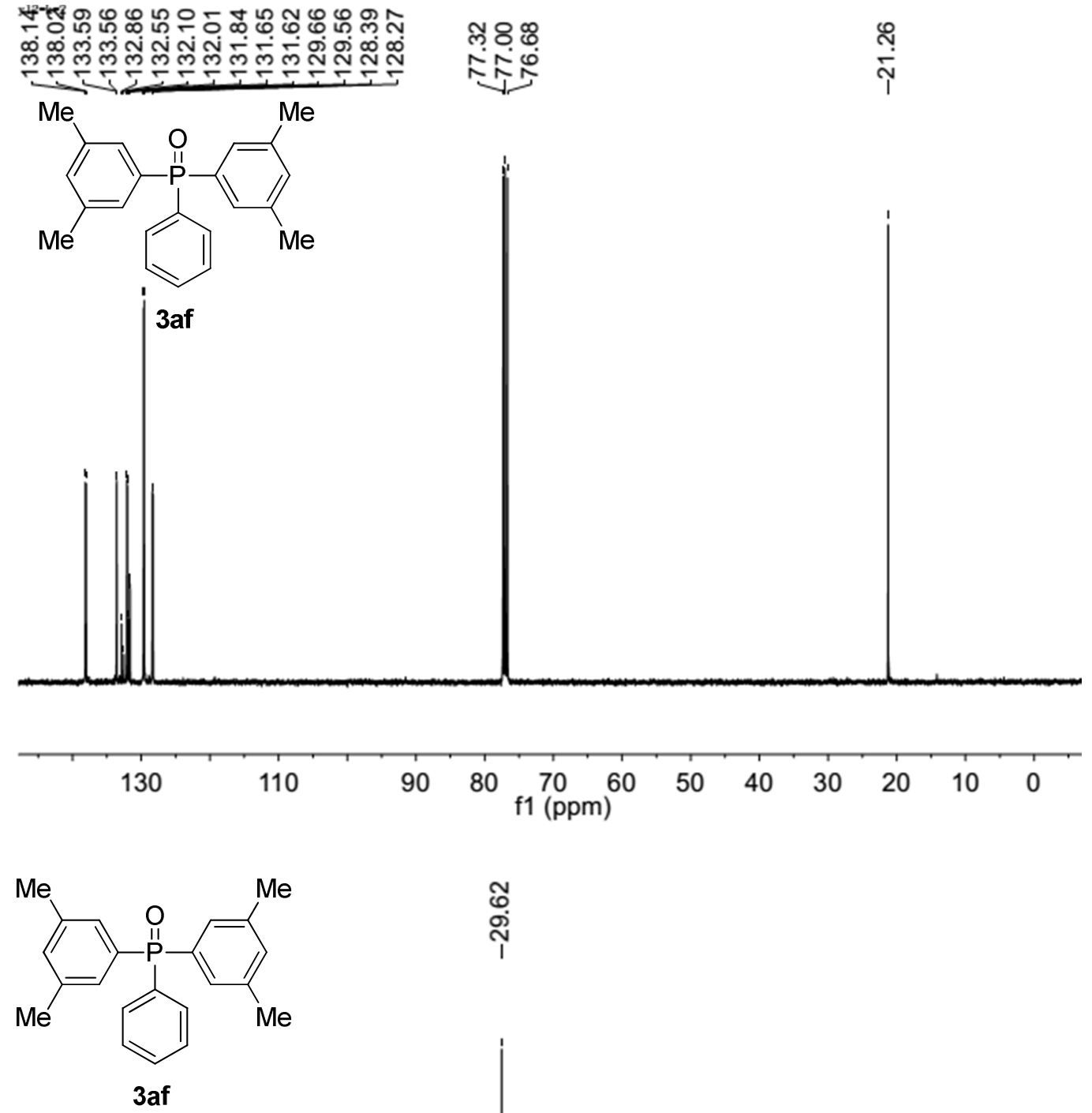

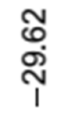

\begin{tabular}{|c|c|c|c|c|c|c|c|c|c|}
\hline 75 & 65 & 55 & 45 & $\begin{array}{l}35 \\
\mathrm{f1}(\mathrm{ppm})\end{array}$ & 15 & 5 & 0 & -5 & -20 \\
\hline
\end{tabular}




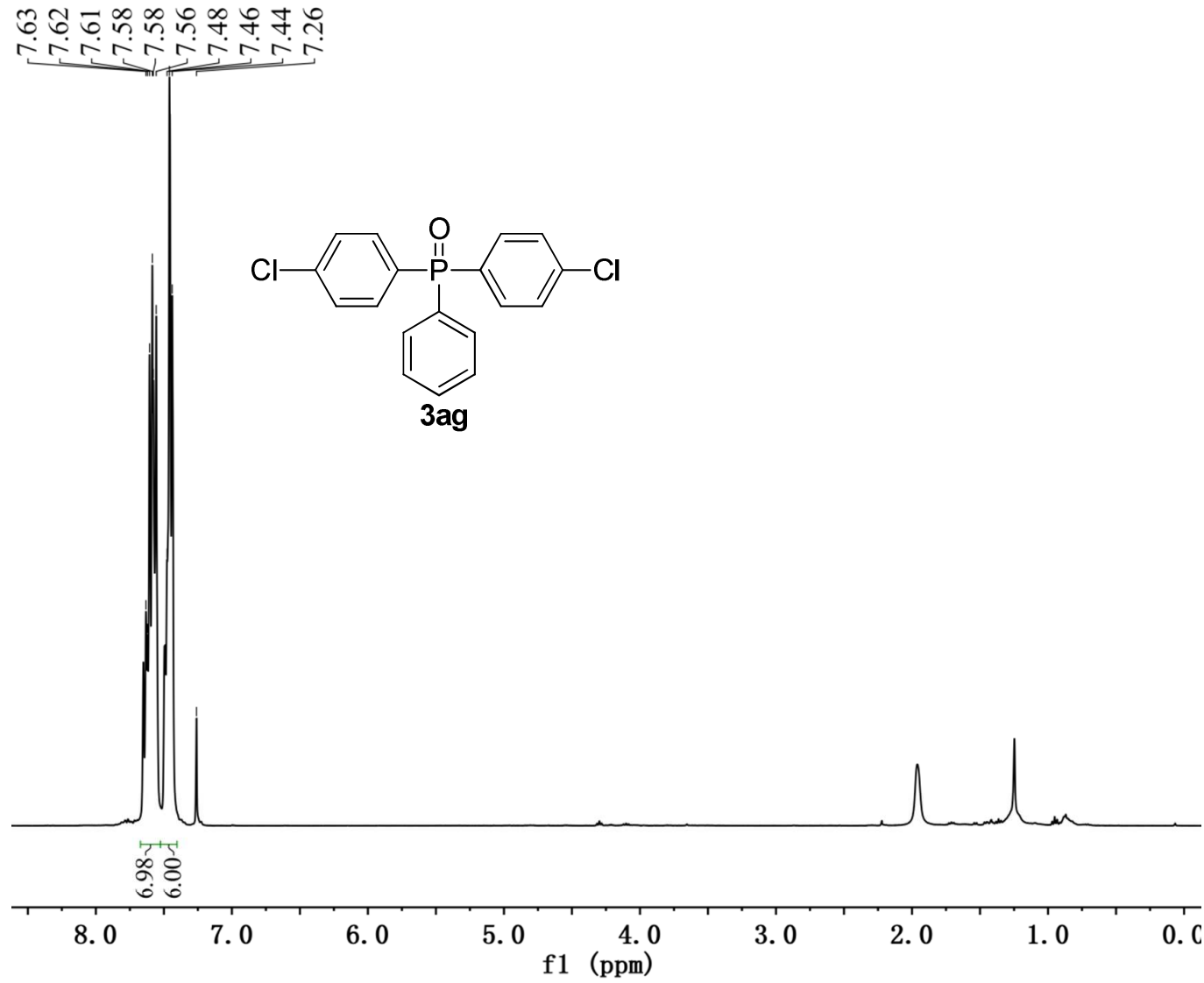

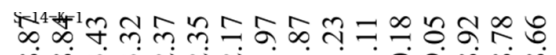

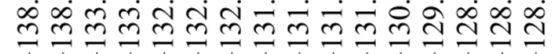
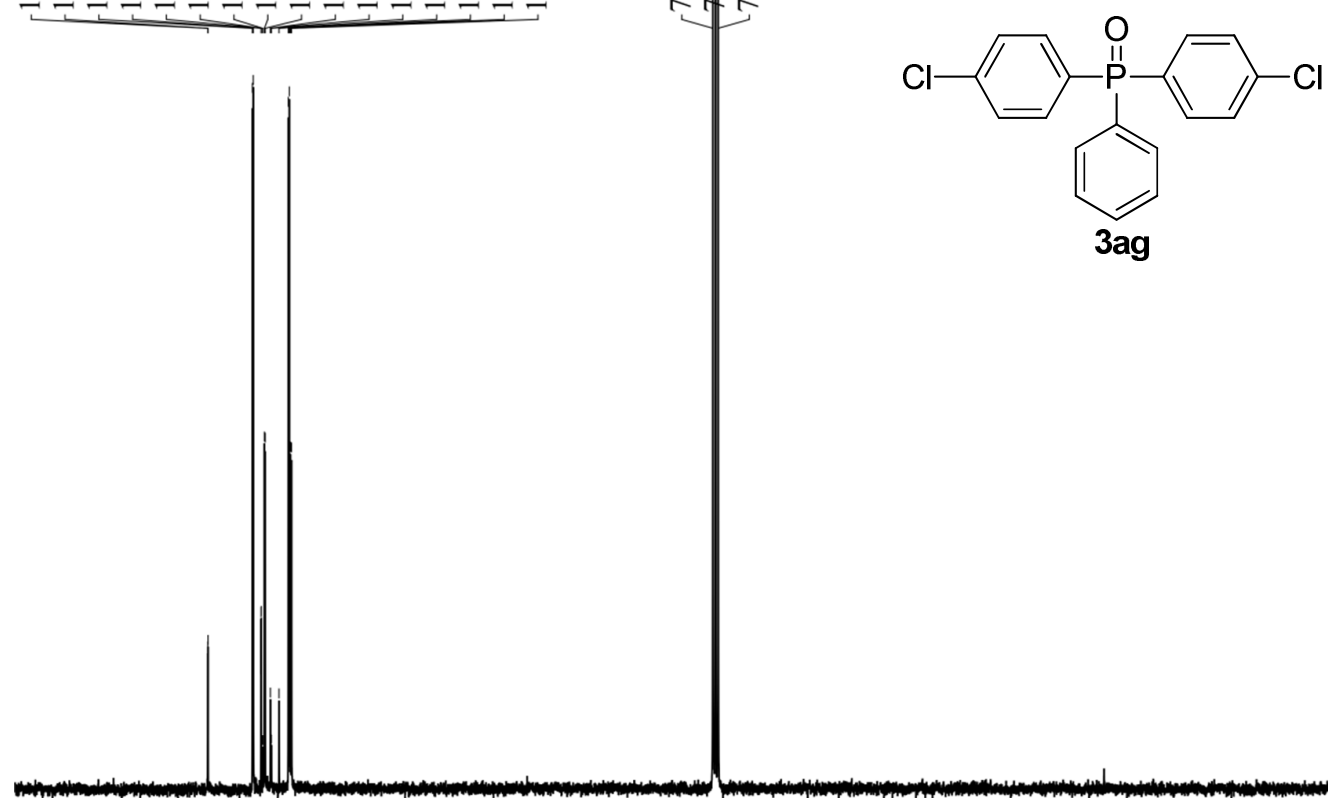

160

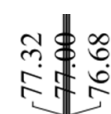

3ag

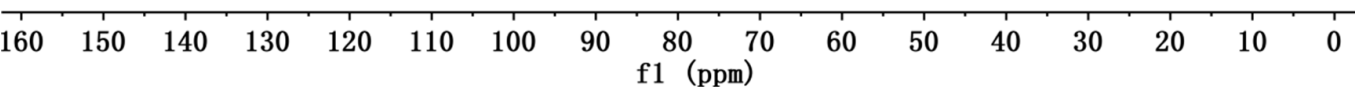




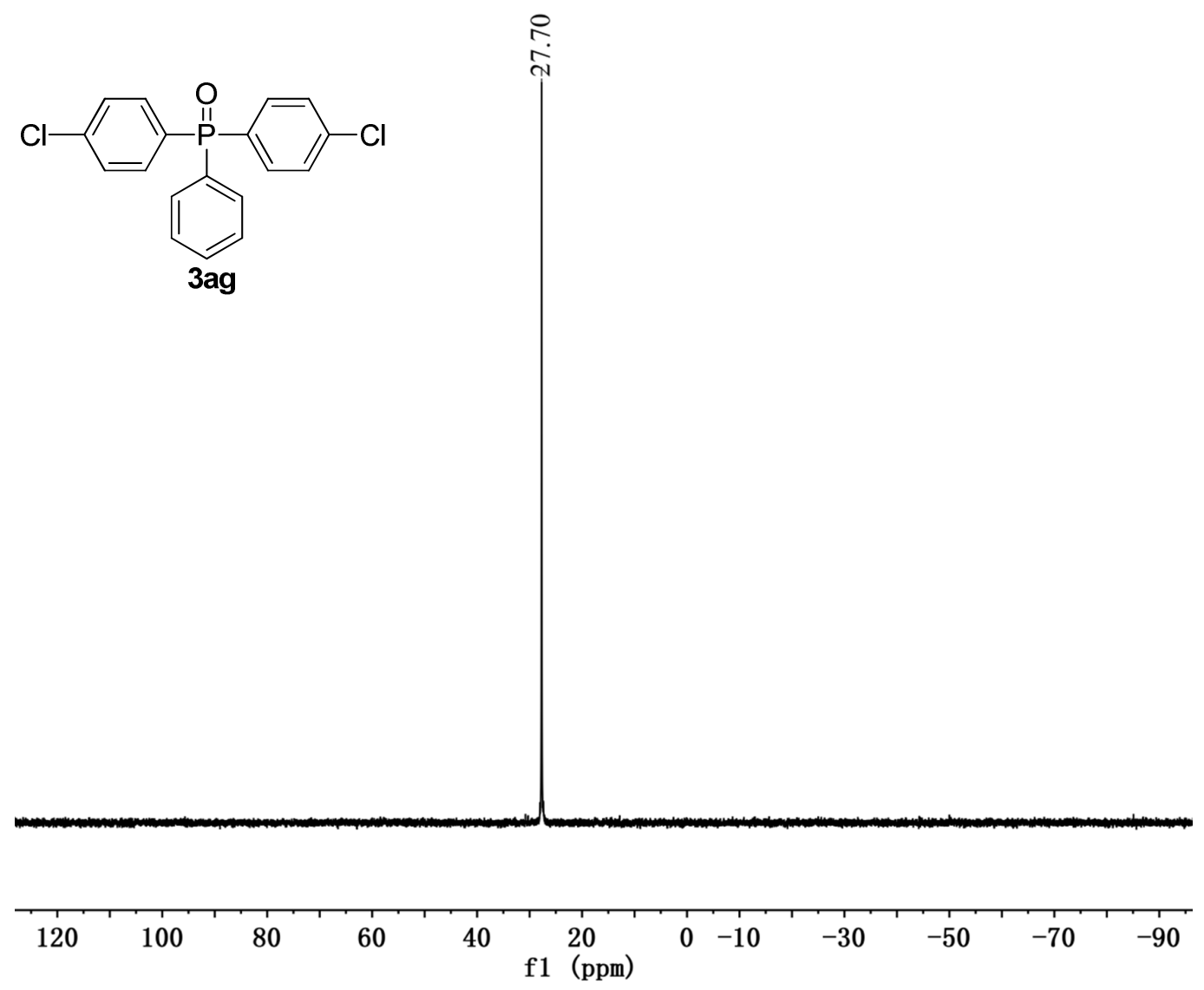

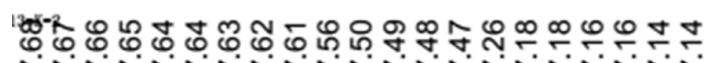

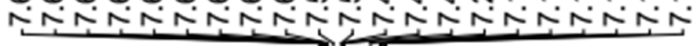

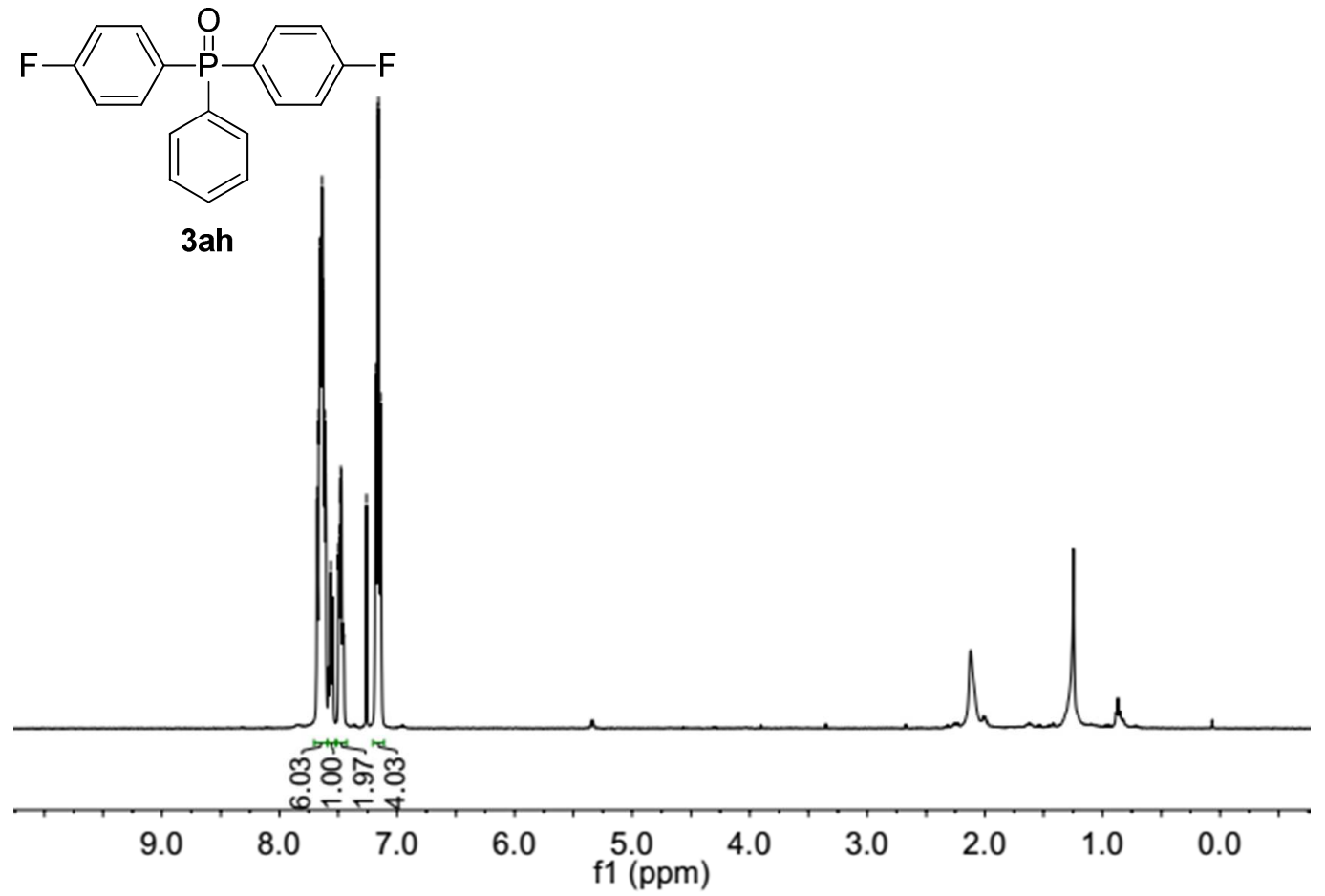




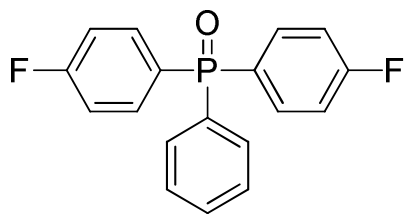

3ah
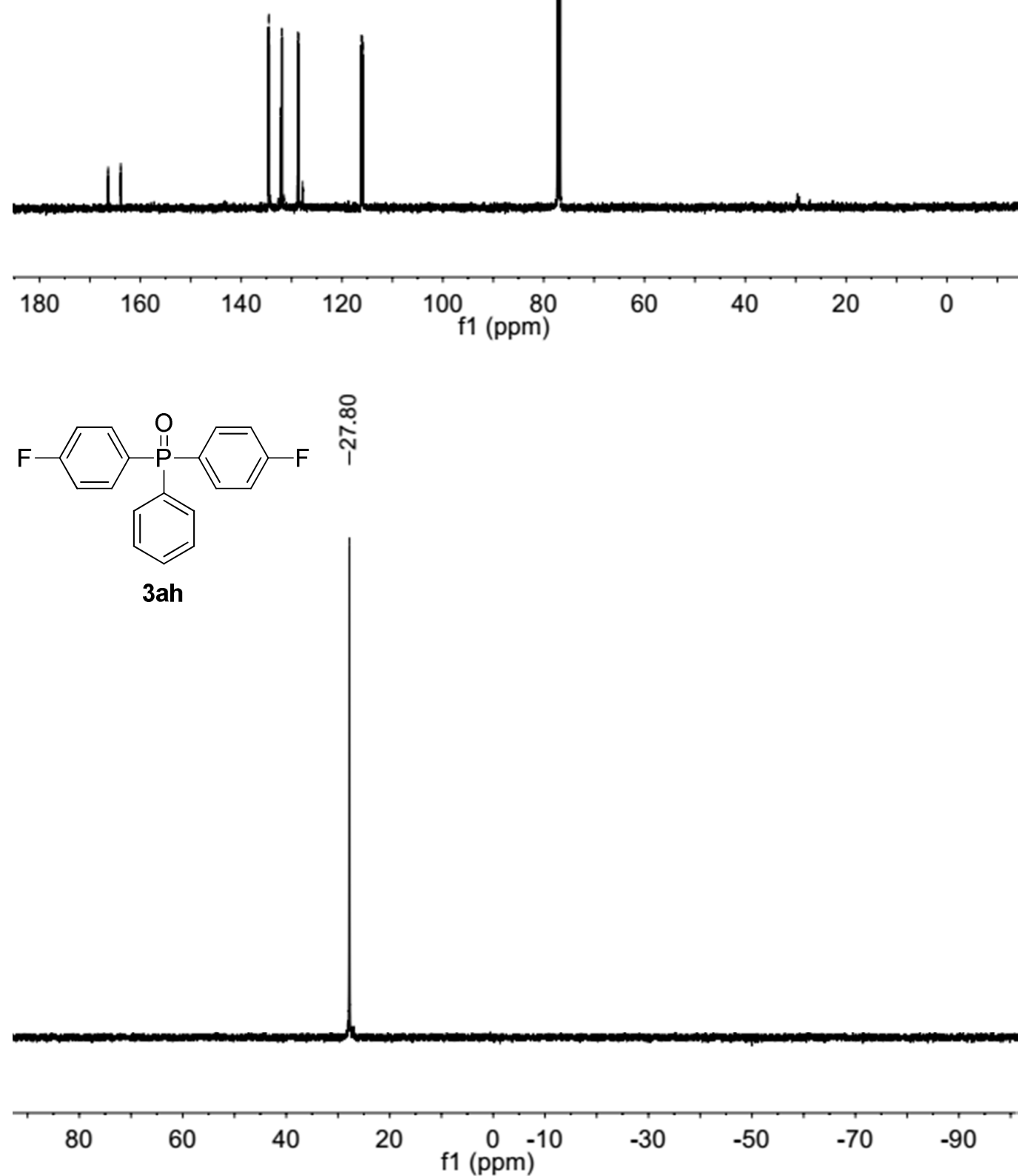


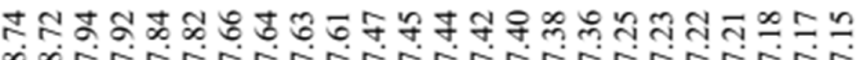

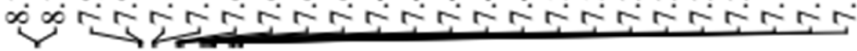

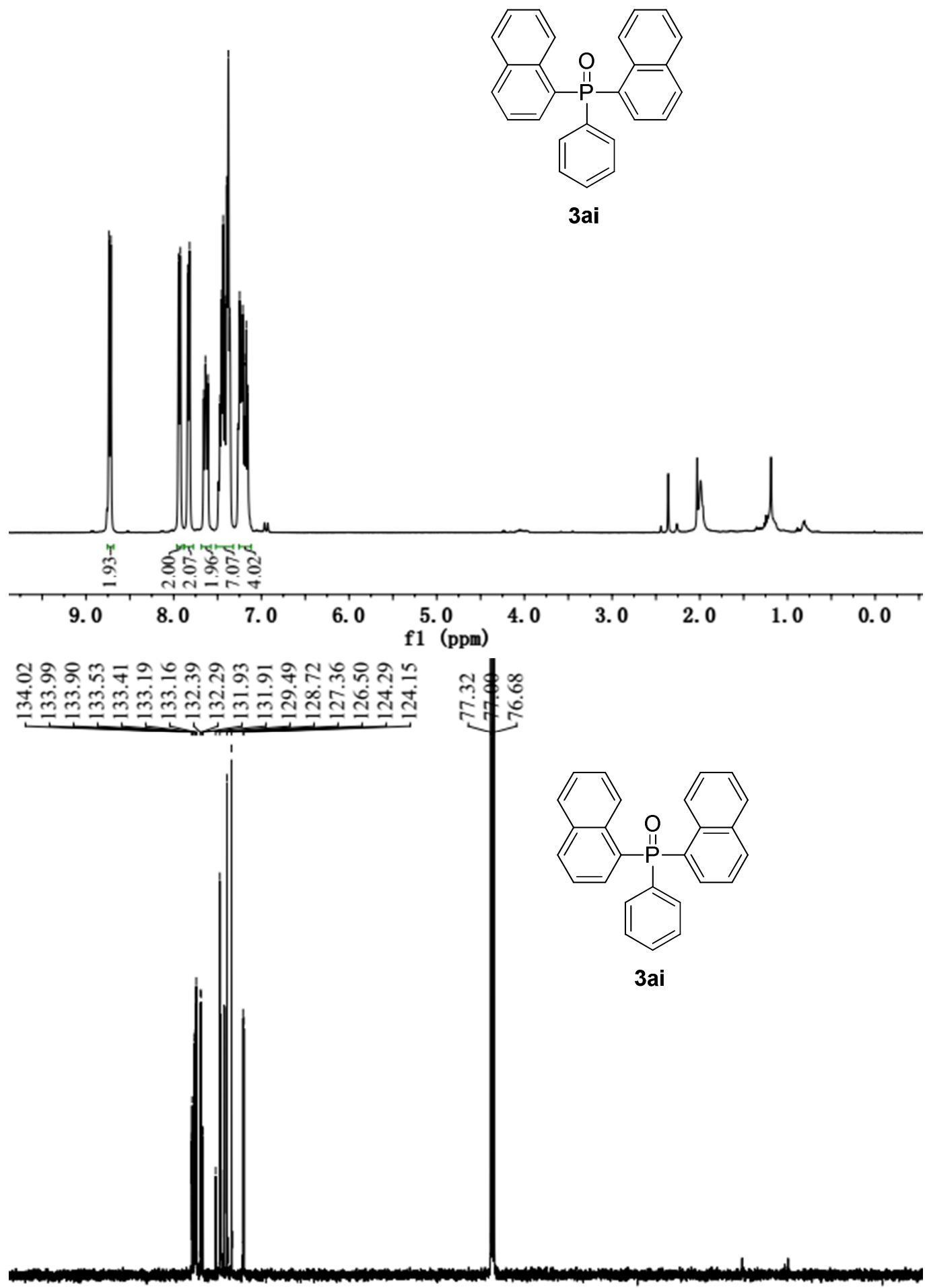

3ai

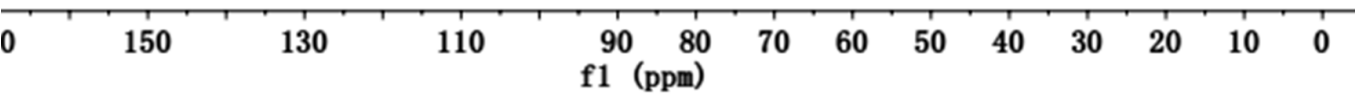




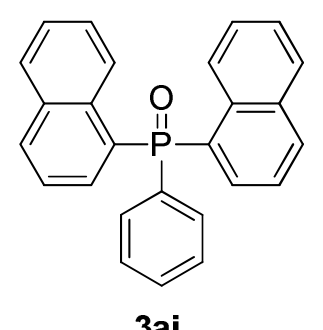

กี

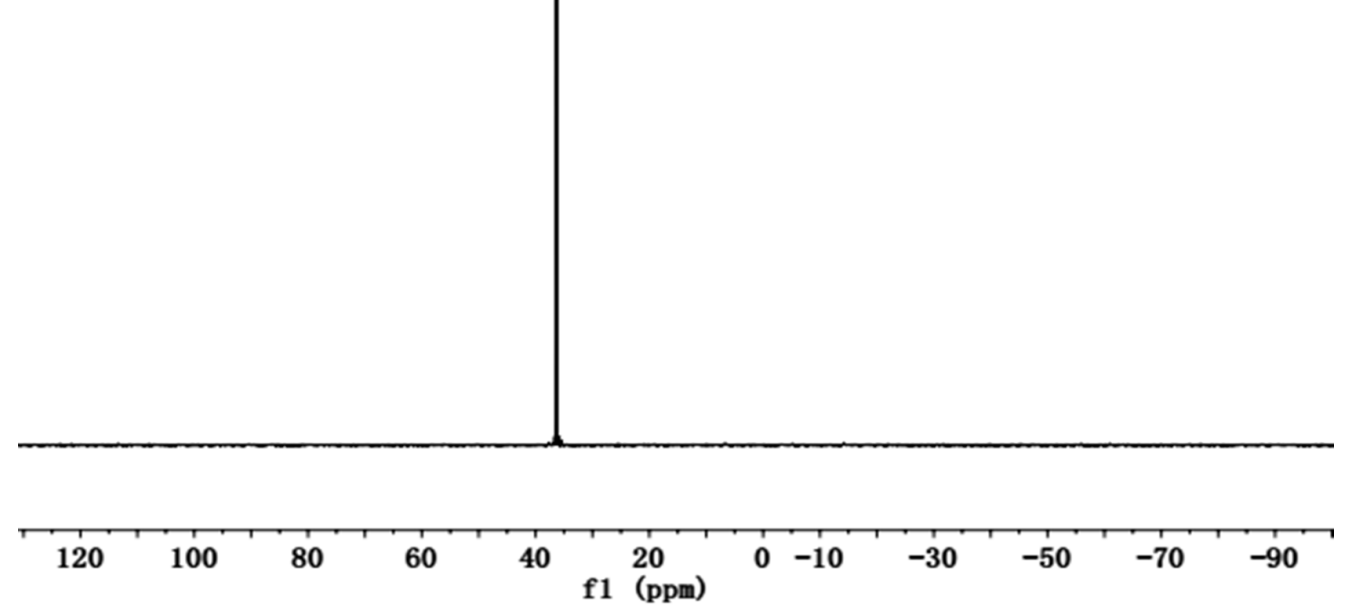

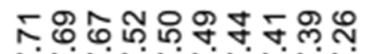

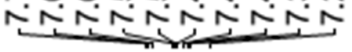

ర్లో

กู่نั<smiles>O=P(Br)(Br)c1ccccc1</smiles>

3aj

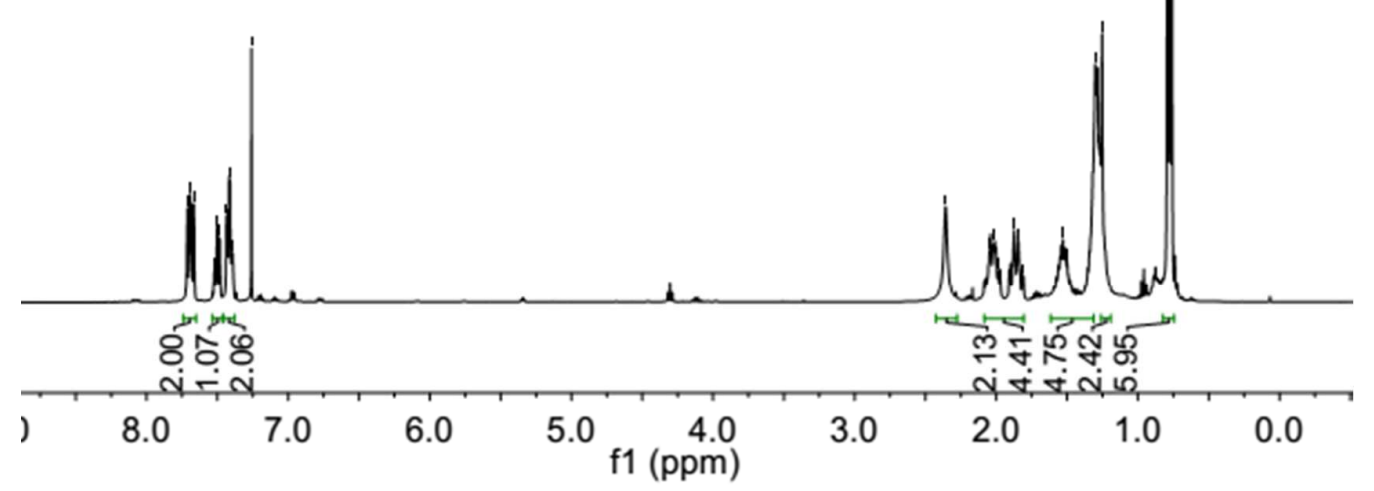




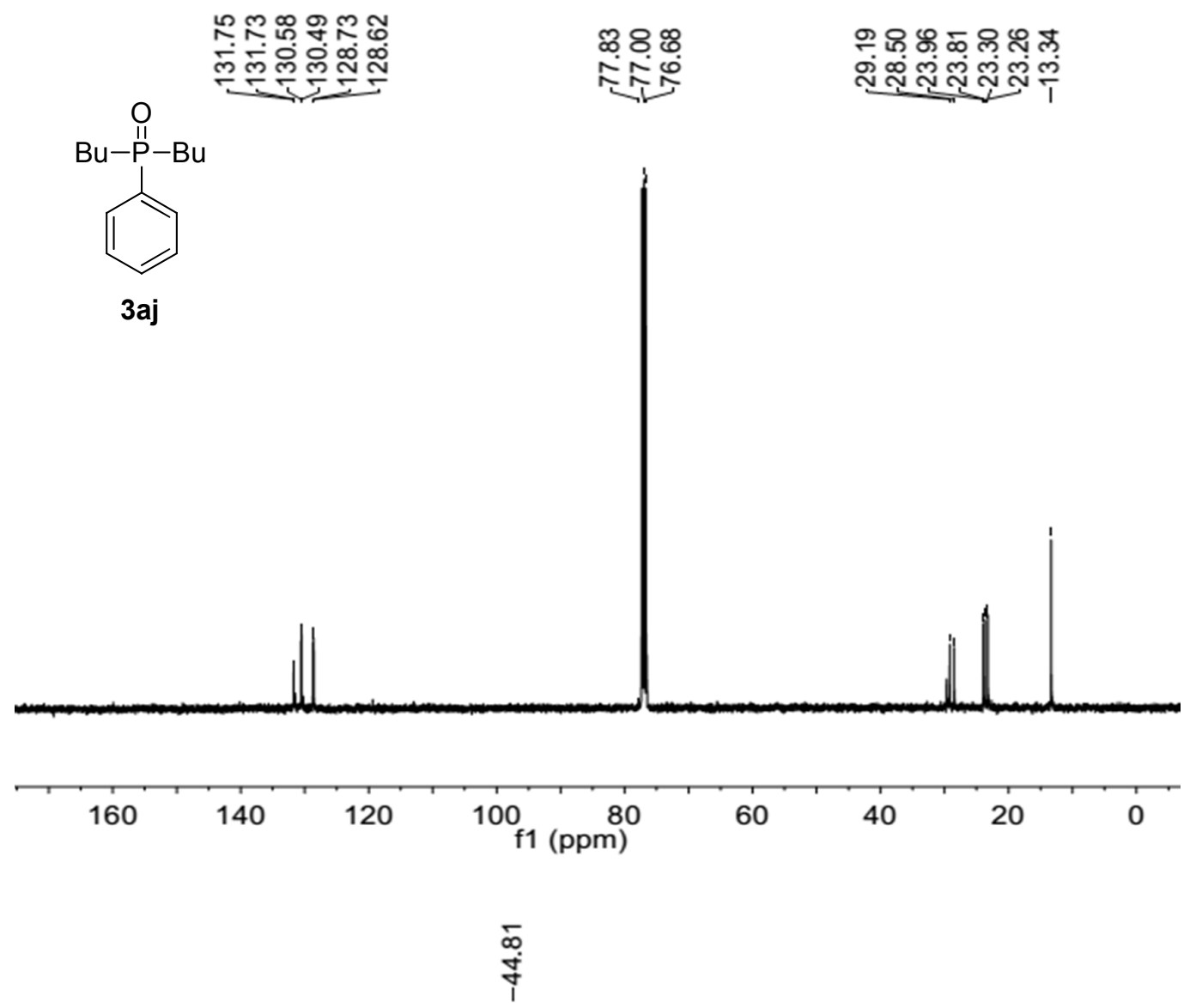<smiles></smiles>

3aj

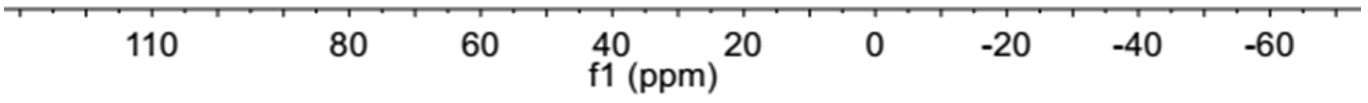




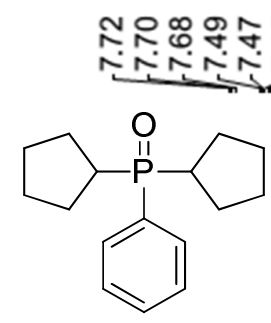

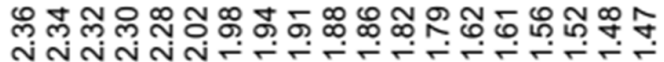

3ak

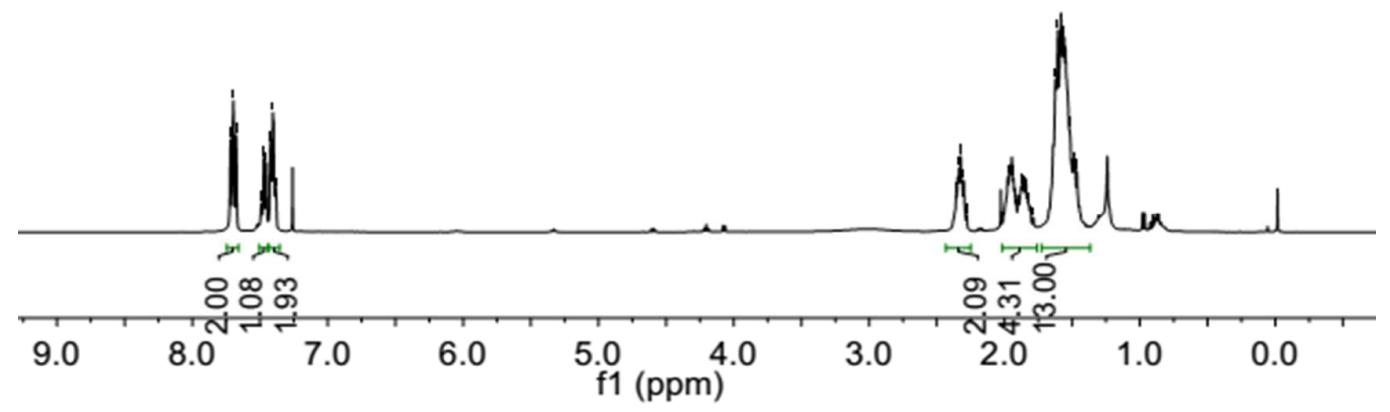

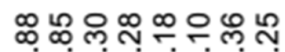

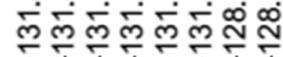

స్ల $8 \%$

全全

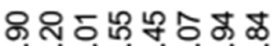

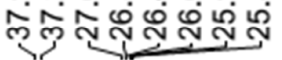

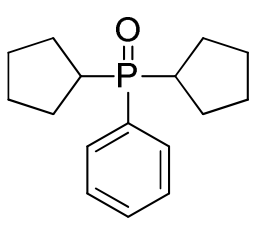

3ak

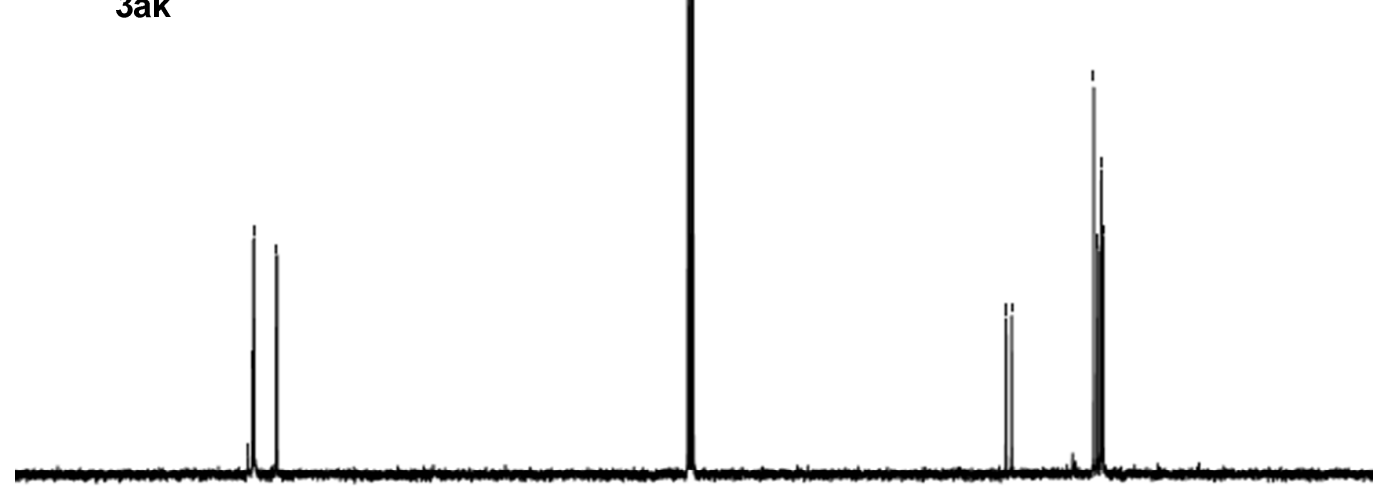

150

130

110

$90 \quad 80 \quad 70 \quad 60$

50

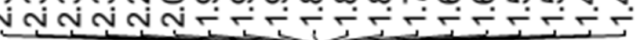




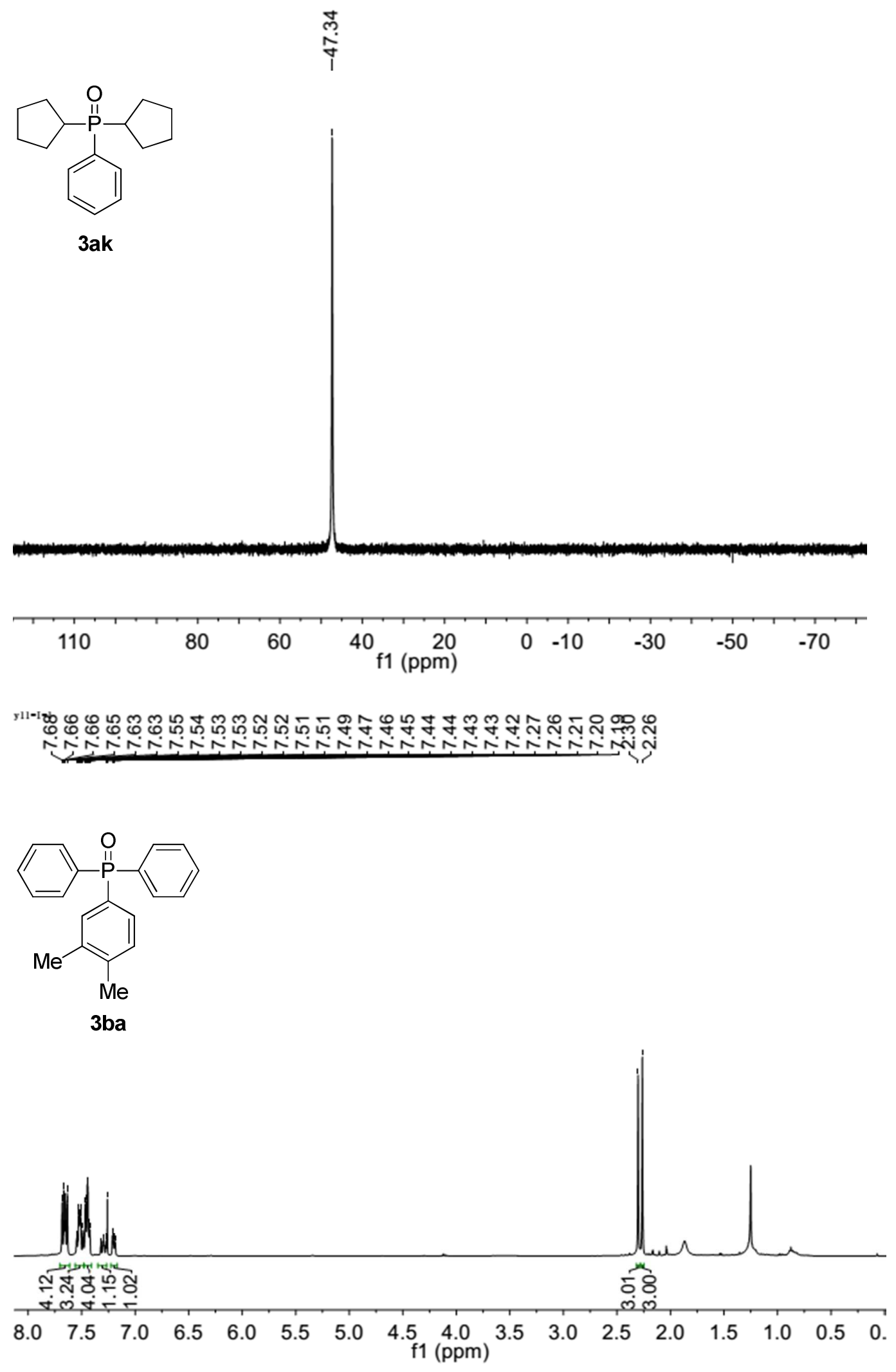



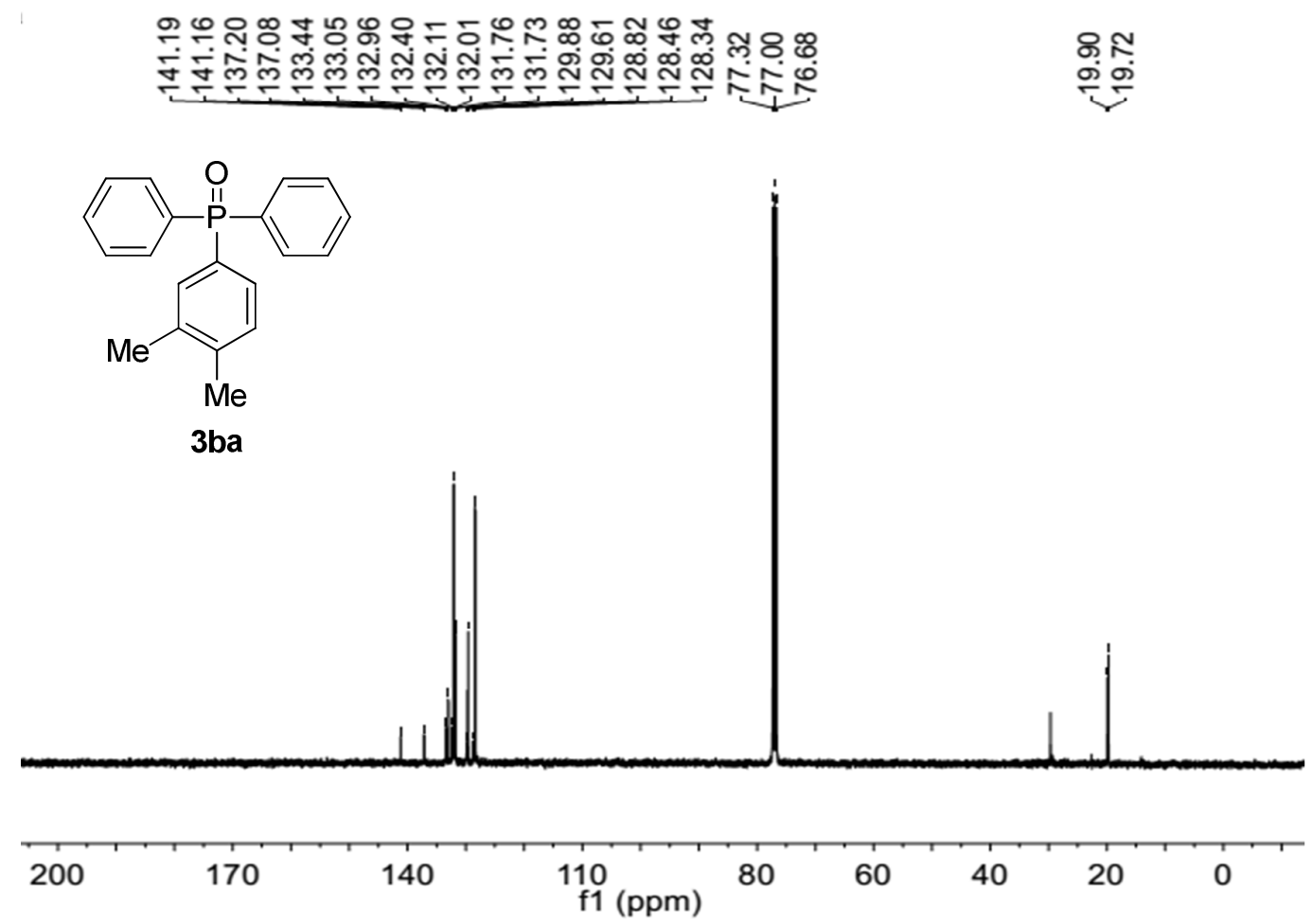

ষ্ণ

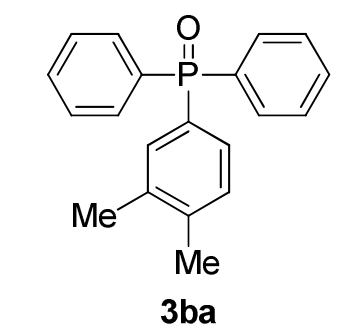




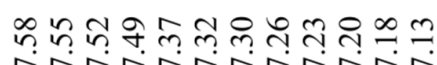

꾸윰ำ

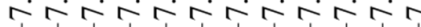<smiles>Cc1cccc(P(=O)(c2cccc(C)c2)c2ccc(C)c(C)c2)c1</smiles>

$3 b b$

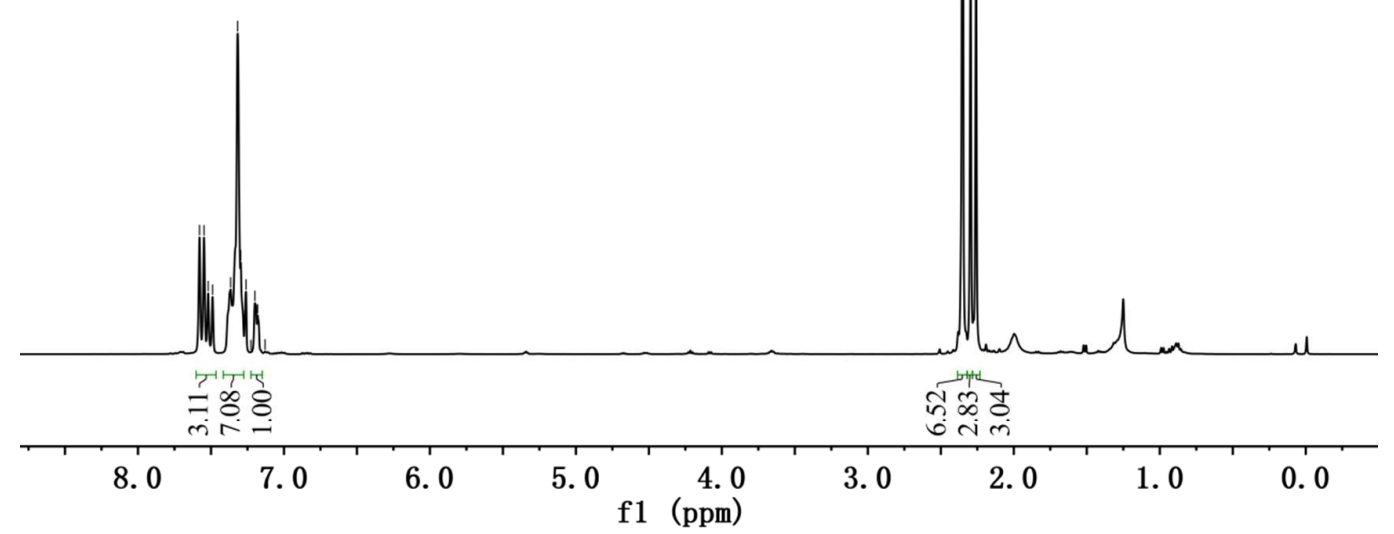

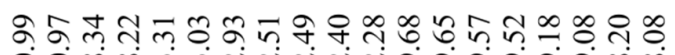

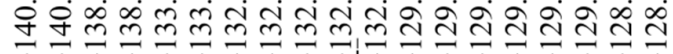

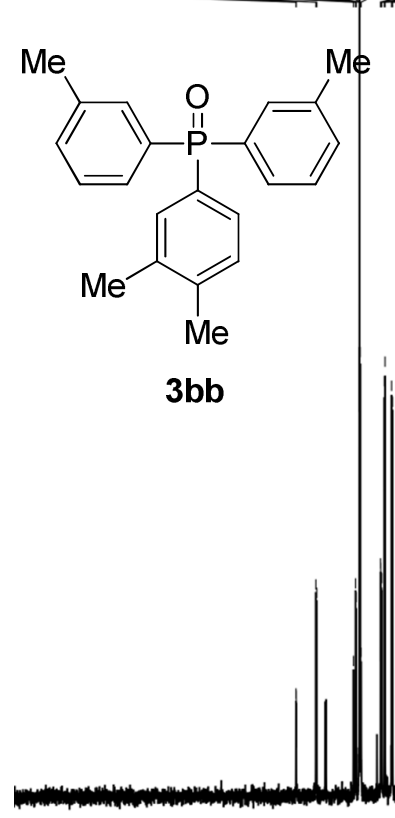

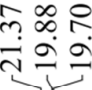

$170 \quad 150 \quad 130 \quad 110 \quad \begin{gathered}90 \\ \mathrm{f} 1(\mathrm{ppm})\end{gathered}$




$$
\text { 宅 }
$$<smiles>Cc1cccc(P(=O)(c2cccc(C)c2)c2ccc(C)c(C)c2)c1</smiles>

$3 b b$

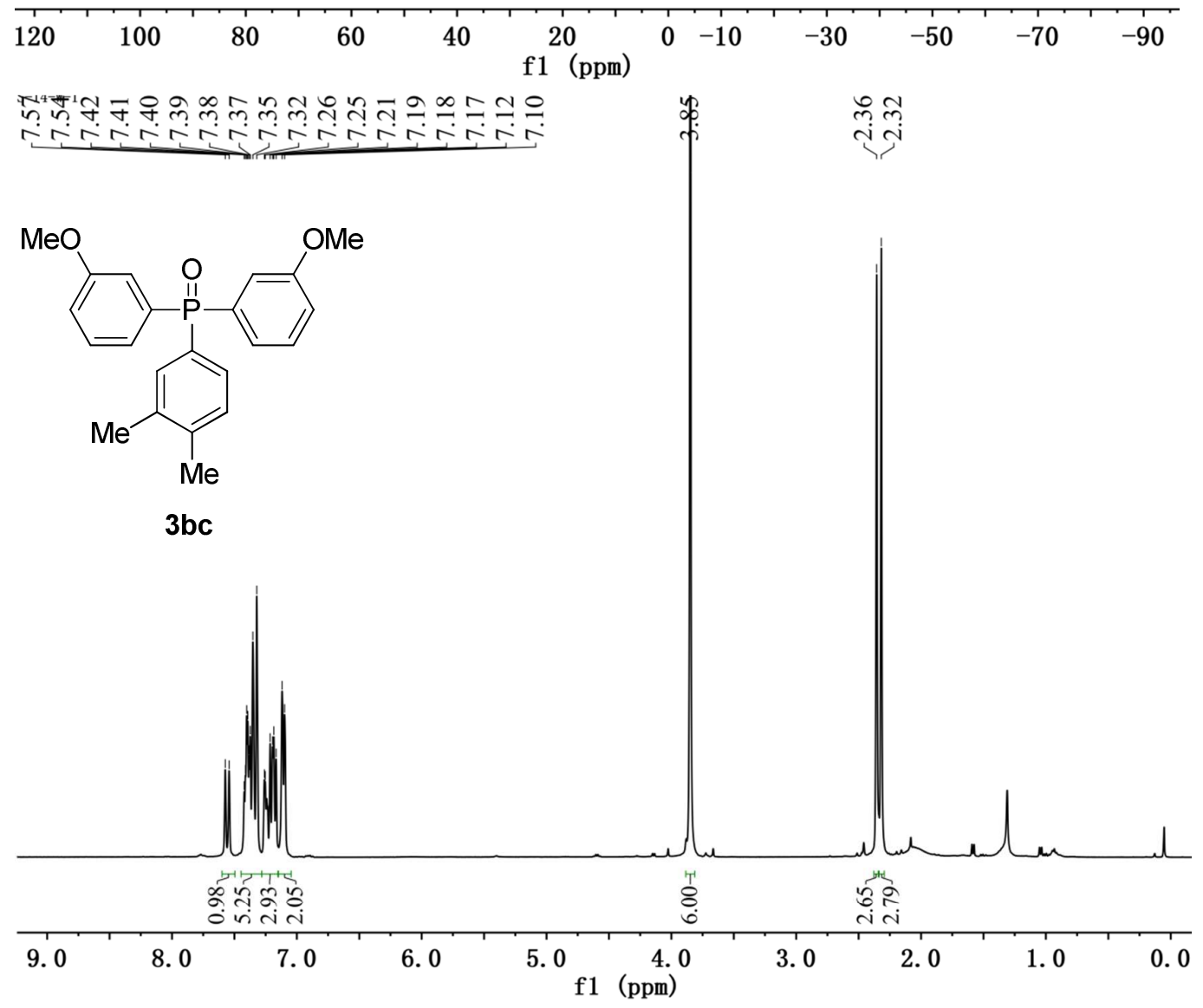



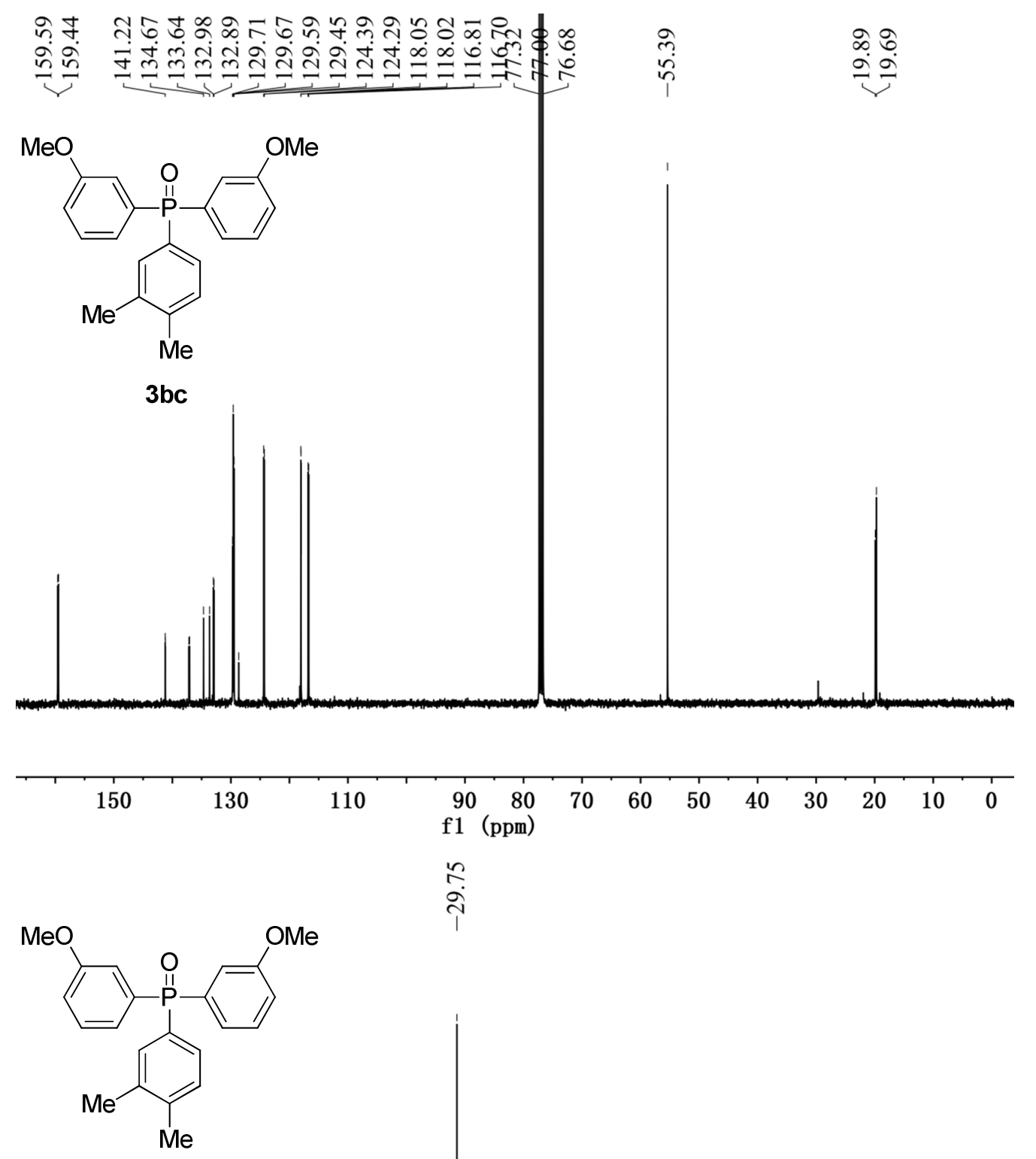

ำ

3bc

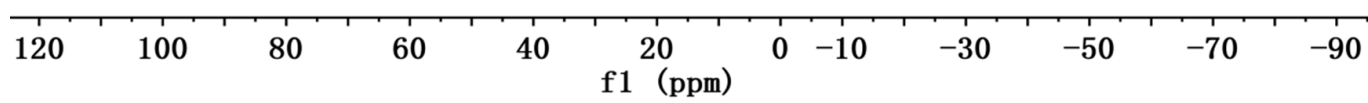




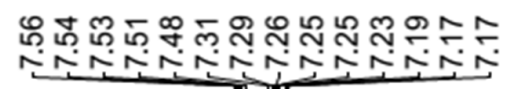

్ㅠ్ㅠ్ㅠ

ชู่

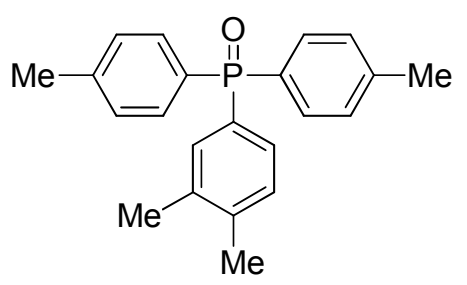

3bd

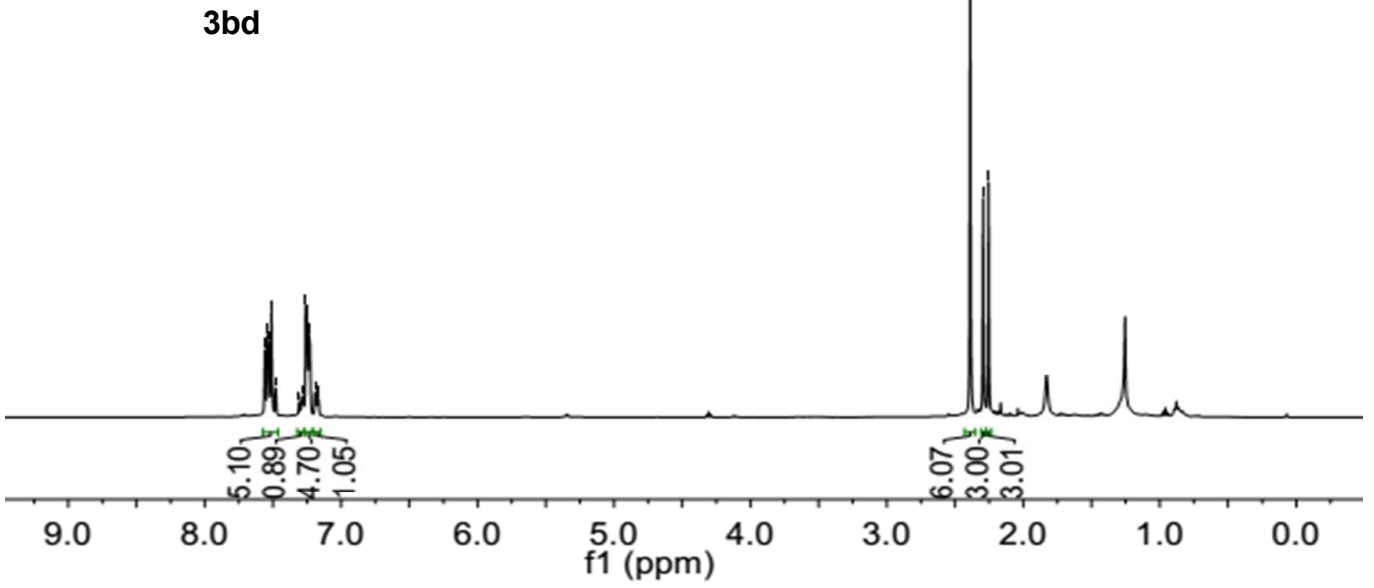

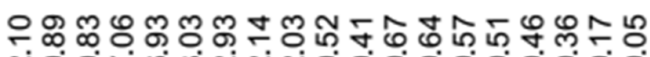

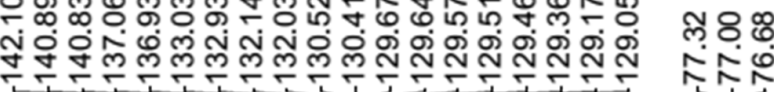

NN先

늄유

ํํㄴ

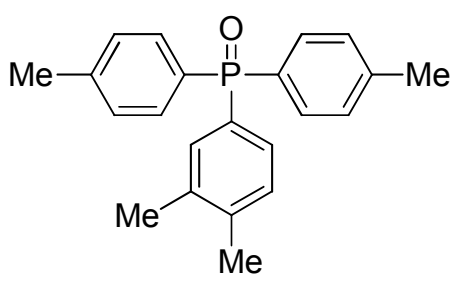

3bd

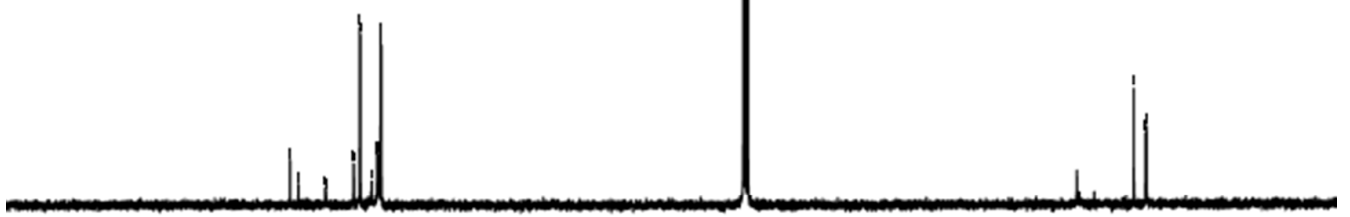

\begin{tabular}{|c|c|c|c|c|c|c|}
\hline 160 & 140 & 120 & $\begin{array}{c}100 \\
\mathrm{f} 1(\mathrm{ppm})\end{array}$ & 60 & 40 & 20 \\
\hline
\end{tabular}




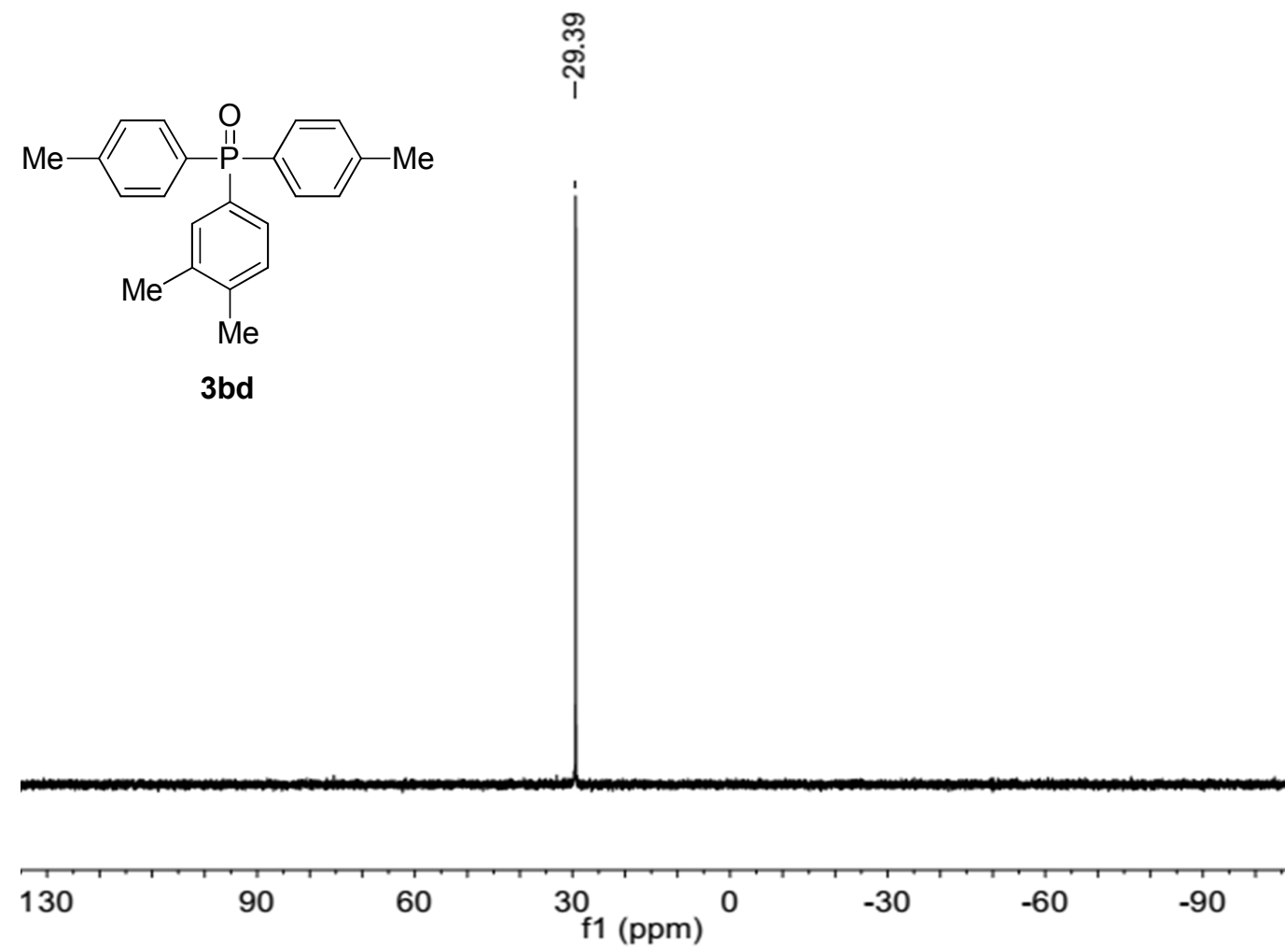

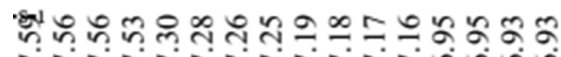

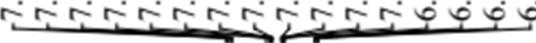
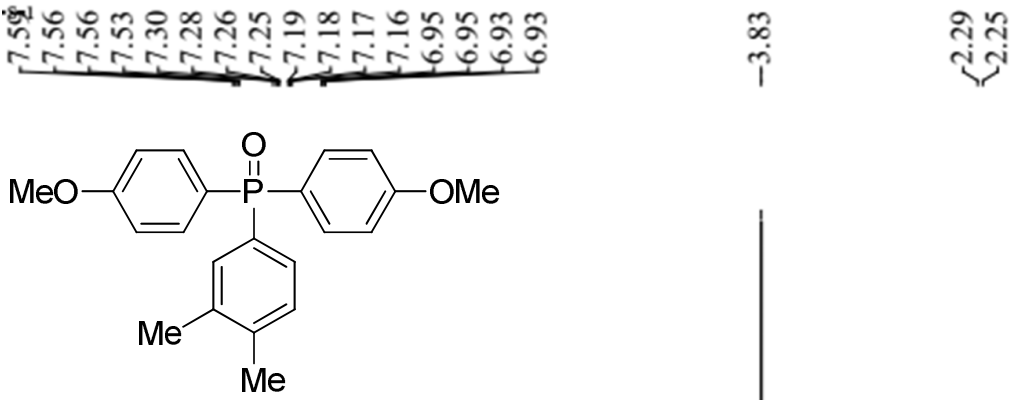

3be

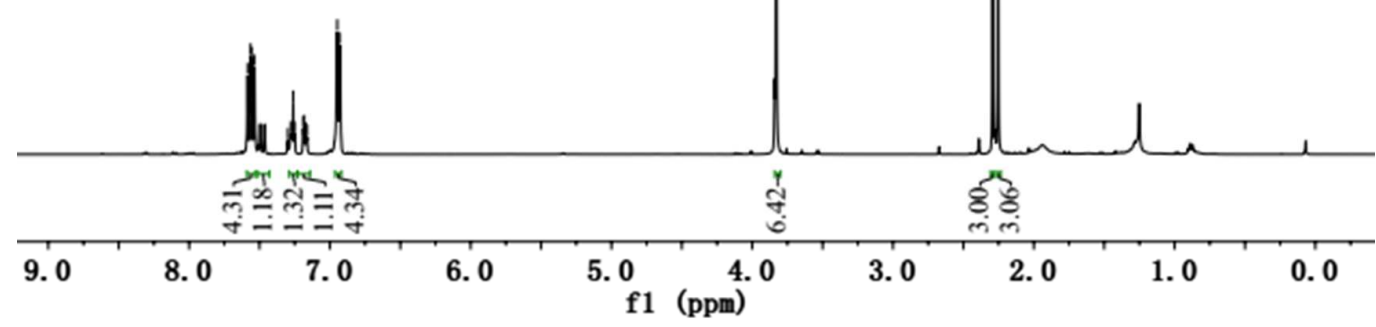



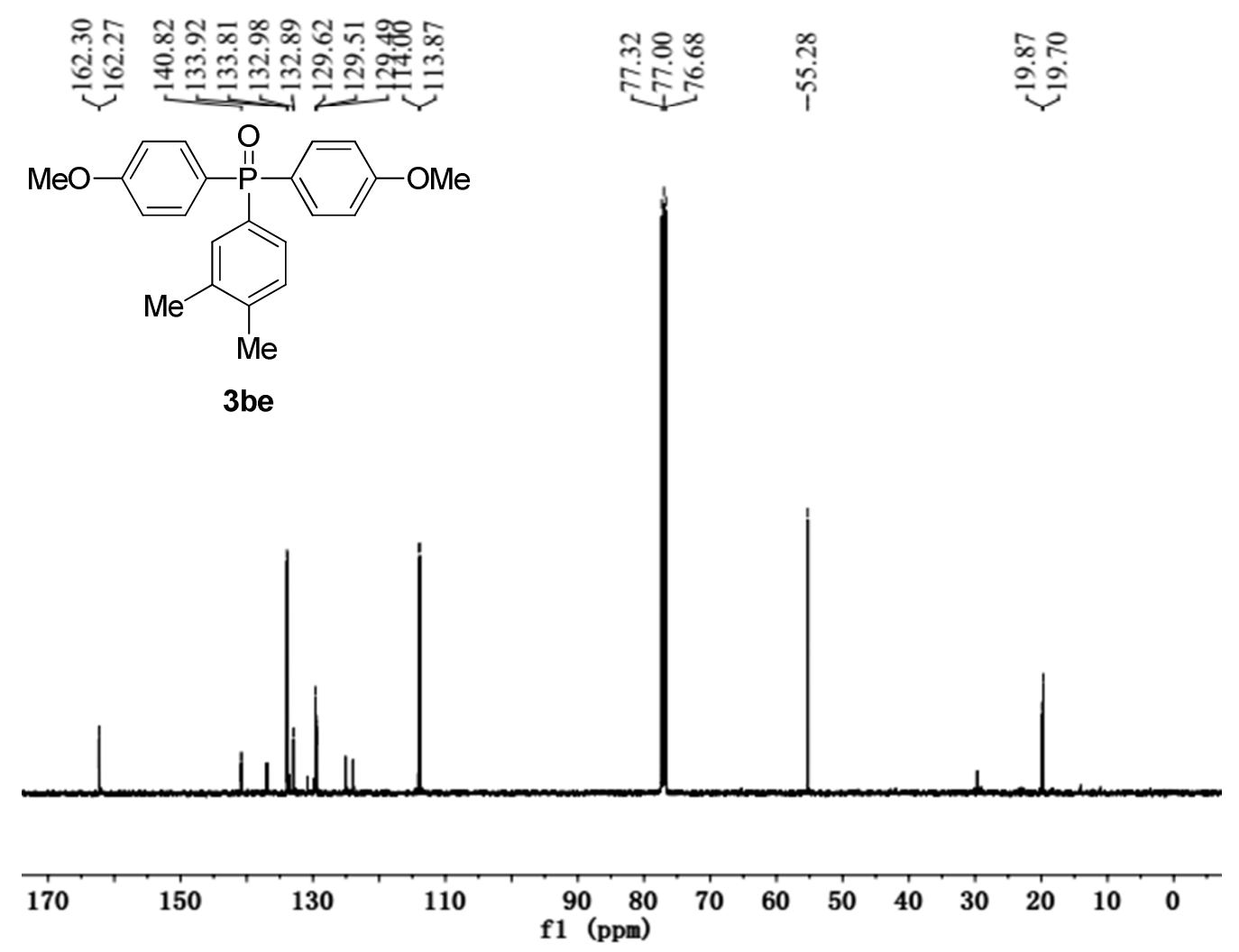

$$
\begin{aligned}
& \multirow{1}{*}{} \\
& \stackrel{1}{1}
\end{aligned}
$$

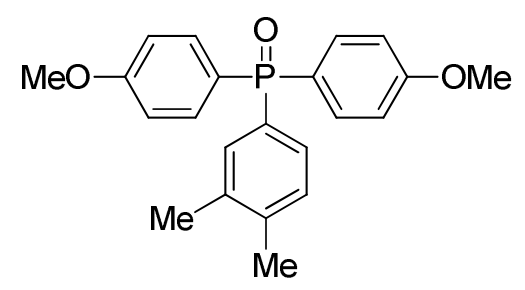

3 be

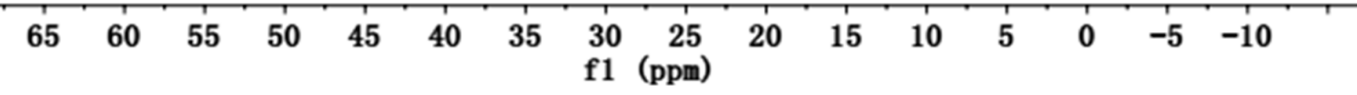




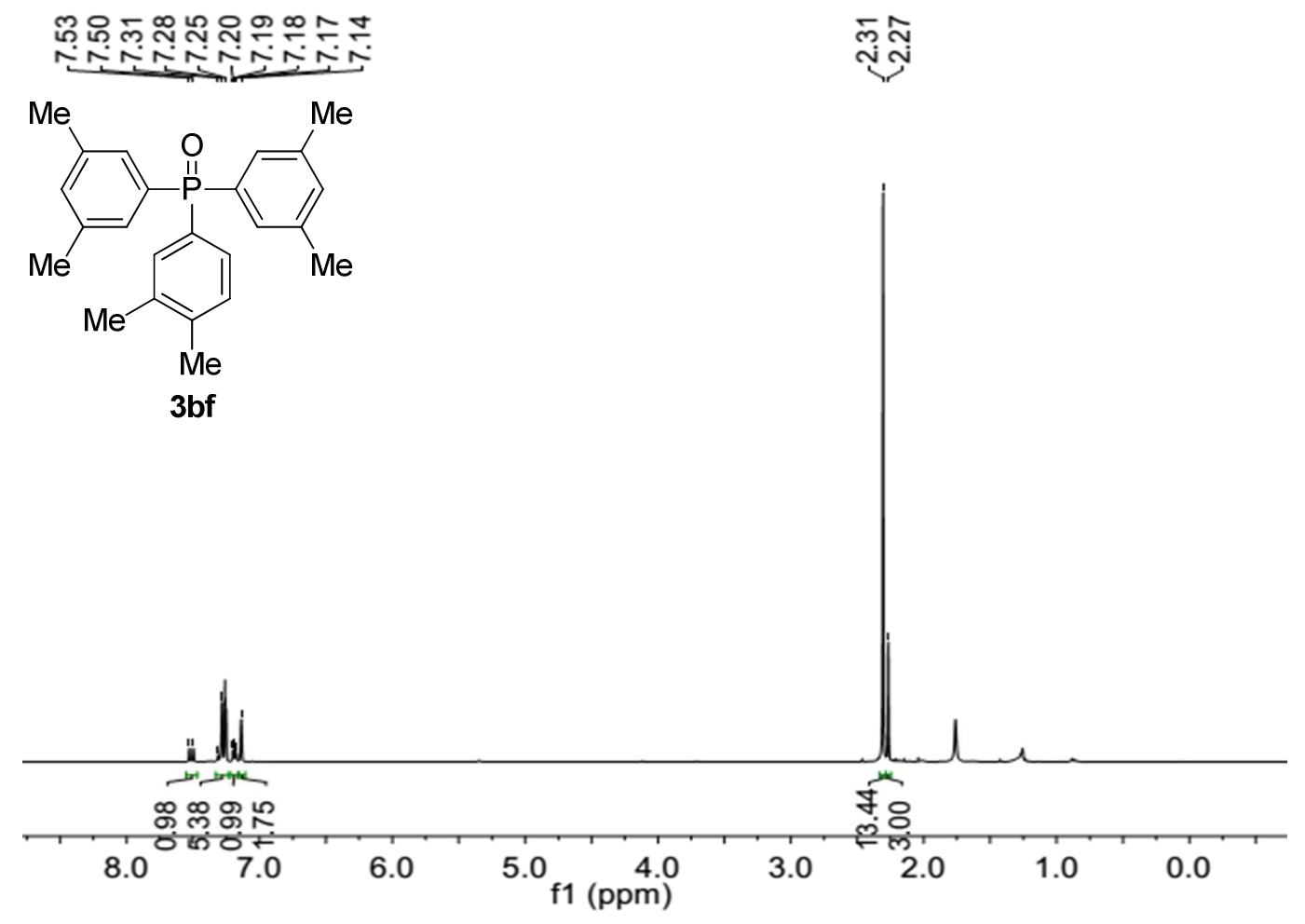

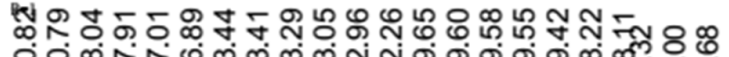

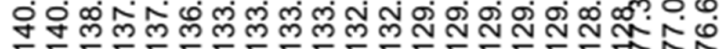

సัณ

ล்ํำ<smiles>Cc1cc(C)cc(P(=O)(c2ccc(C)c(C)c2)c2ccc(C)c(C)c2)c1</smiles>
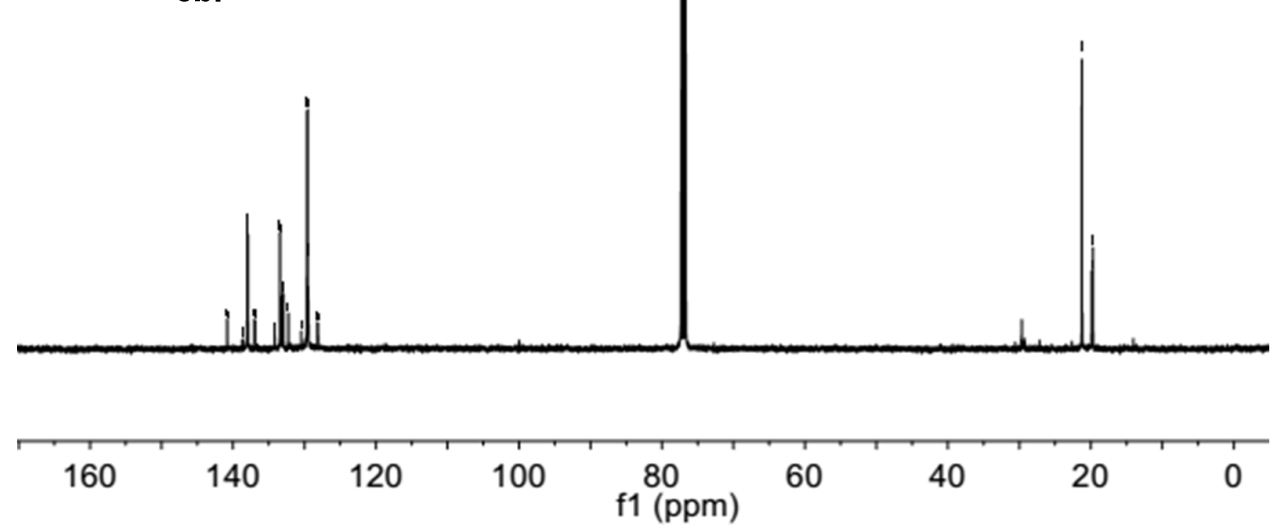


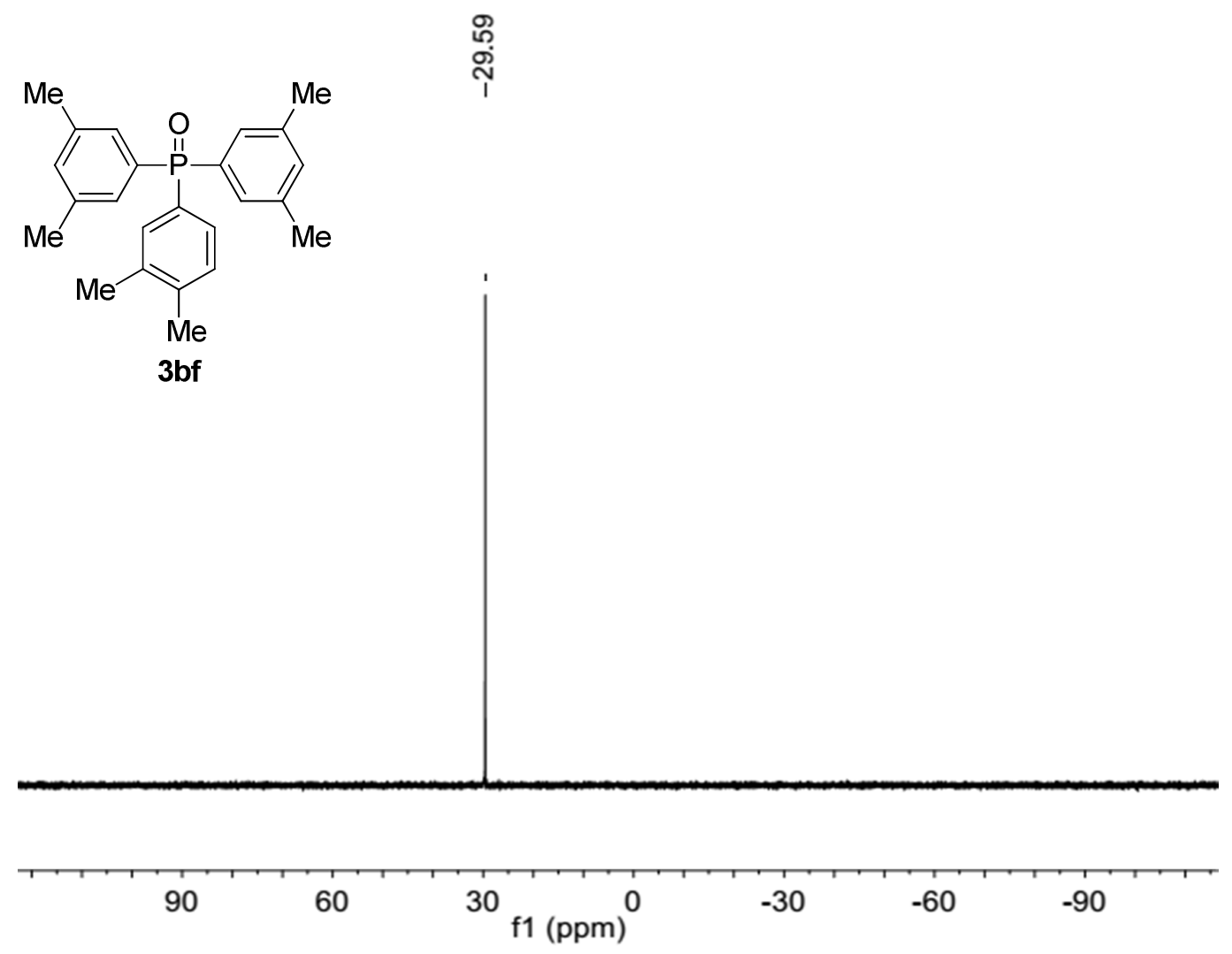

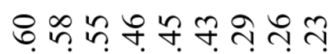

NNNNNN

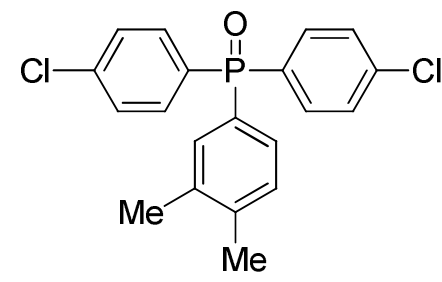

3 bg

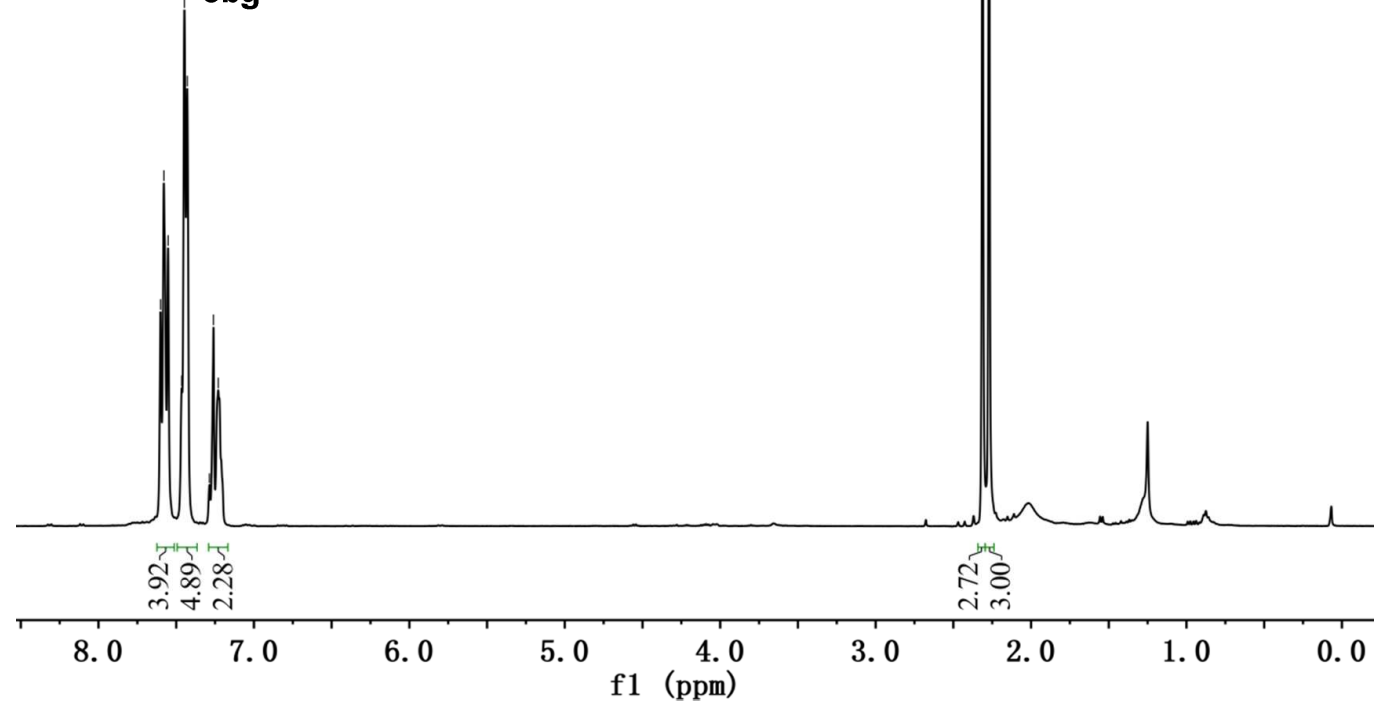




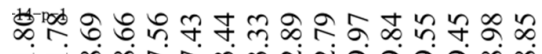

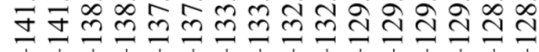
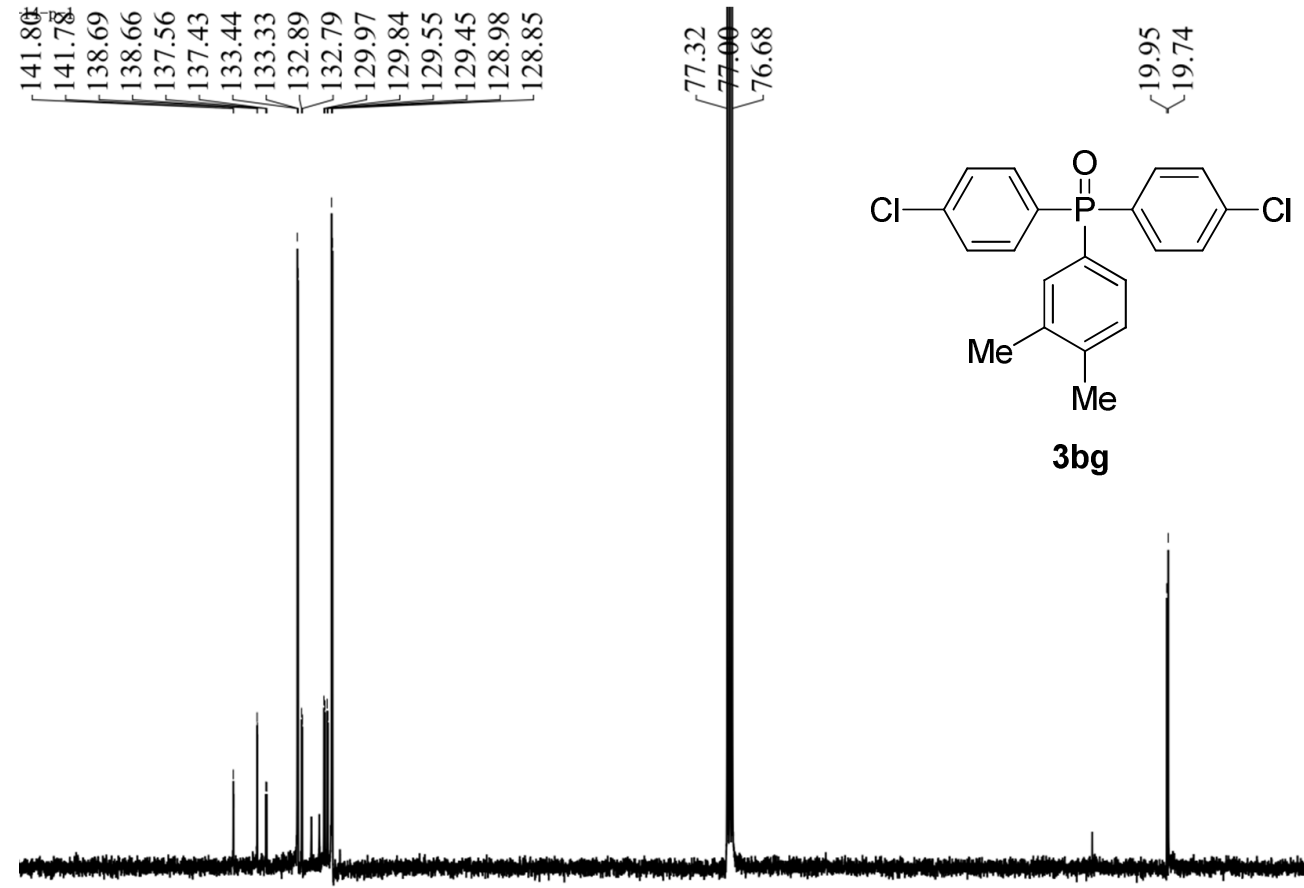

$3 \mathrm{bg}$

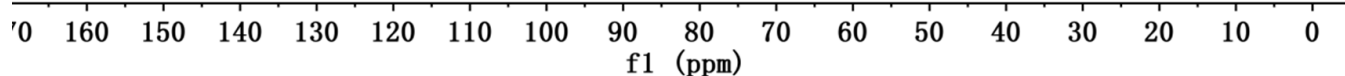

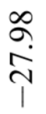

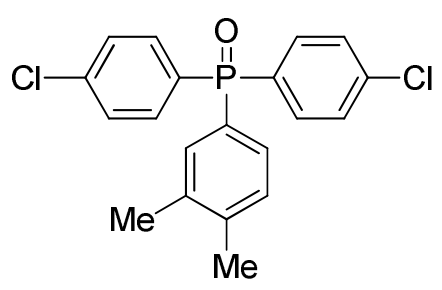

3bg

\begin{tabular}{|c|c|c|c|c|c|c|c|c|c|c|}
\hline 120 & 100 & 80 & 60 & 40 & $\mathrm{f1}^{20}(\mathrm{ppm})$ & 0 & -10 & -30 & -50 & -70 \\
\hline
\end{tabular}



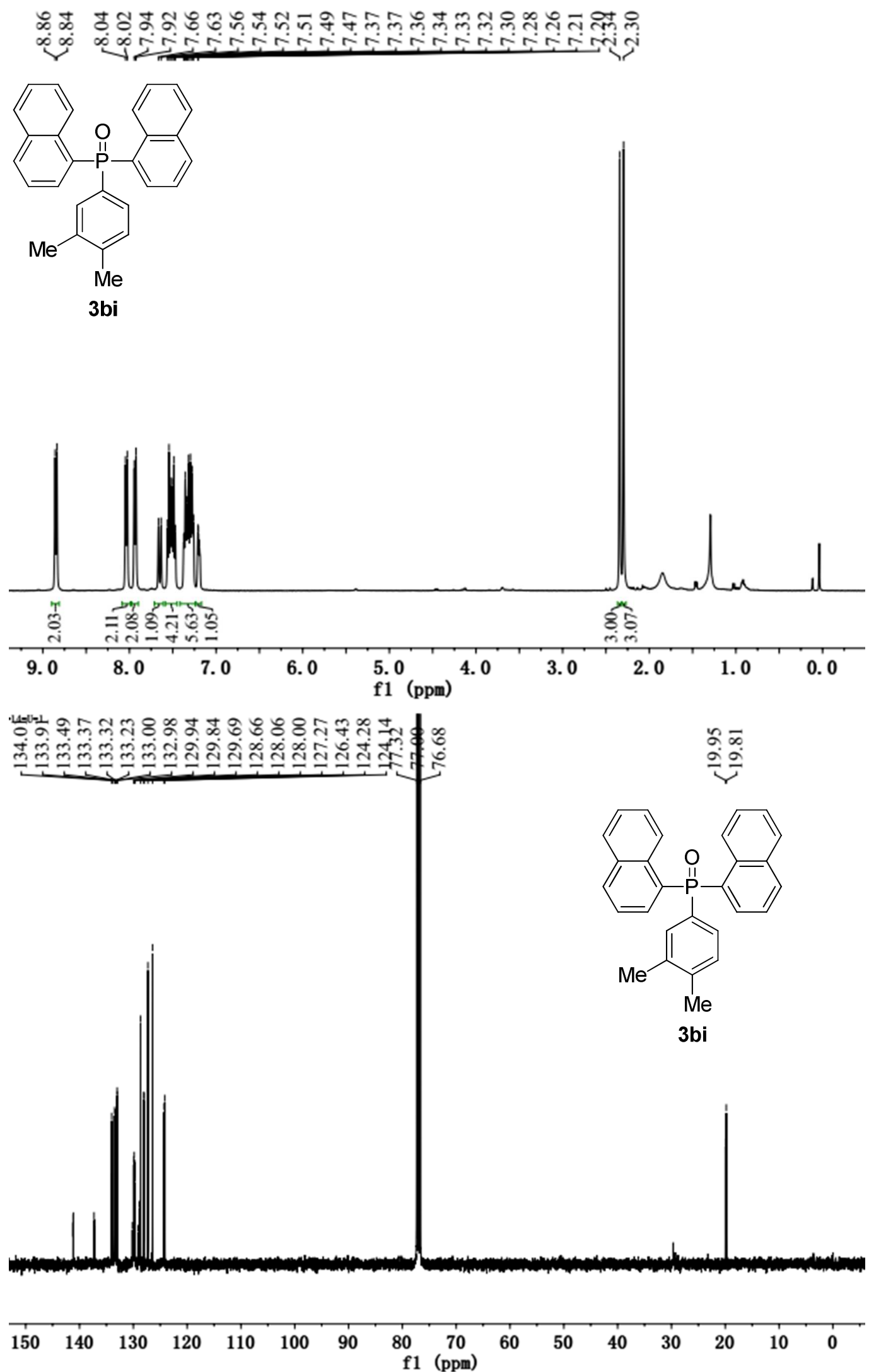

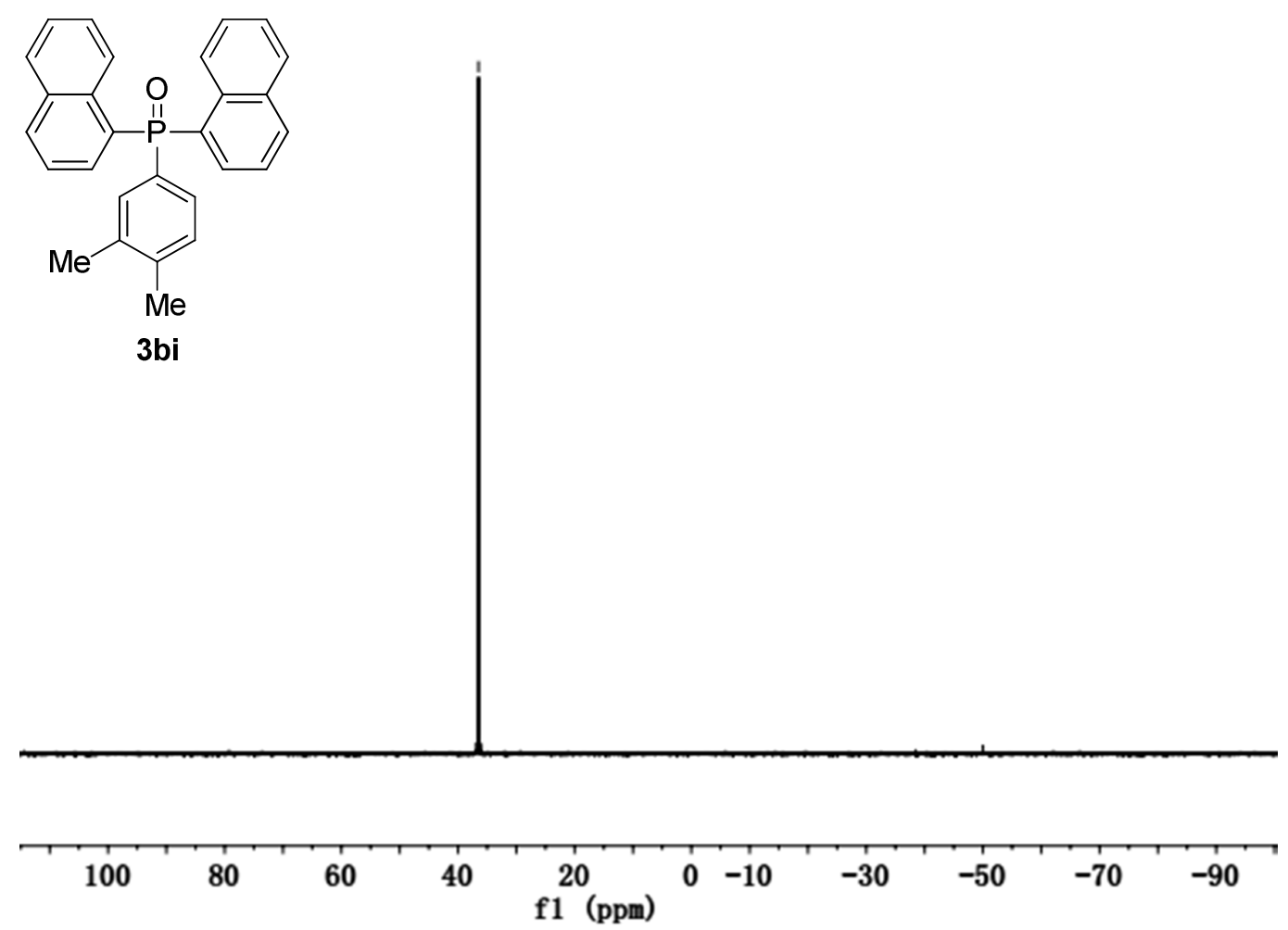

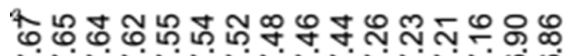

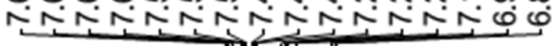

్ㅠㅇㅠ

พิ่

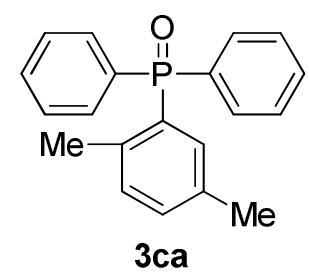

3ca

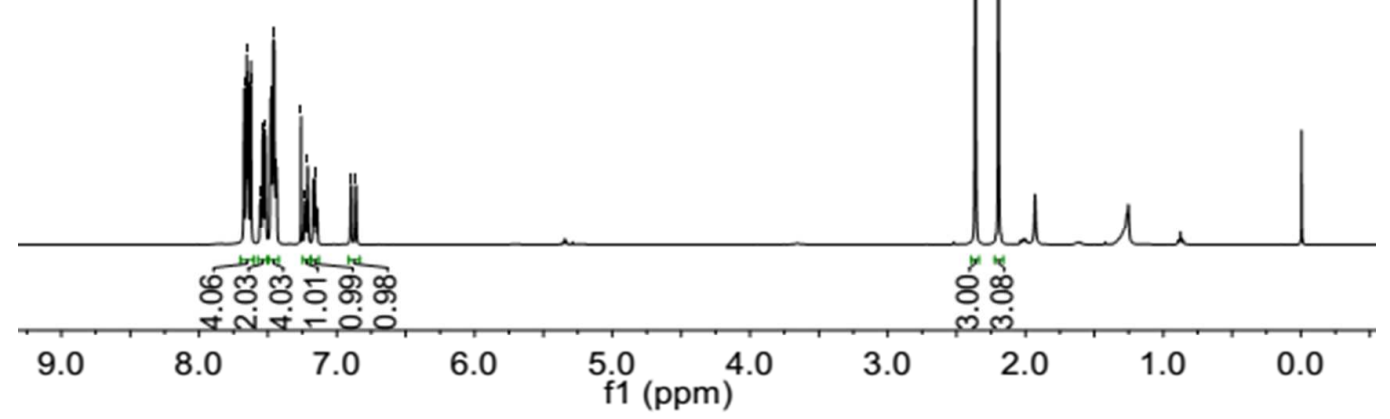



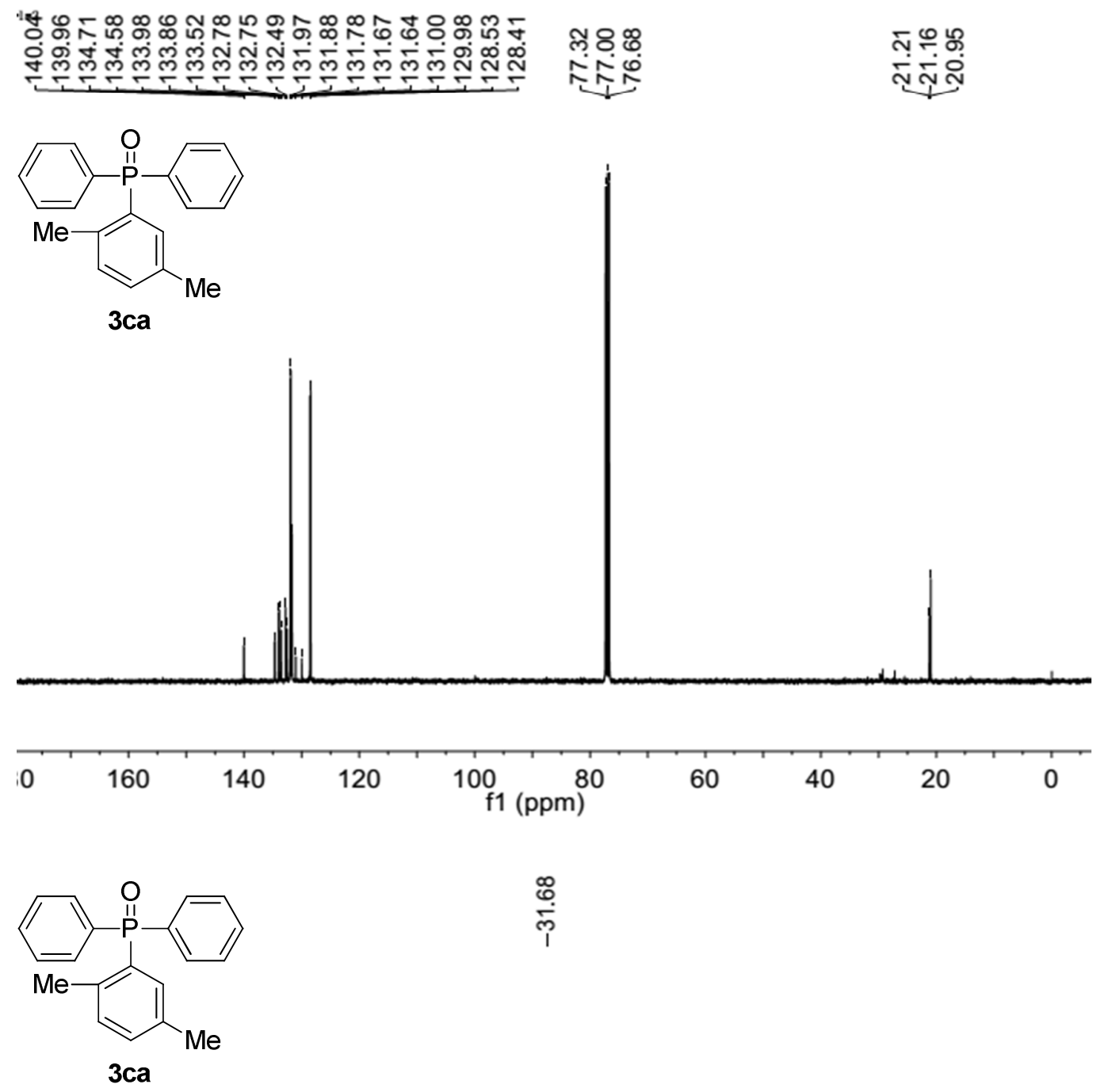

$\frac{\infty}{p}$

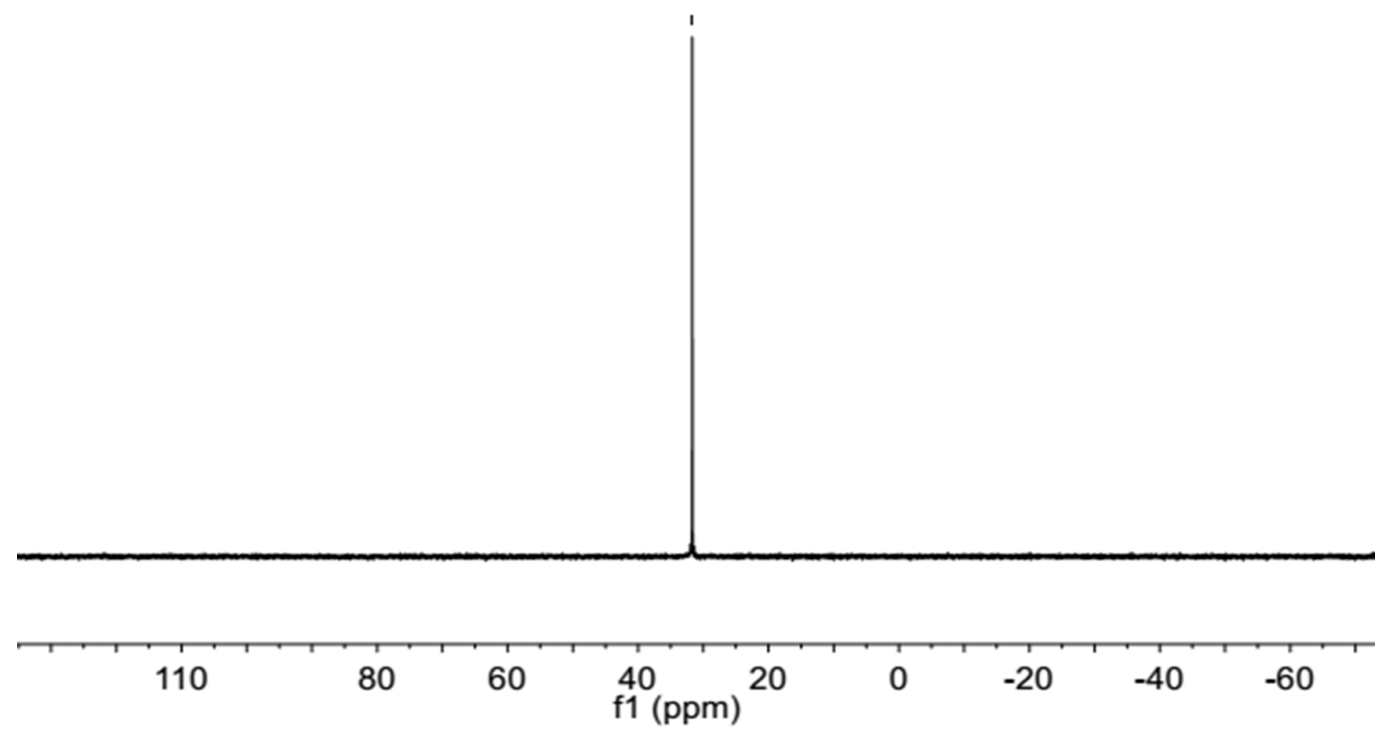




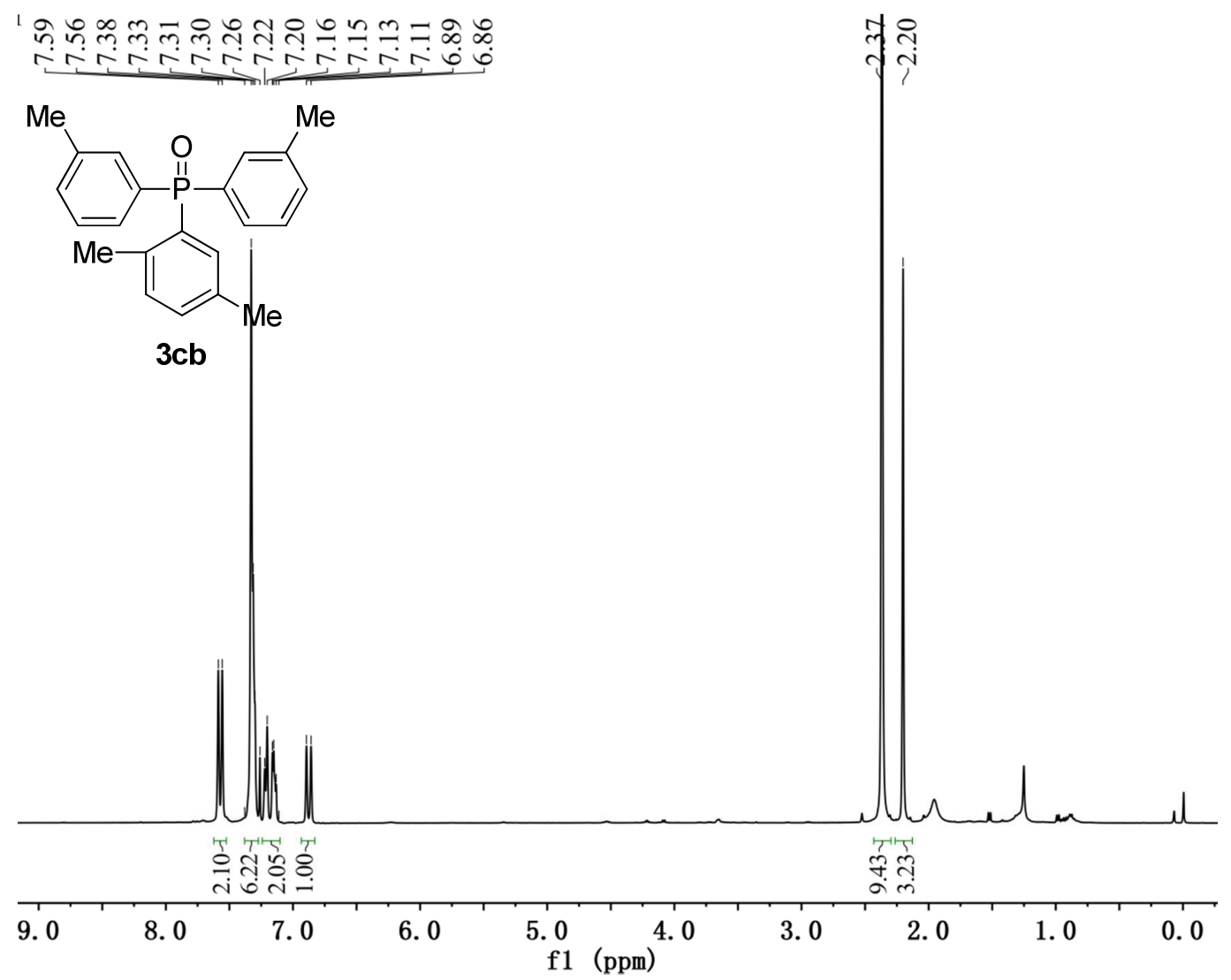

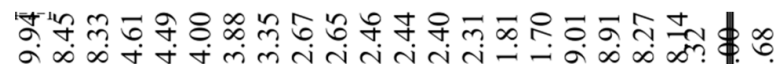

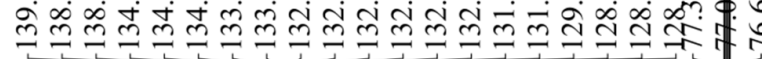<smiles>Cc1cccc(P(=O)(c2cccc(C)c2)c2cccc(C)c2)c1</smiles>

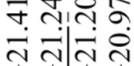



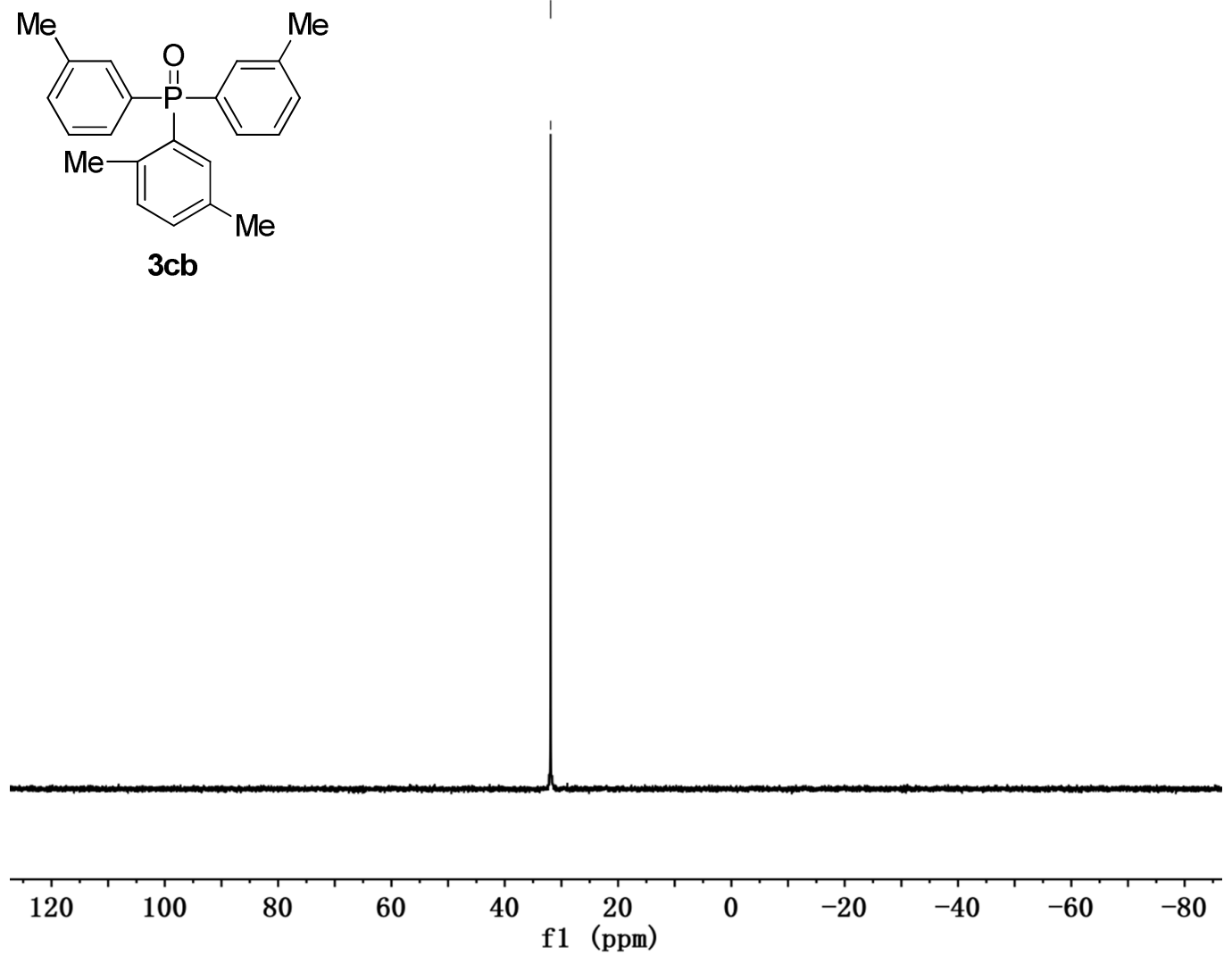

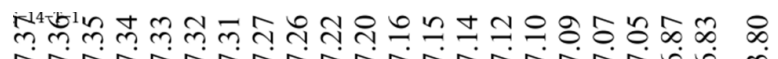

$\underset{m}{\infty}$ iุ

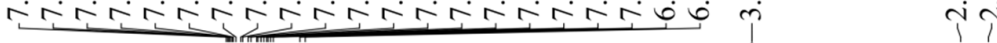<smiles>COc1cccc(P(=O)(c2cccc(OC)c2)c2cccc(C(C)(C)C)c2)c1</smiles>

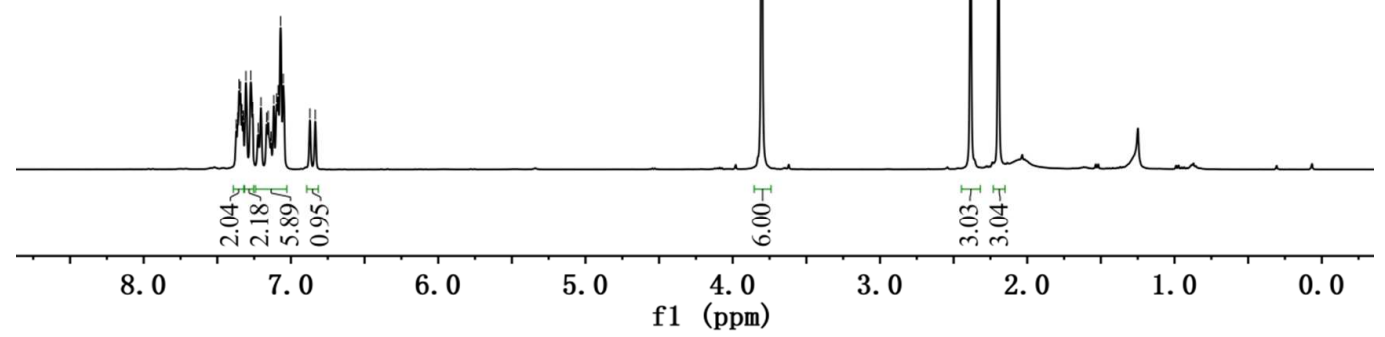



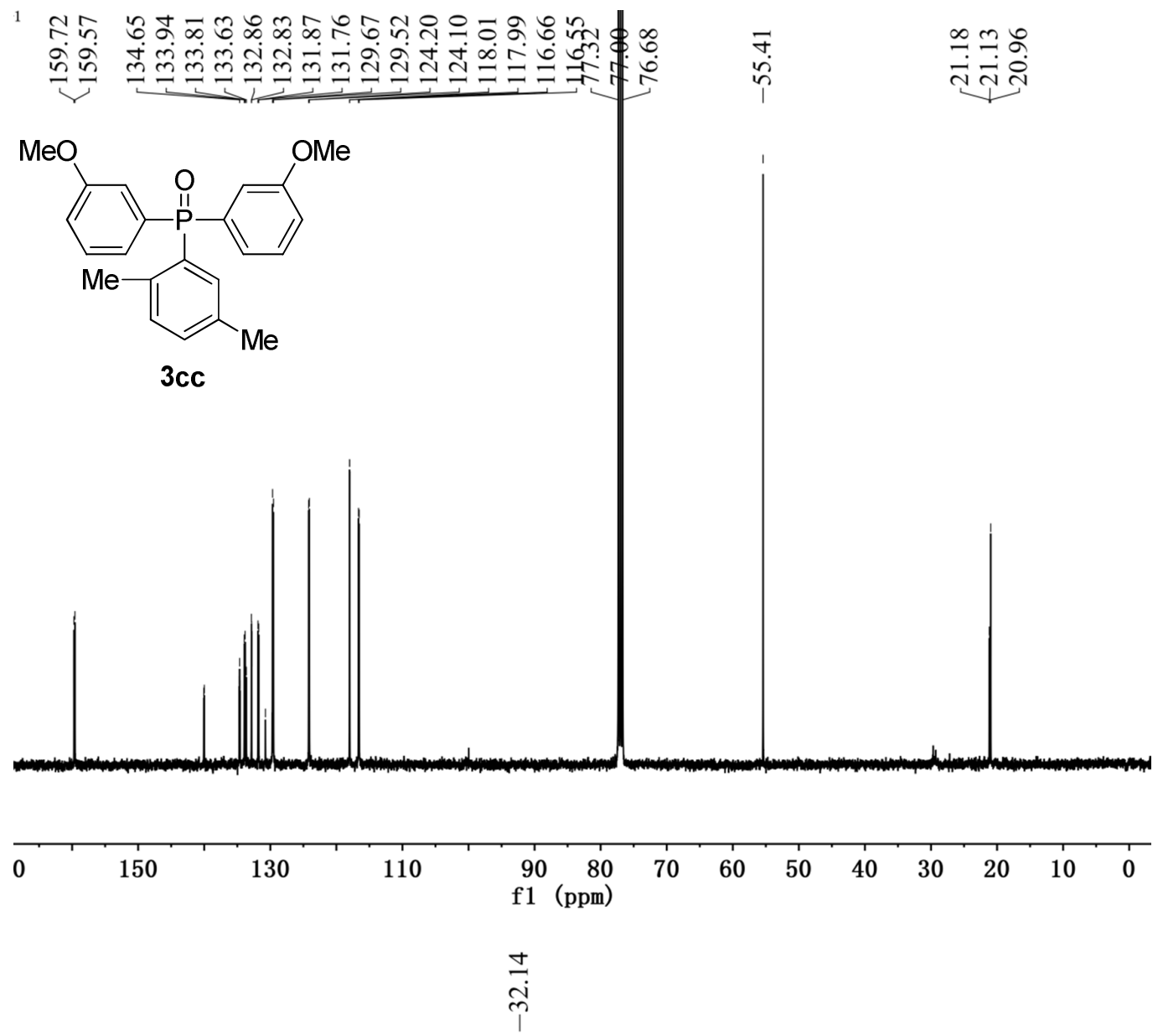<smiles>COc1cccc(P(=O)(c2cccc(OC)c2)c2cc(C)ccc2C)c1</smiles>

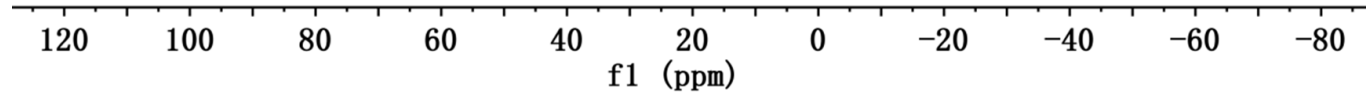




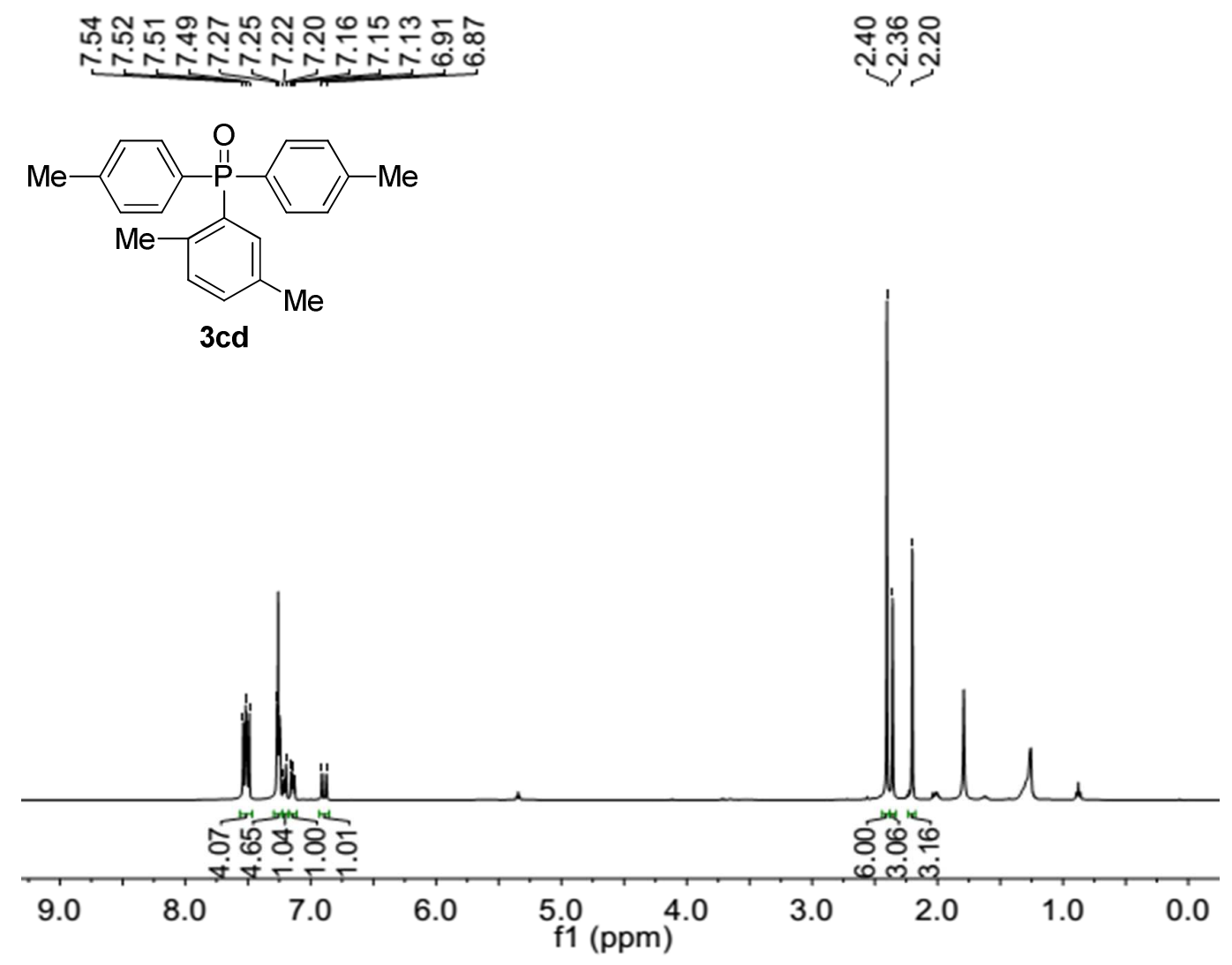

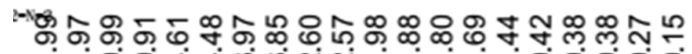

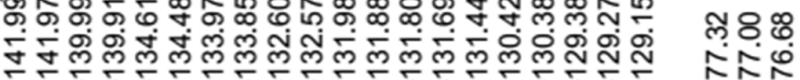

ㅅำ

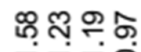

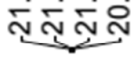<smiles>Cc1ccc(P(=O)(c2ccc(C)cc2)c2ccc(C)cc2C)cc1</smiles>
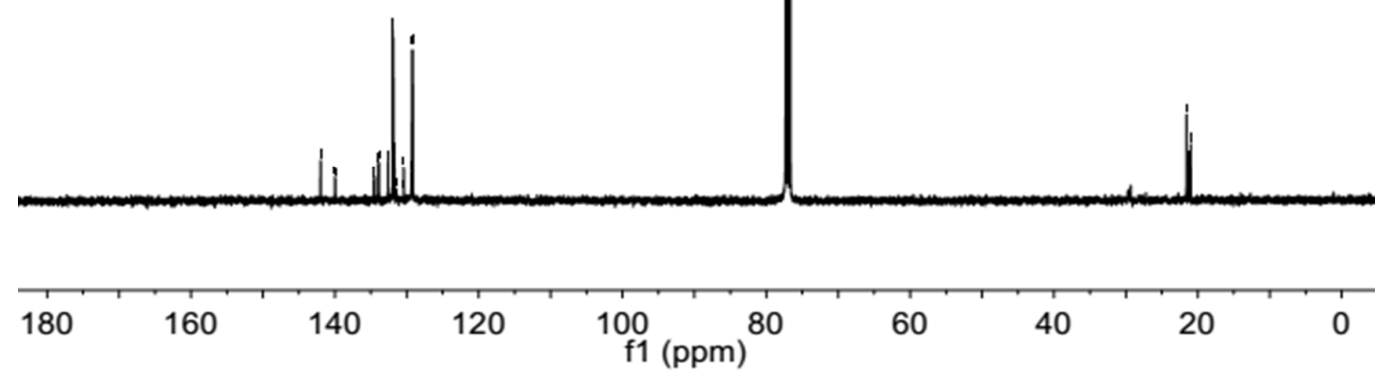


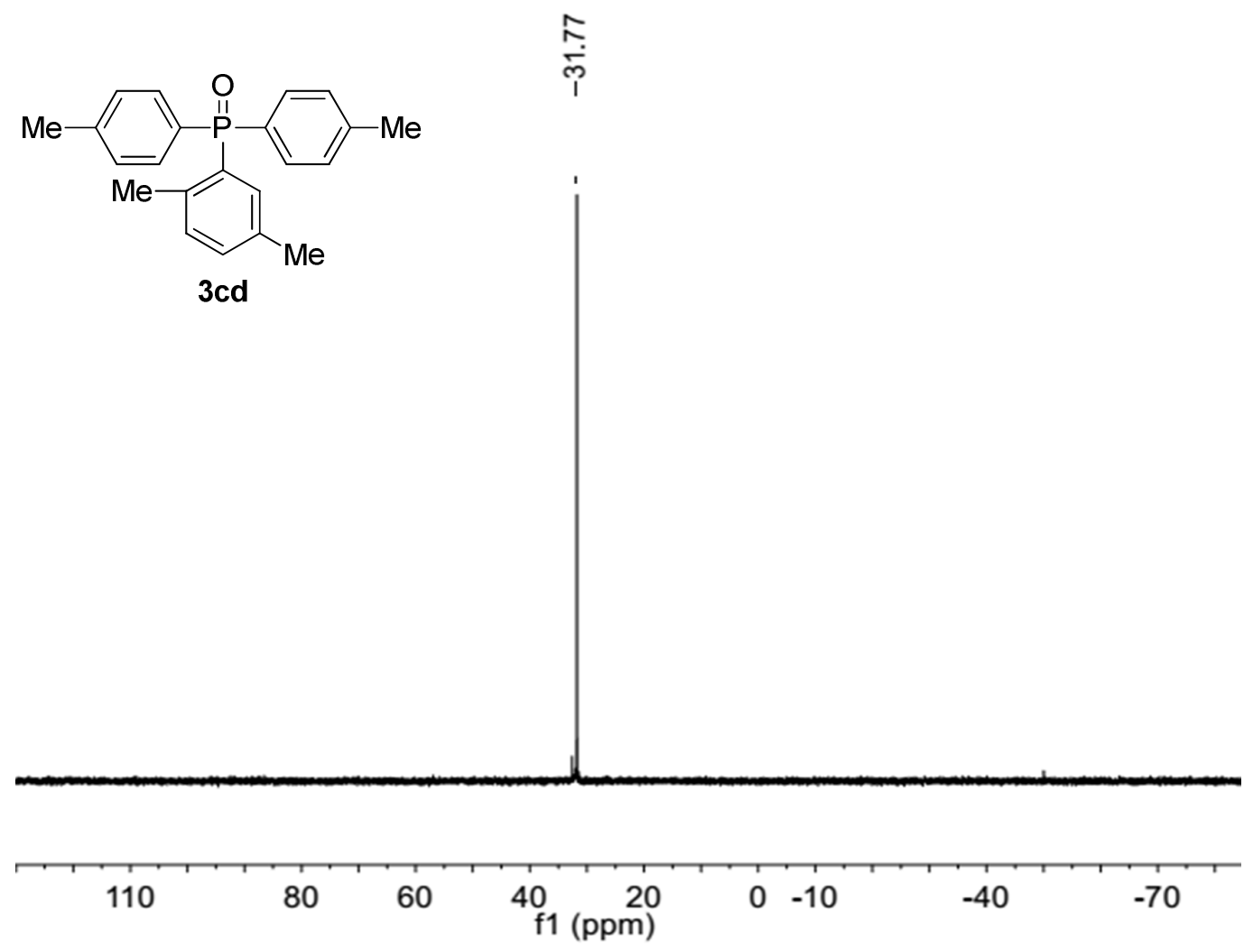

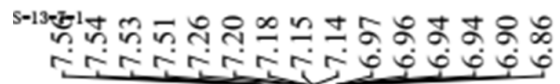

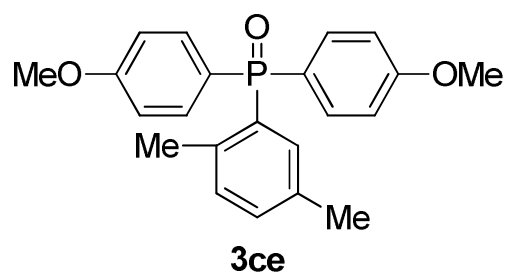

ำ

रุ

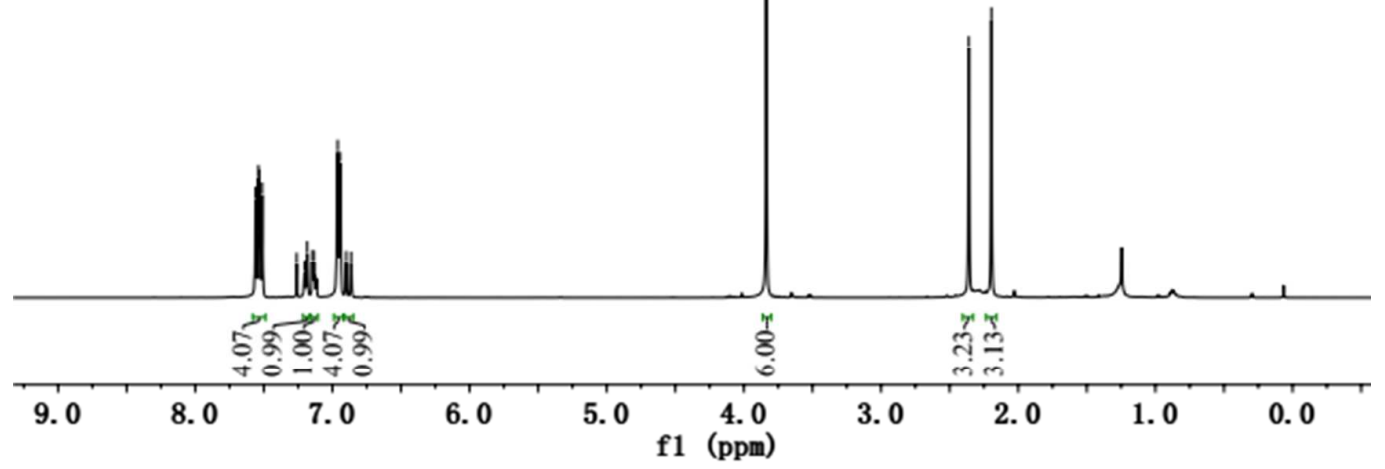



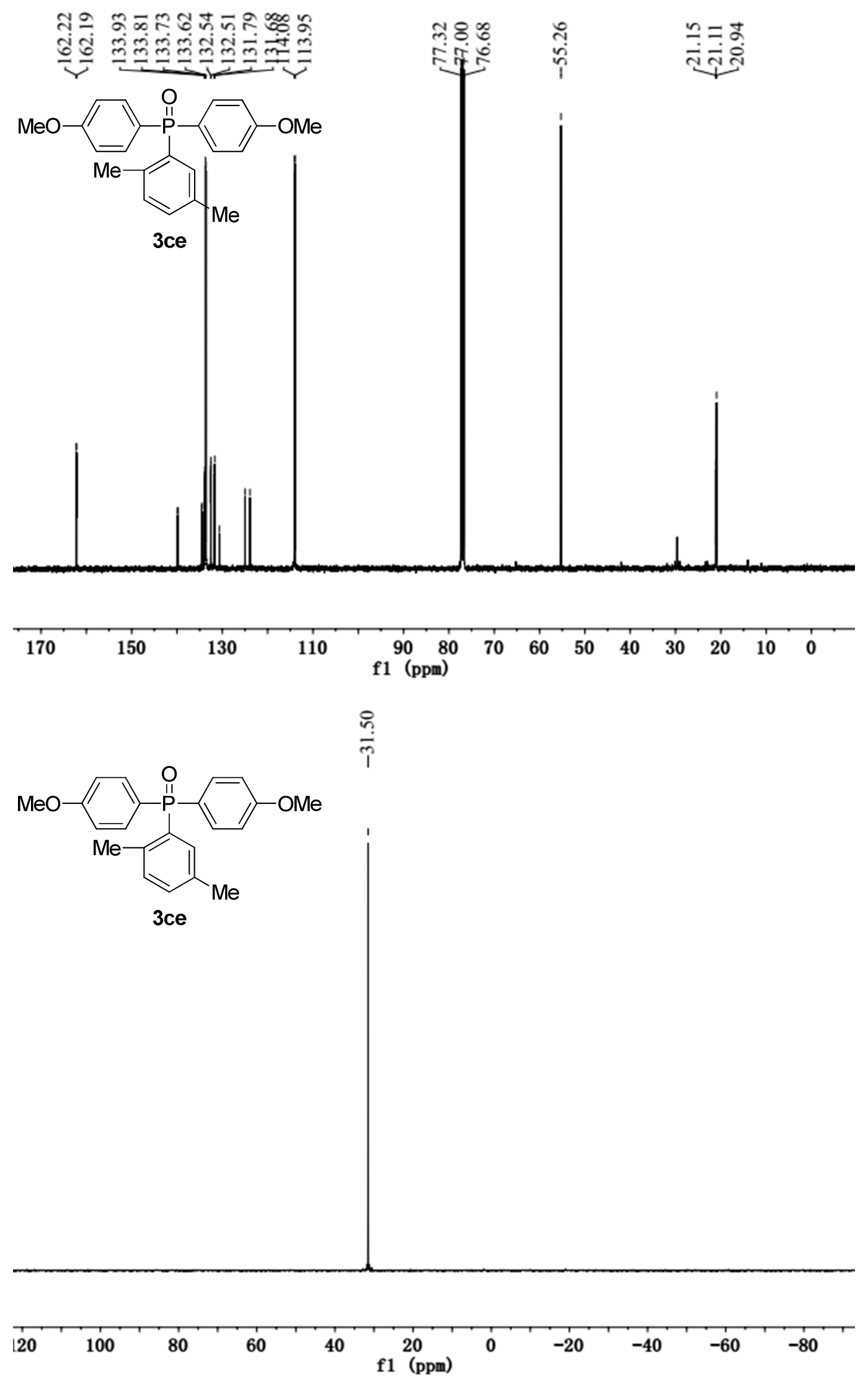


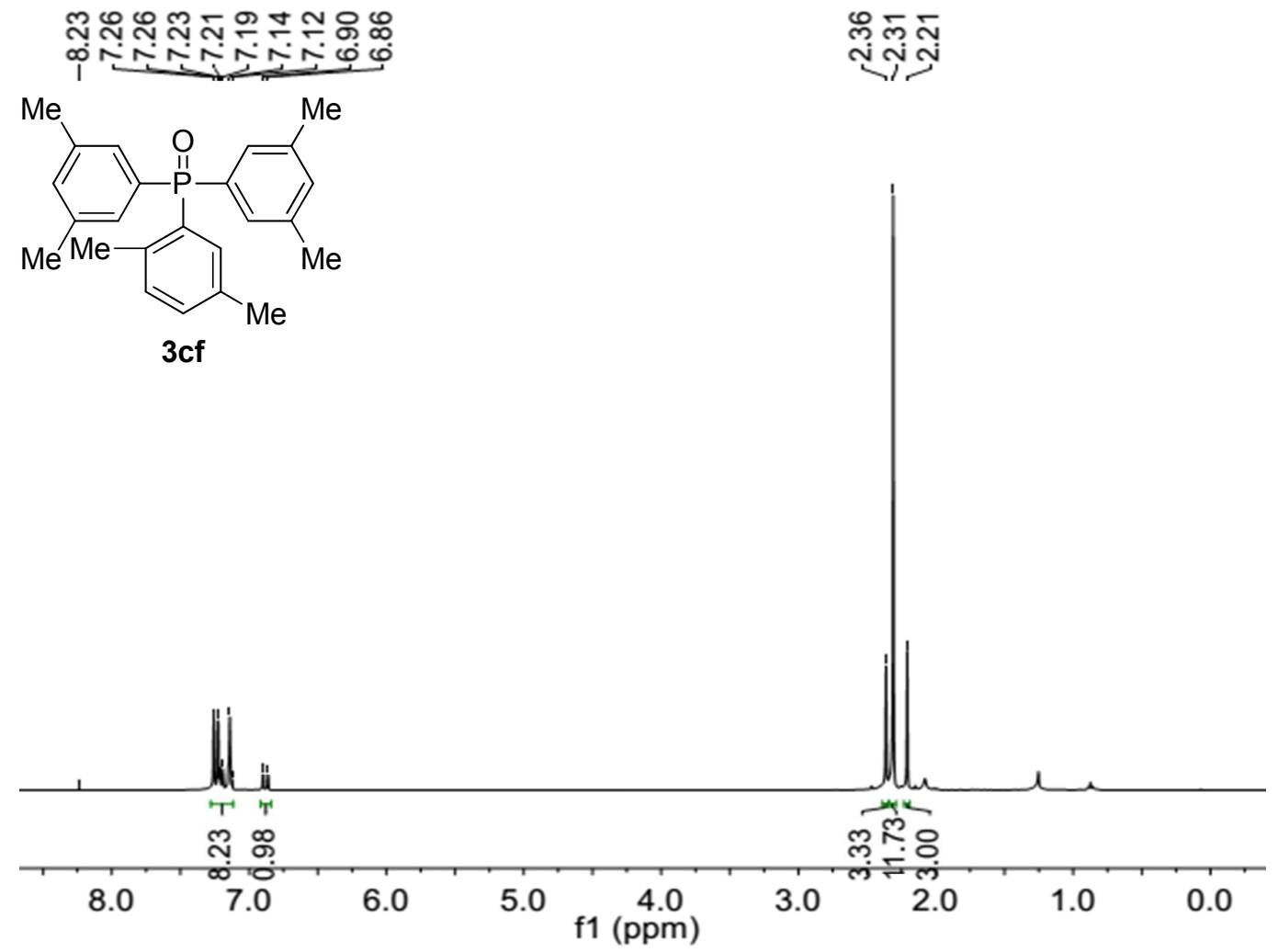

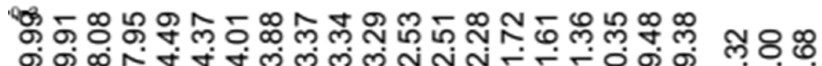

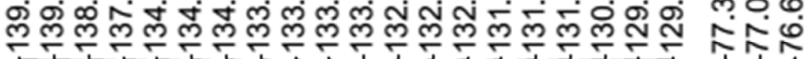

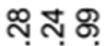

ลูণ<smiles>Cc1cc(C)cc(P(=O)(c2cc(C)cc(C)c2)c2cc(C)cc(C)c2)c1</smiles>

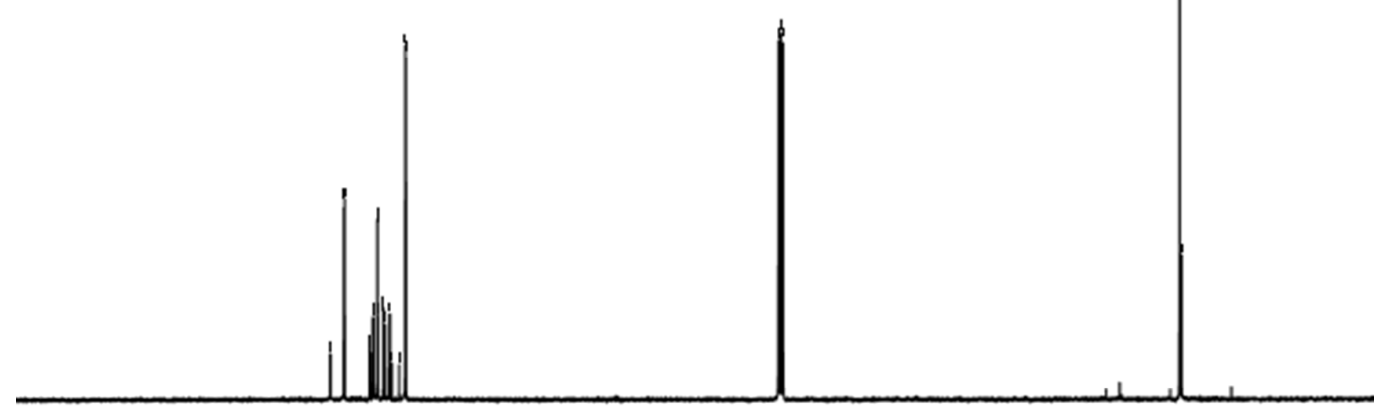

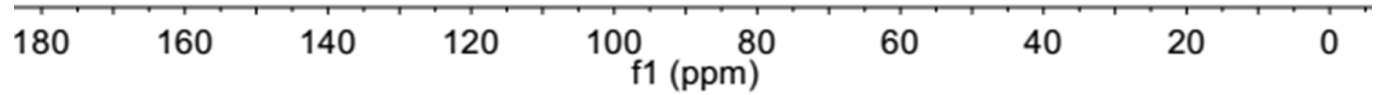




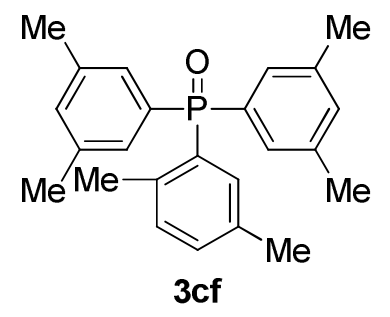

กั่
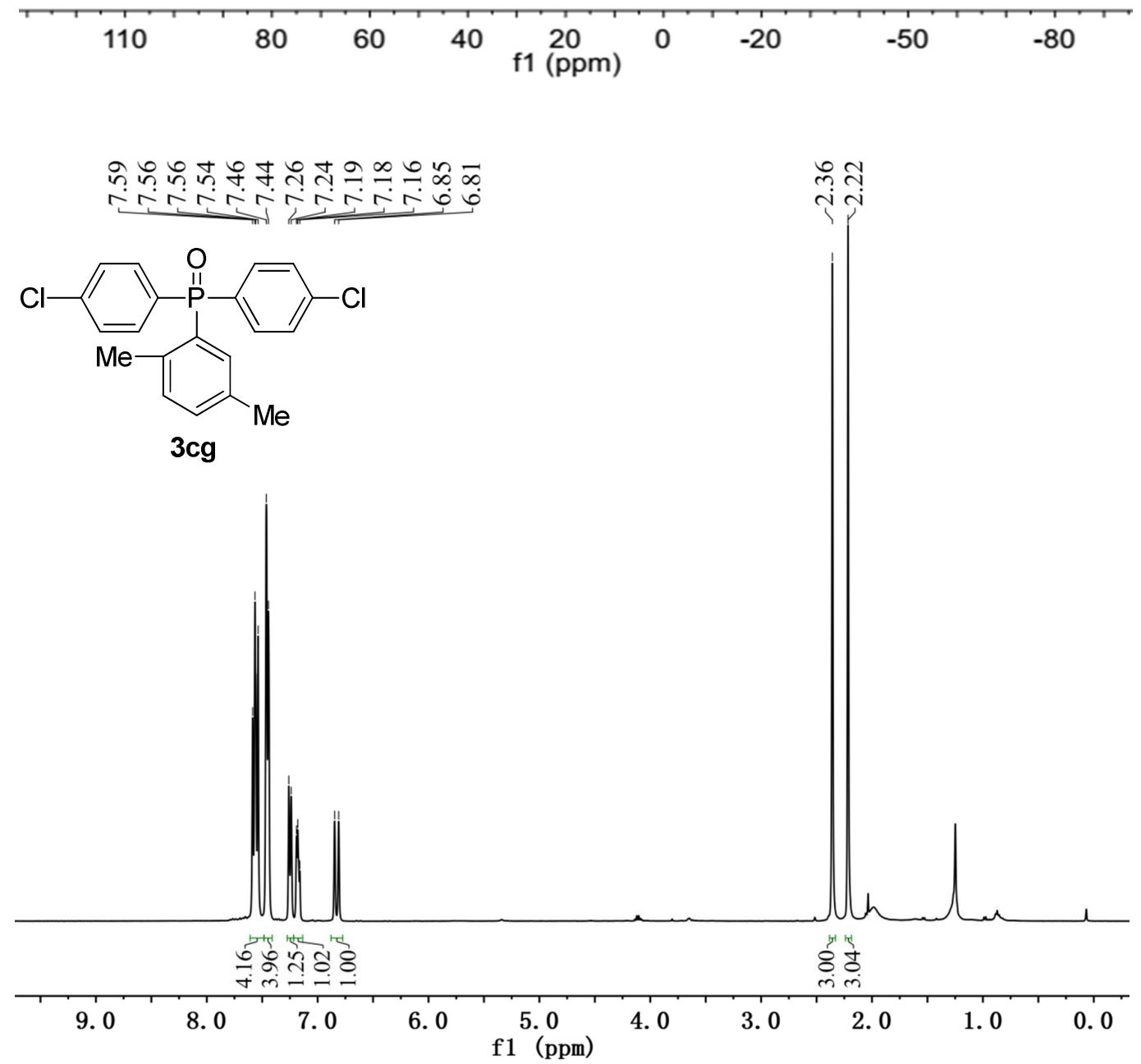

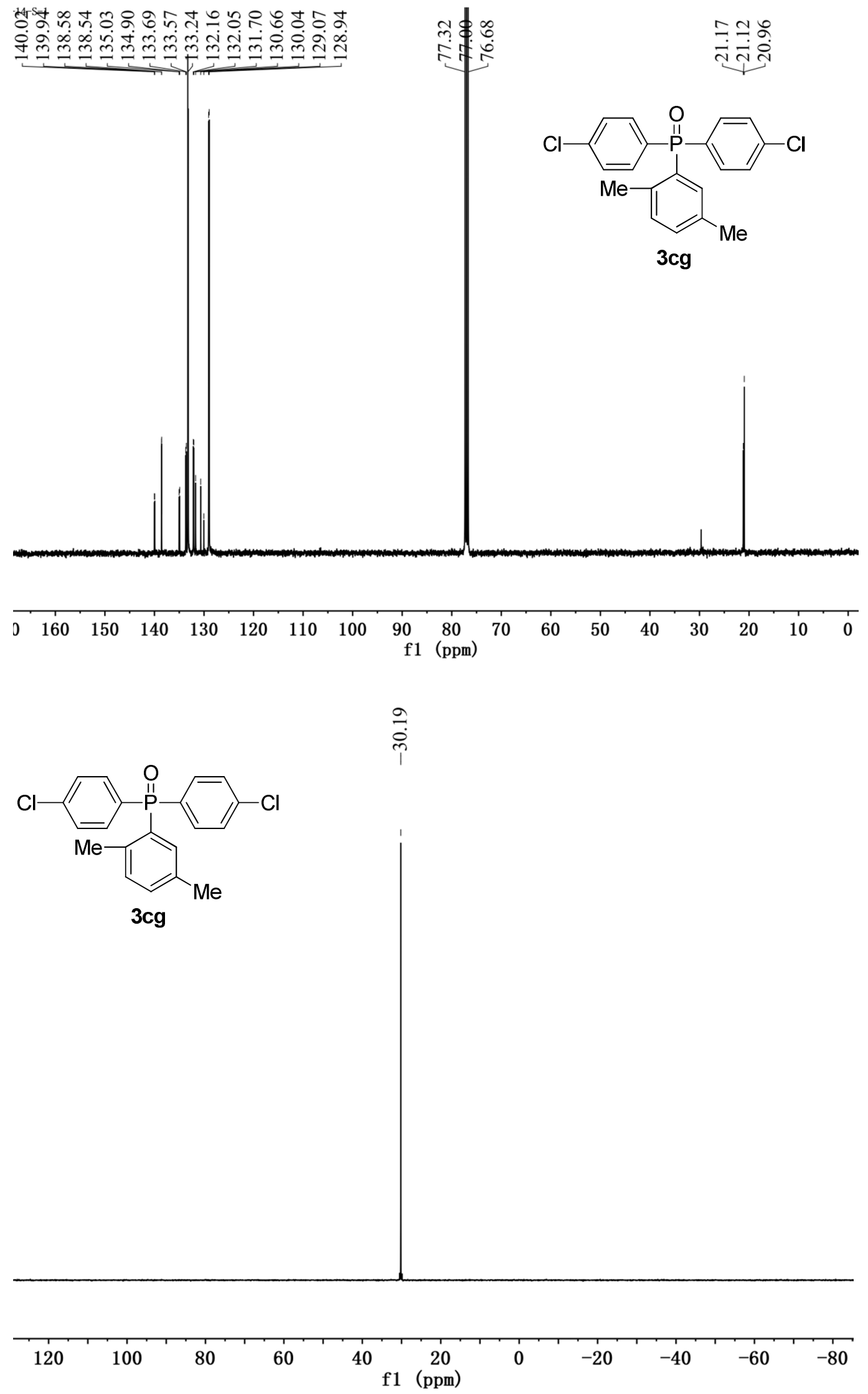

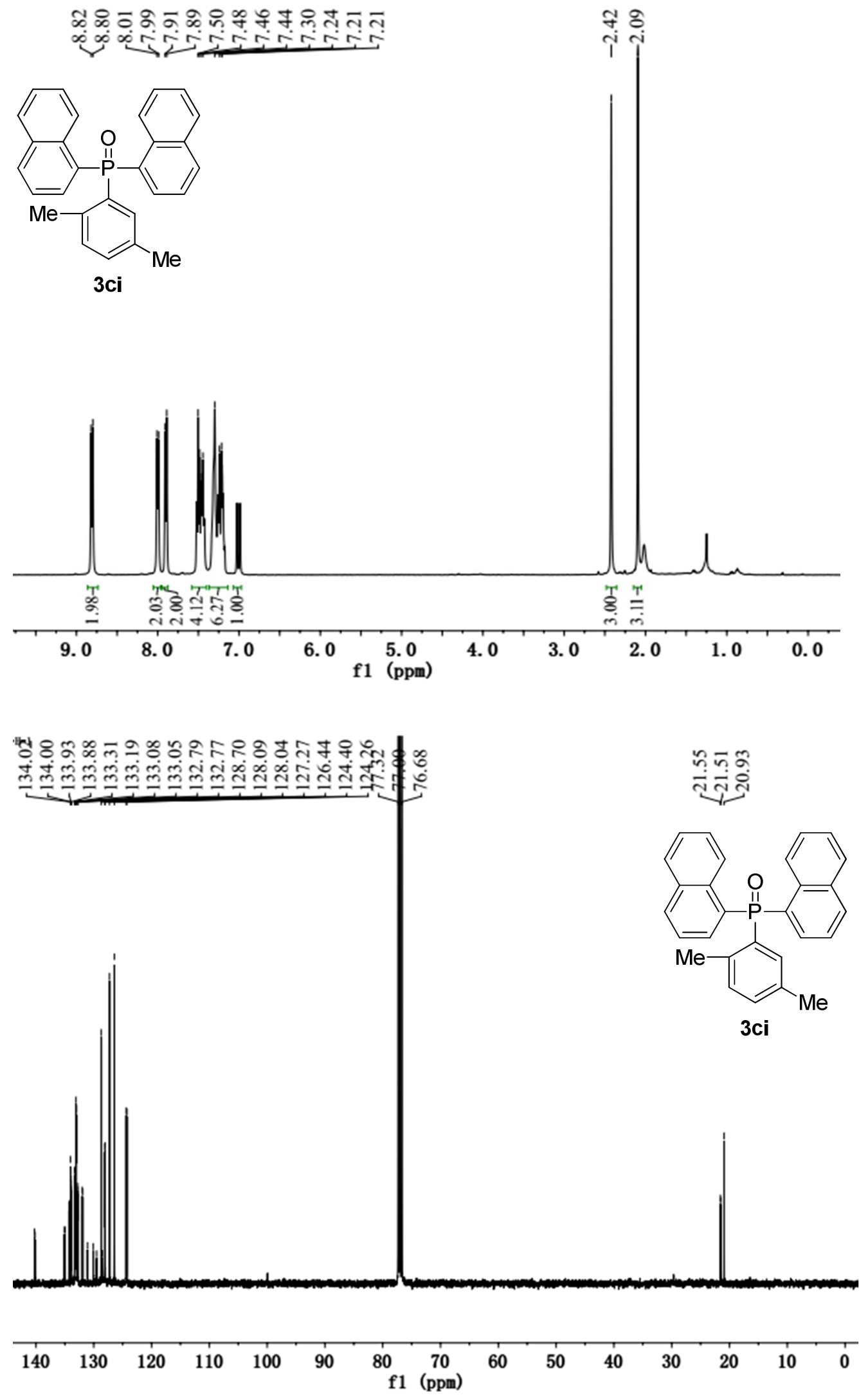

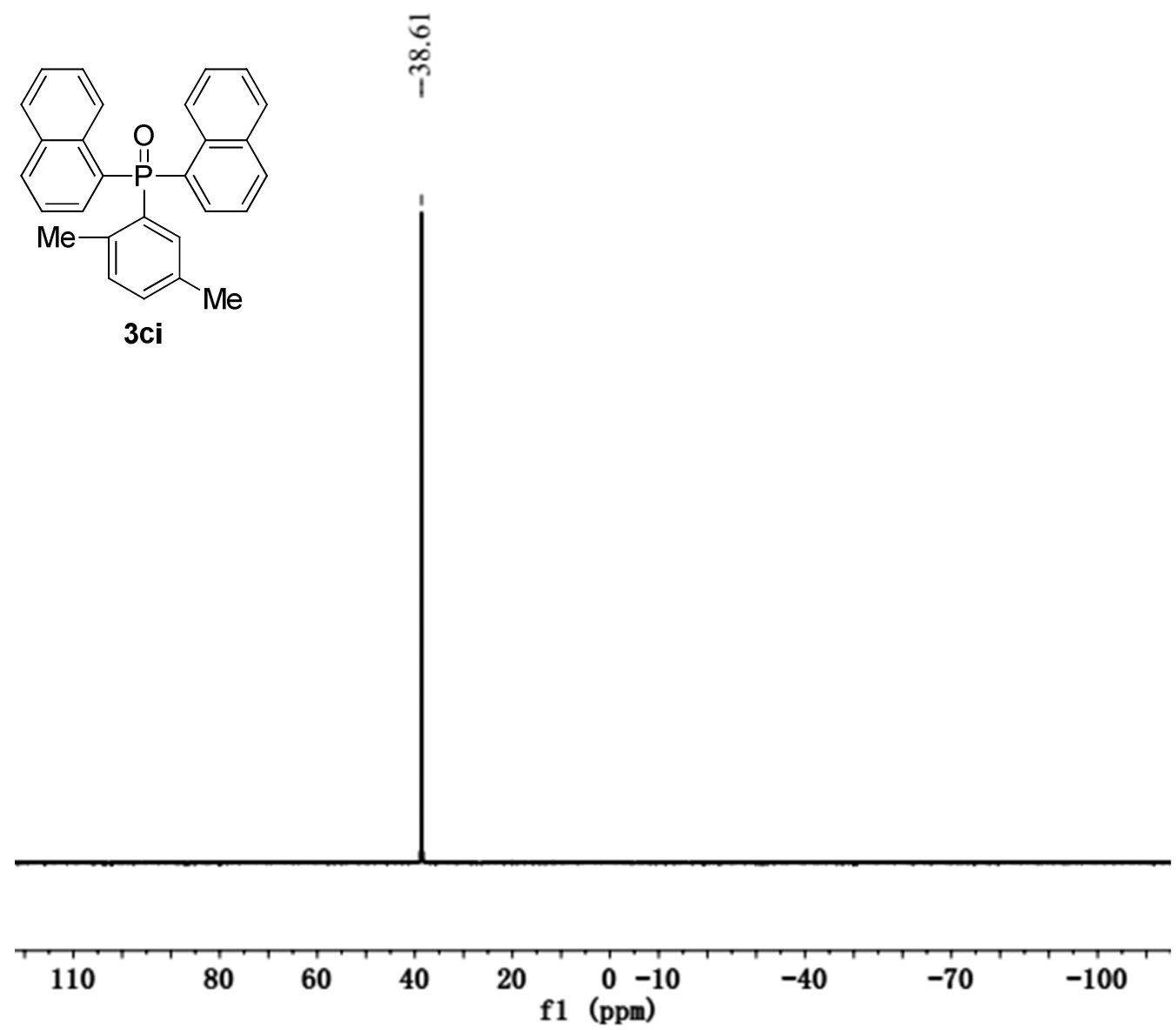

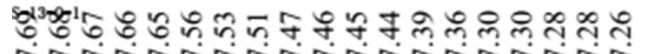

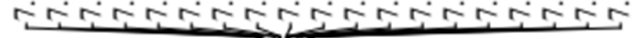

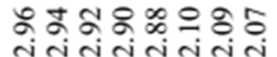

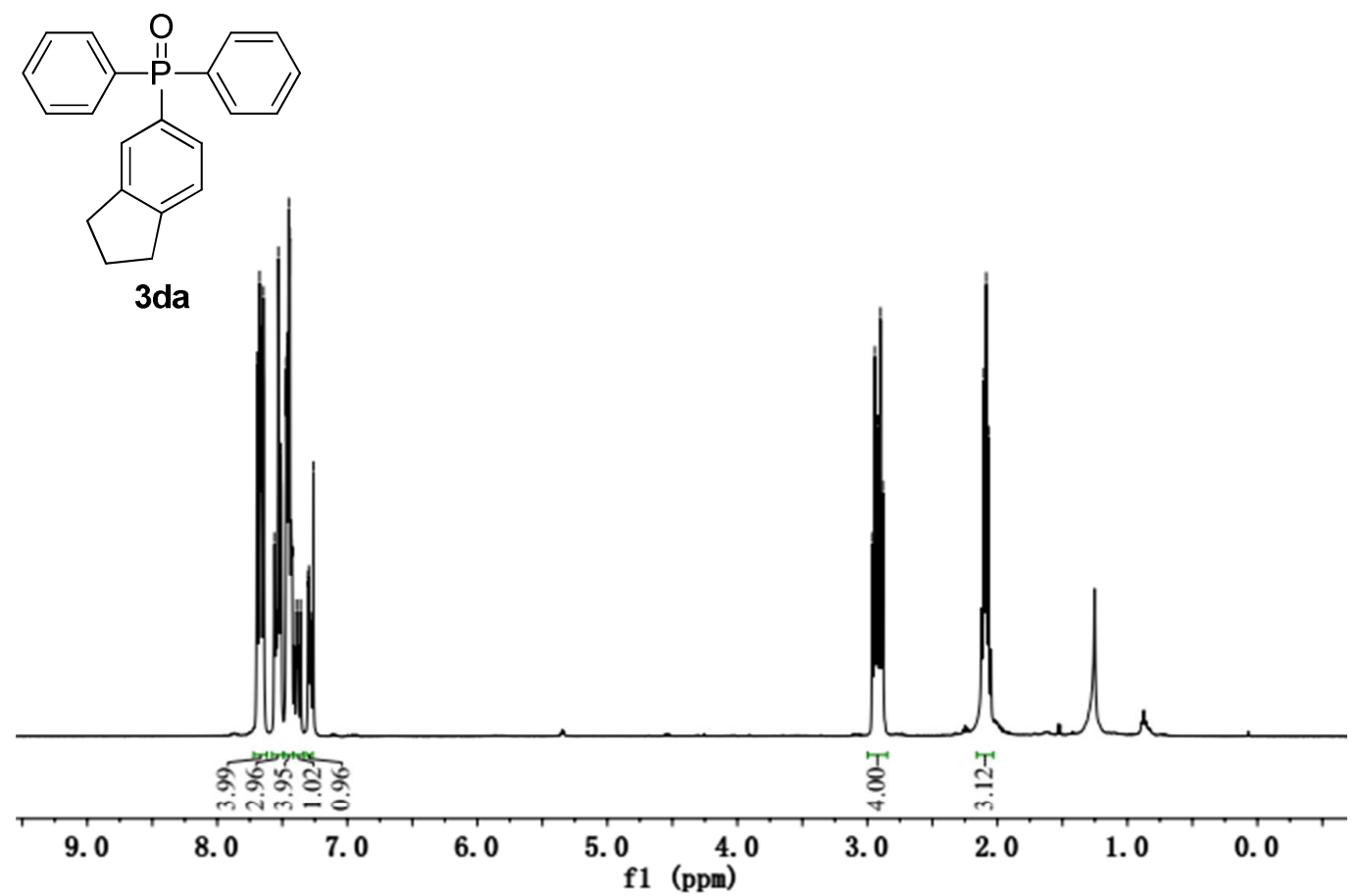



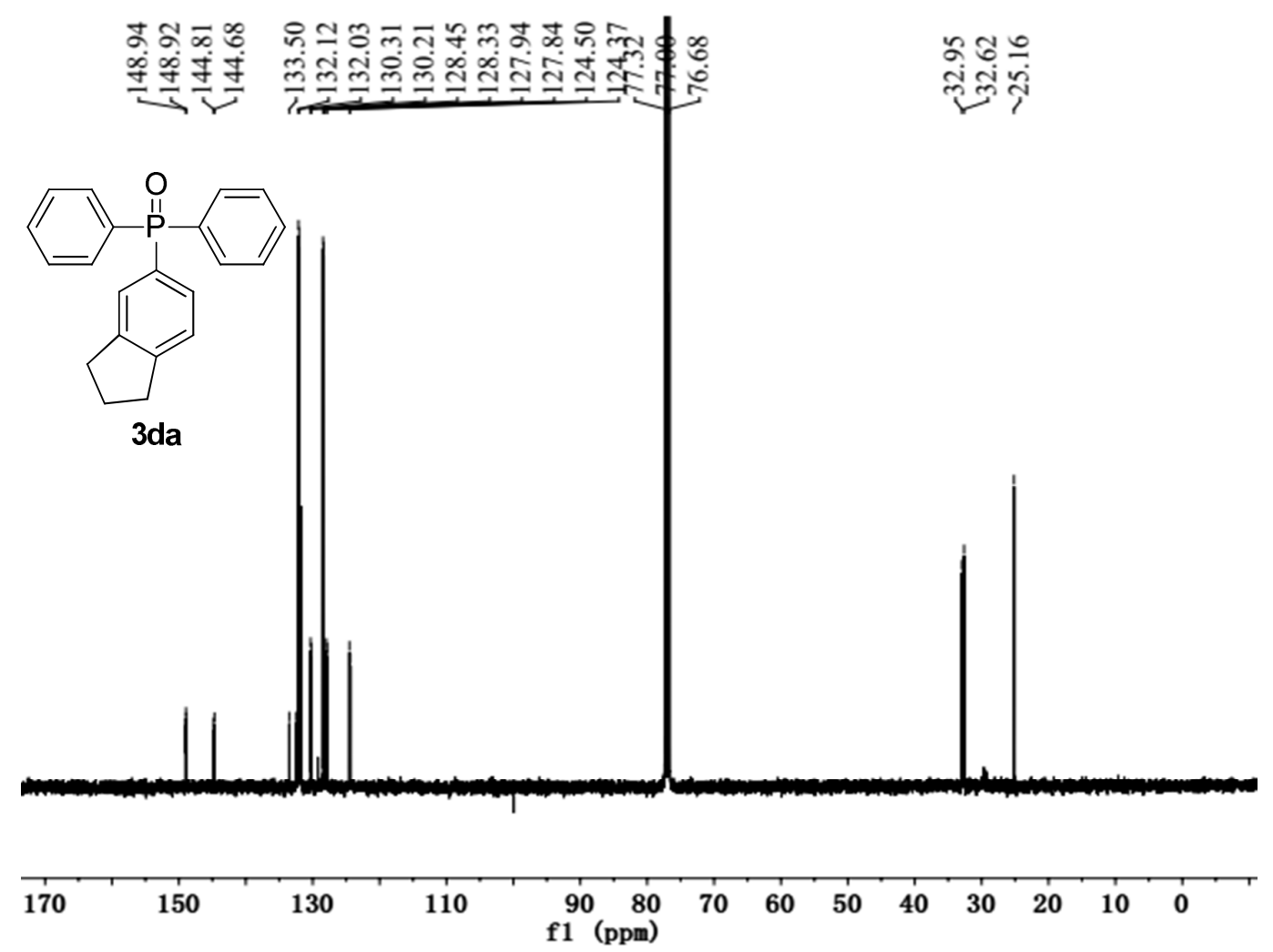

I

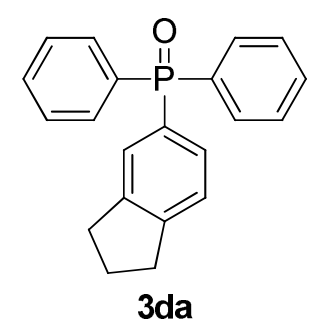

๙ิ่

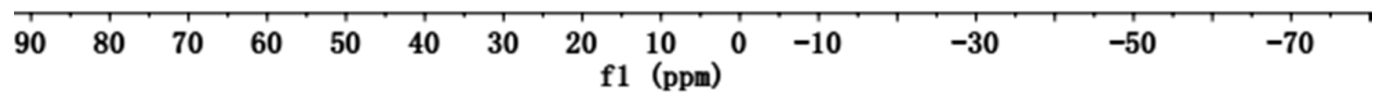



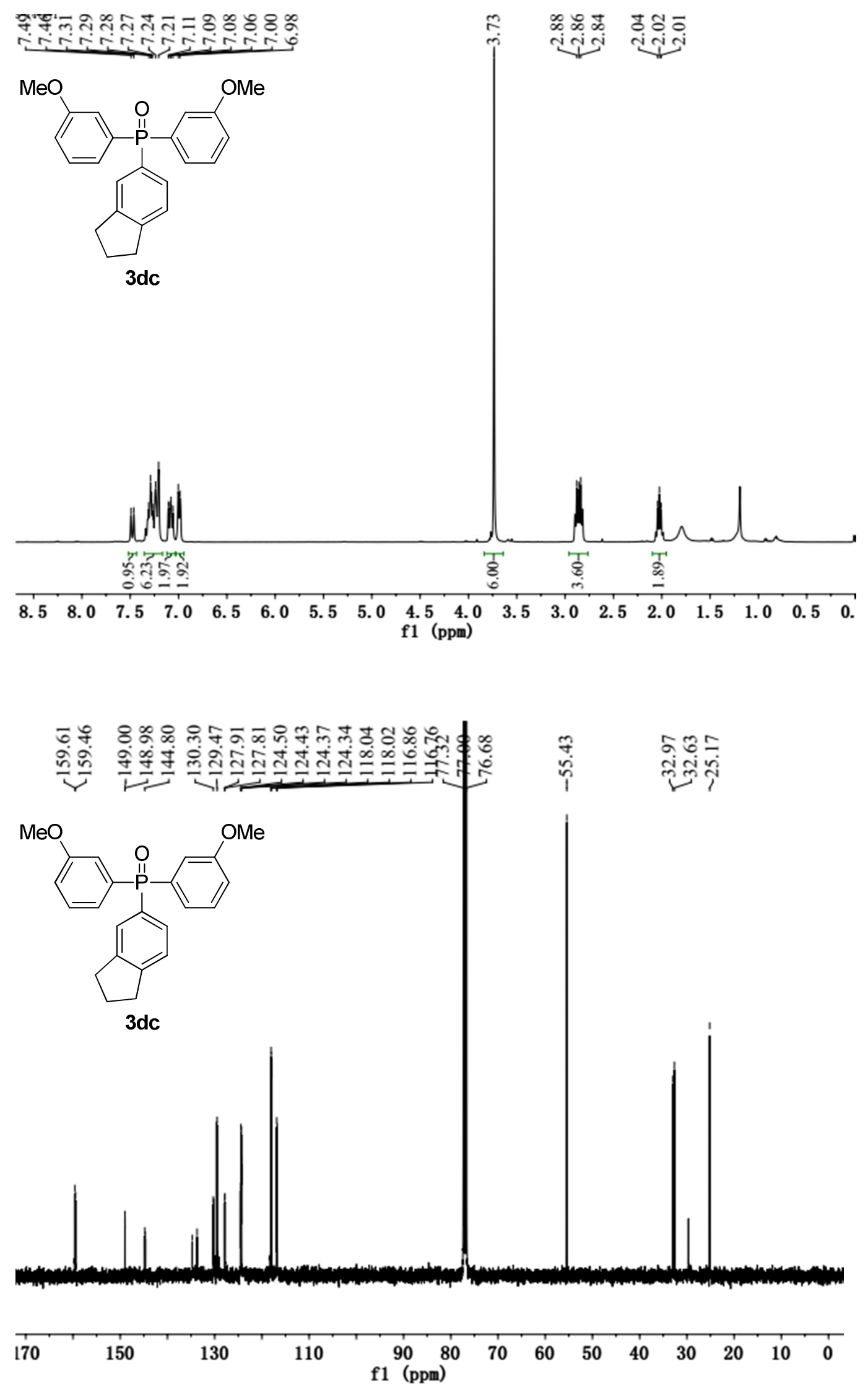
ָิ

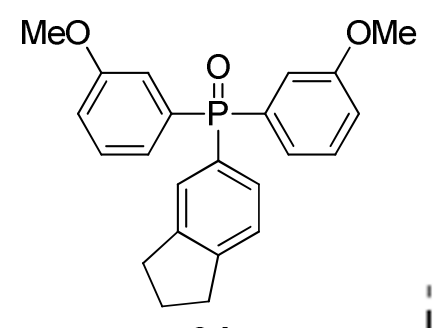

3dc

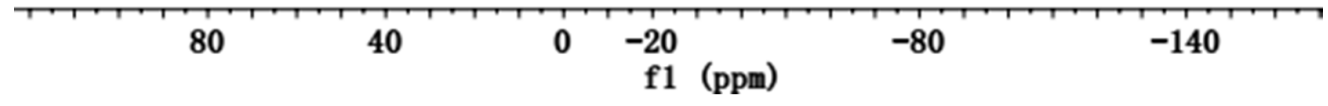

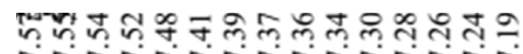

inicisinitir

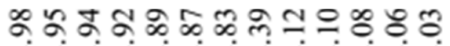

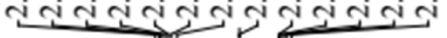

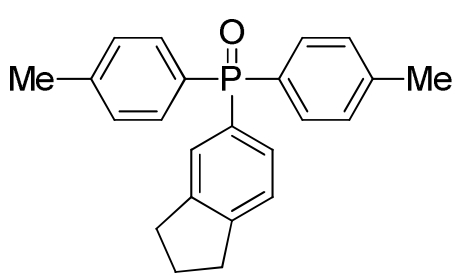

3dd

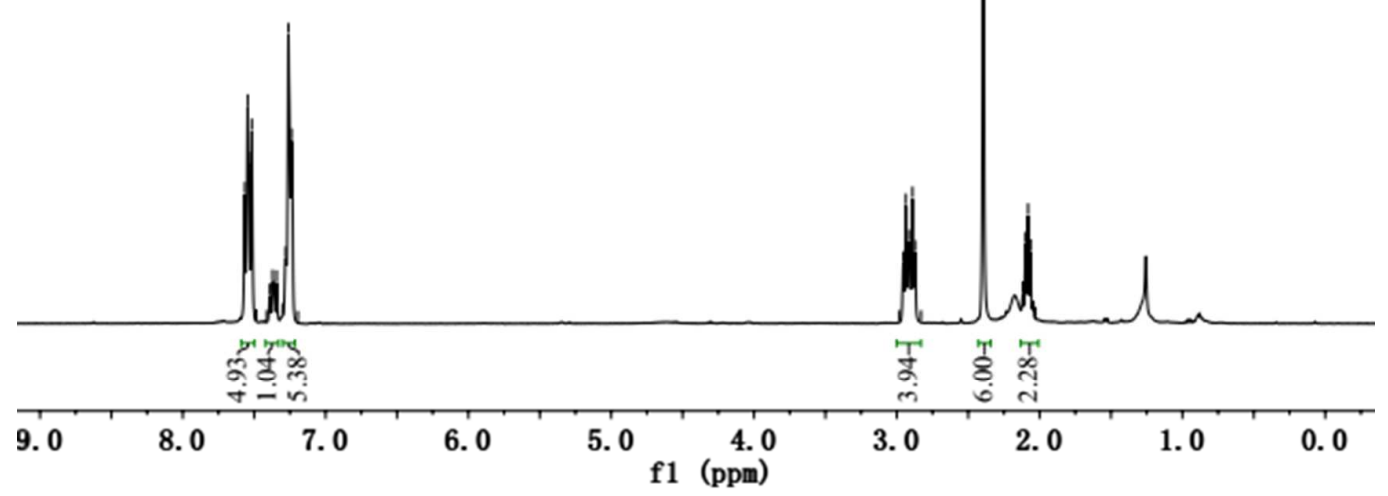



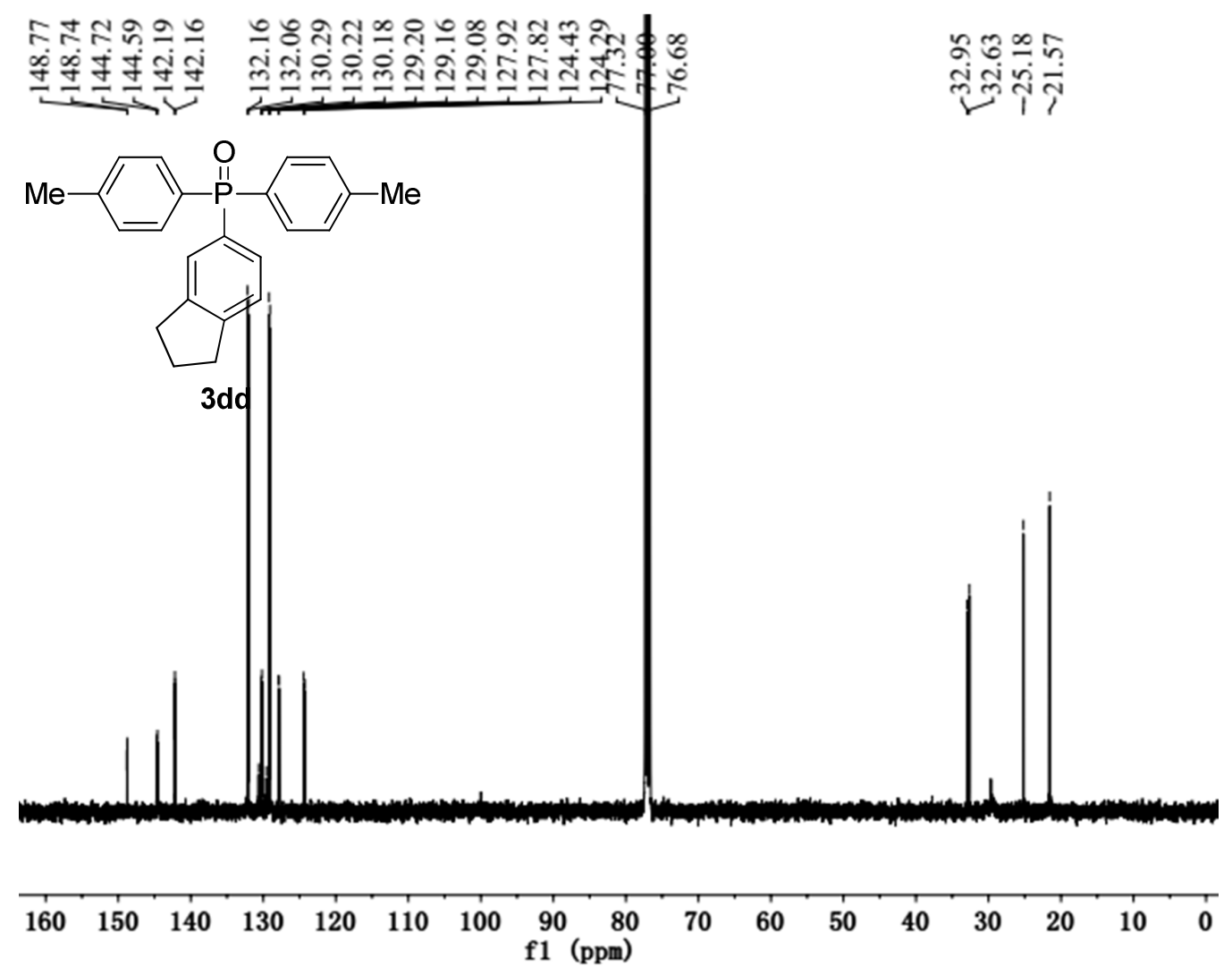

$\stackrel{\infty}{\stackrel{+}{+}}$

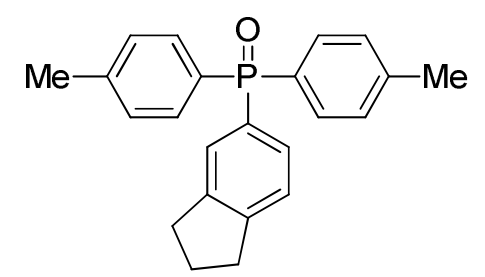

3dd

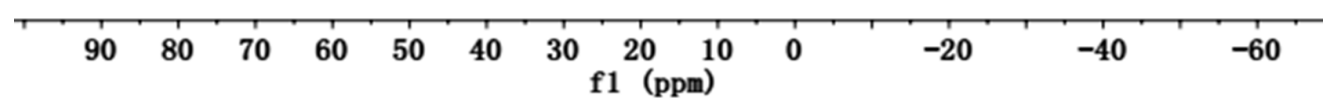



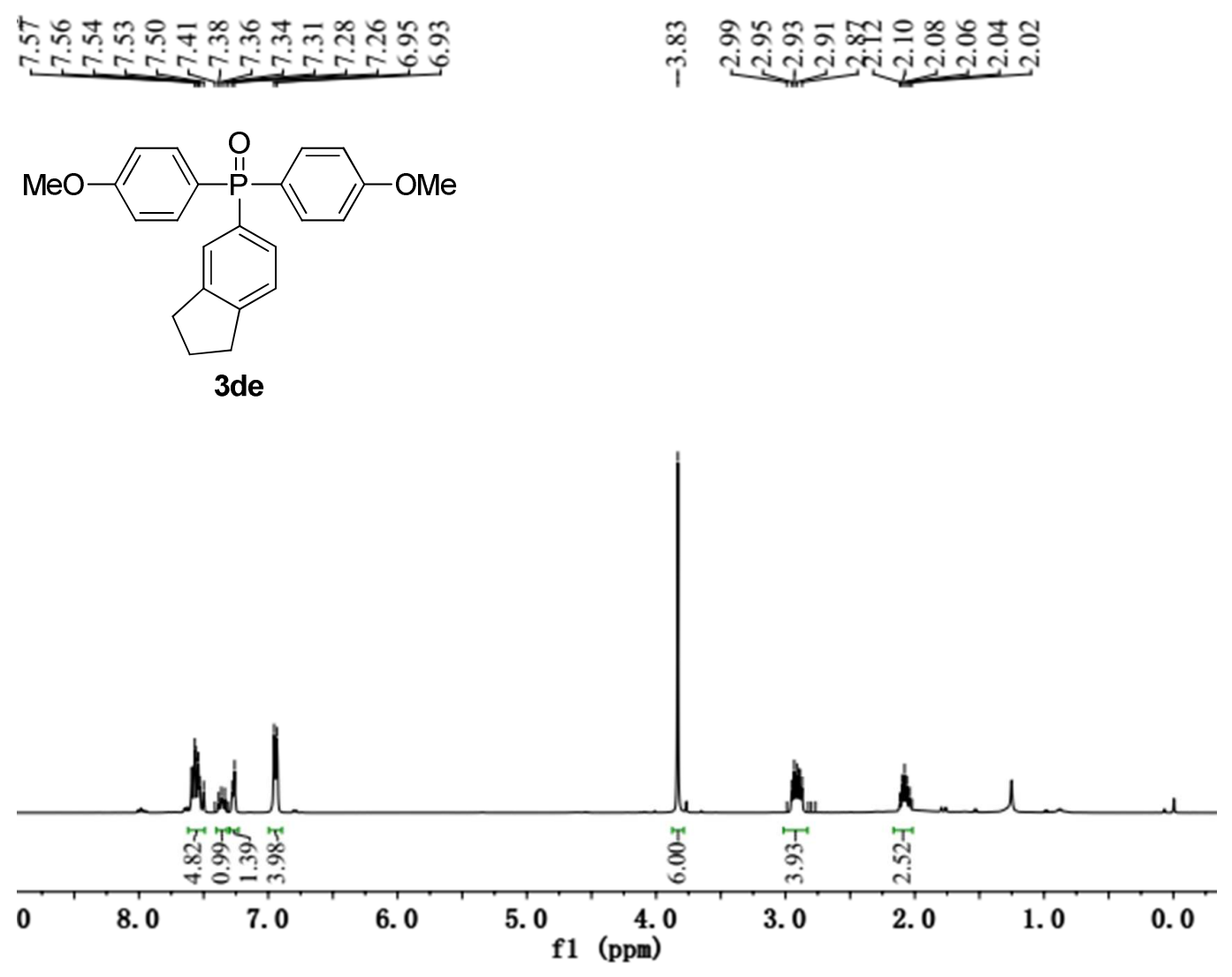

mกิ

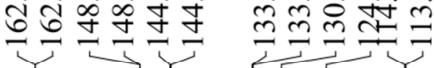
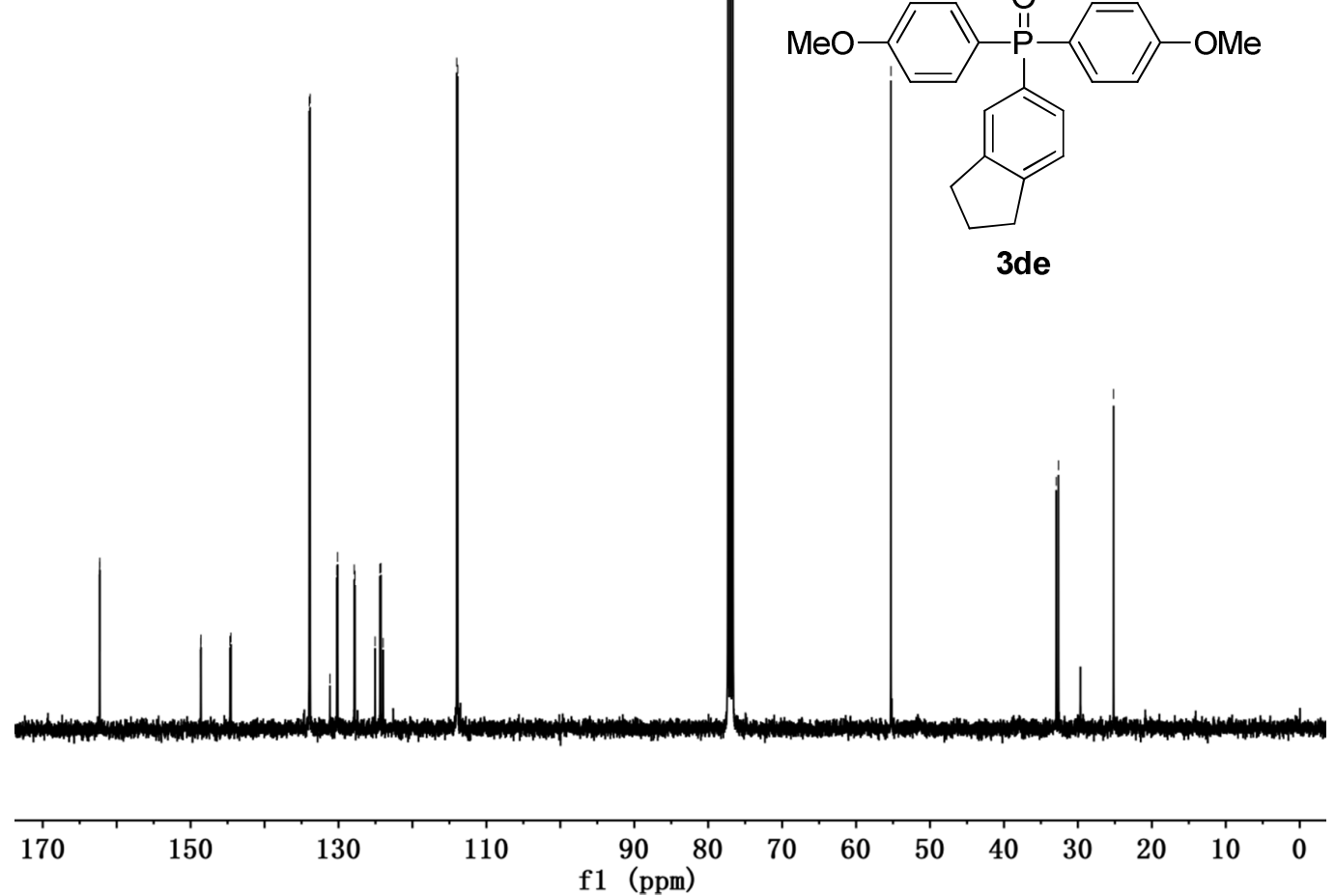


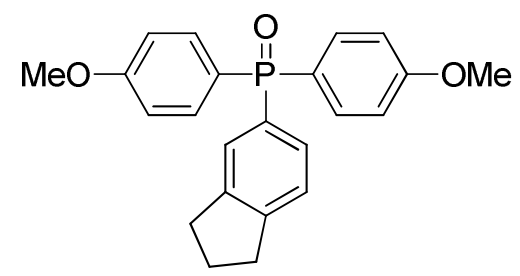

3de
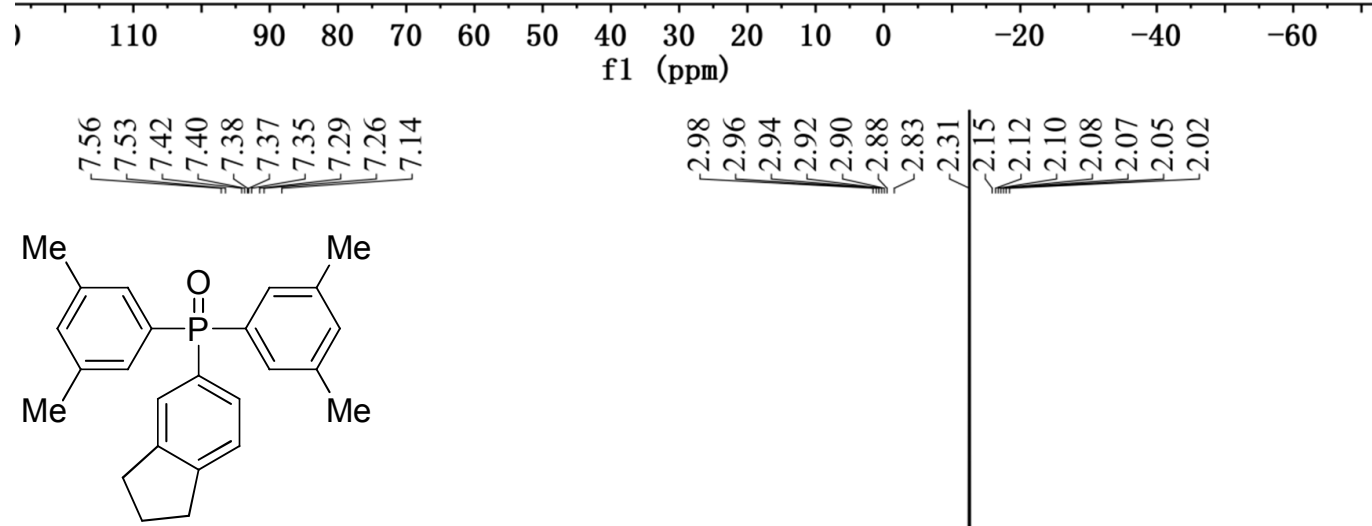

3df

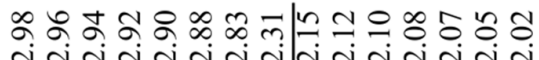

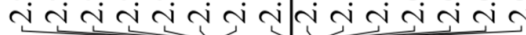

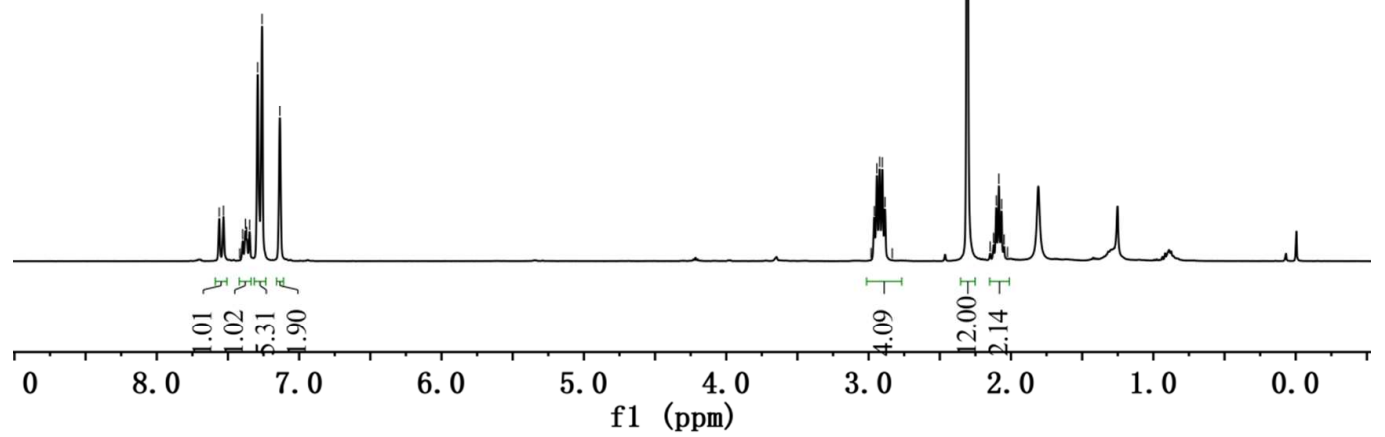



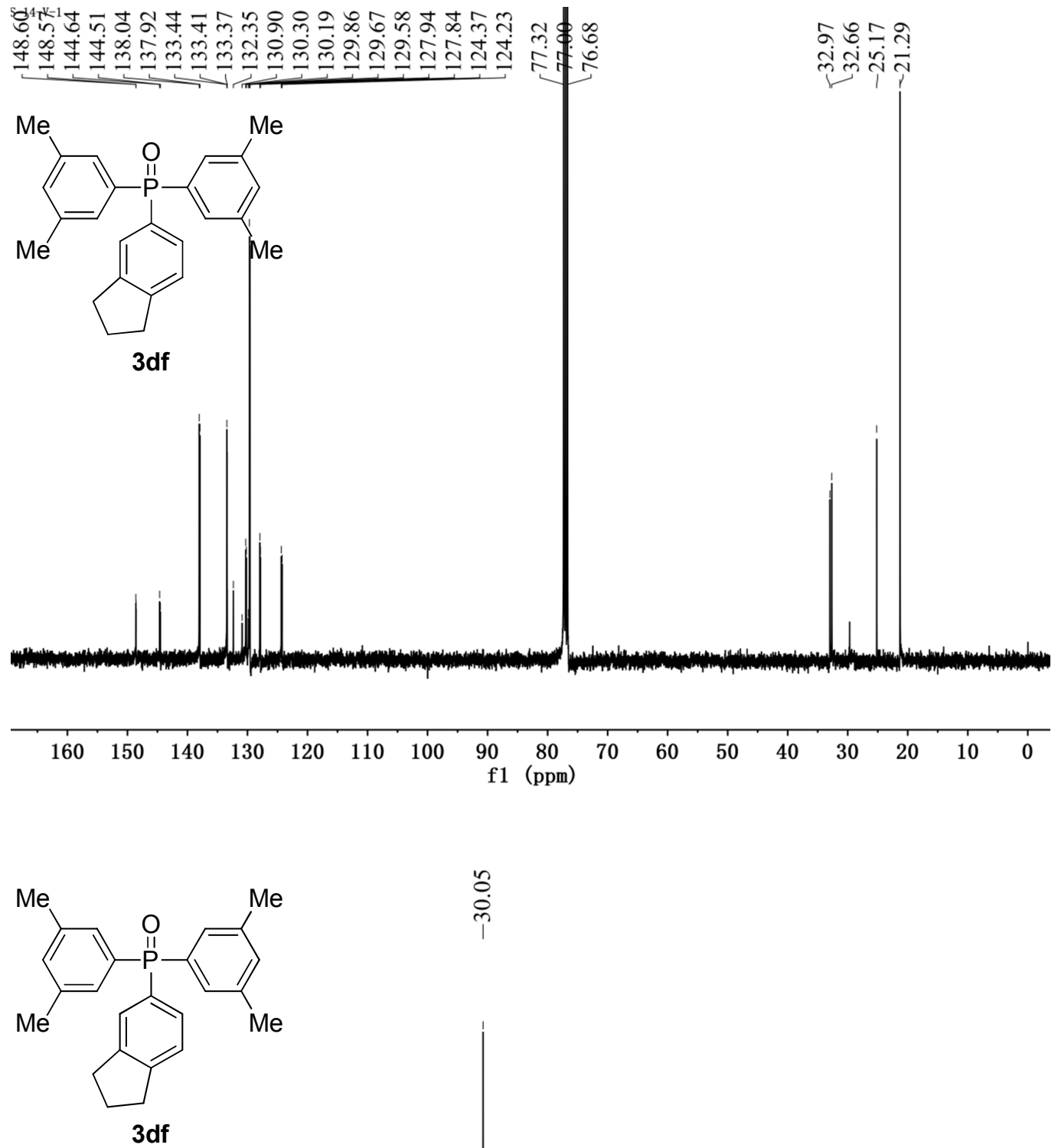

@๐

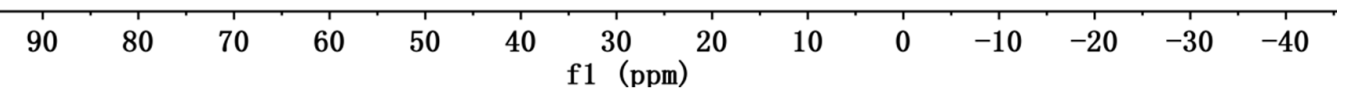




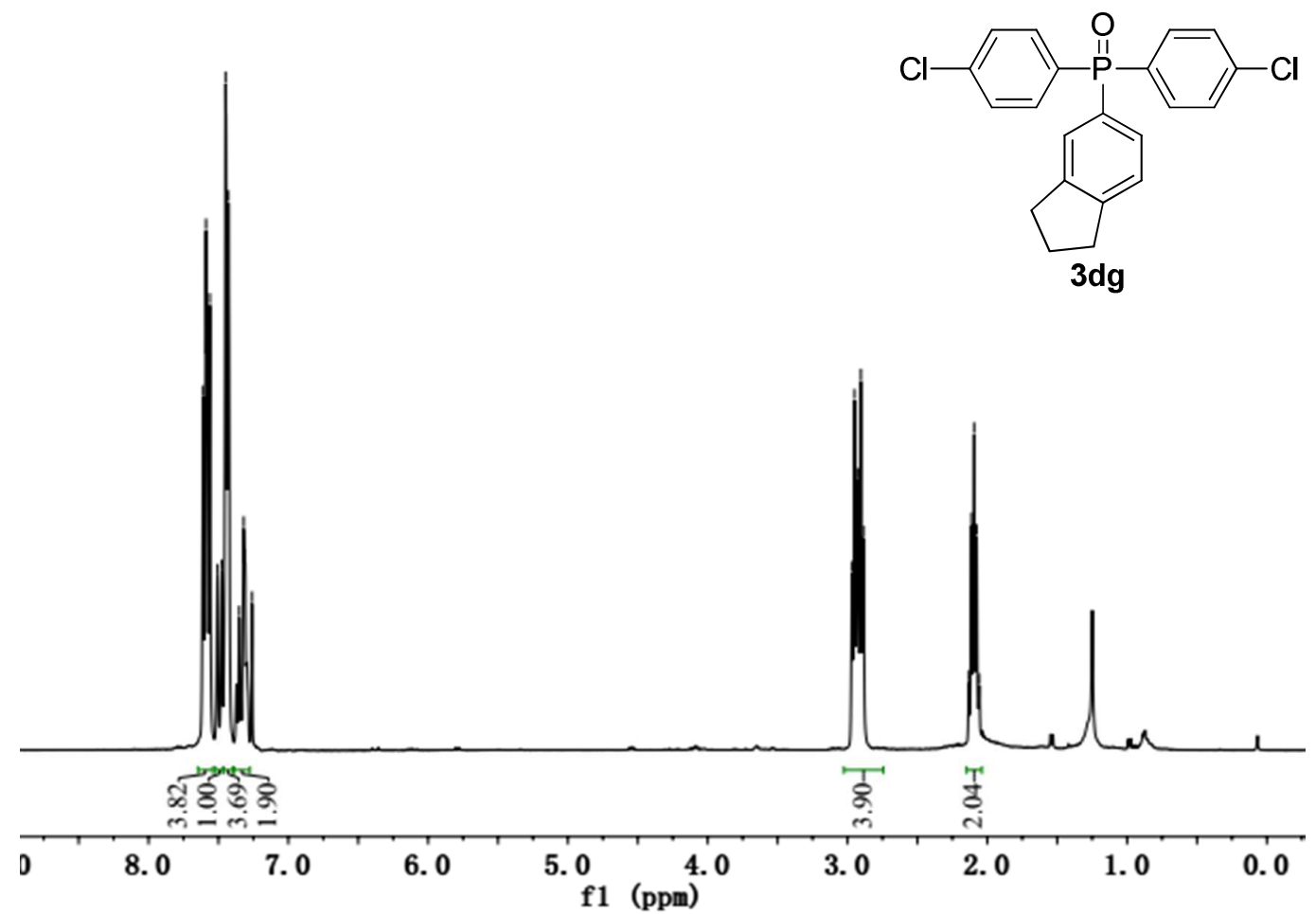

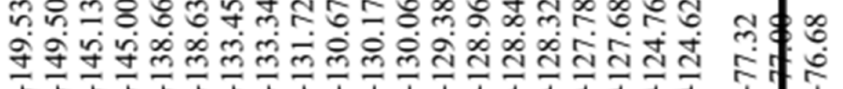<smiles></smiles><smiles></smiles>

)

170 150 130 110 f1 (ppm)

20ำ. ขูู่่ิ 


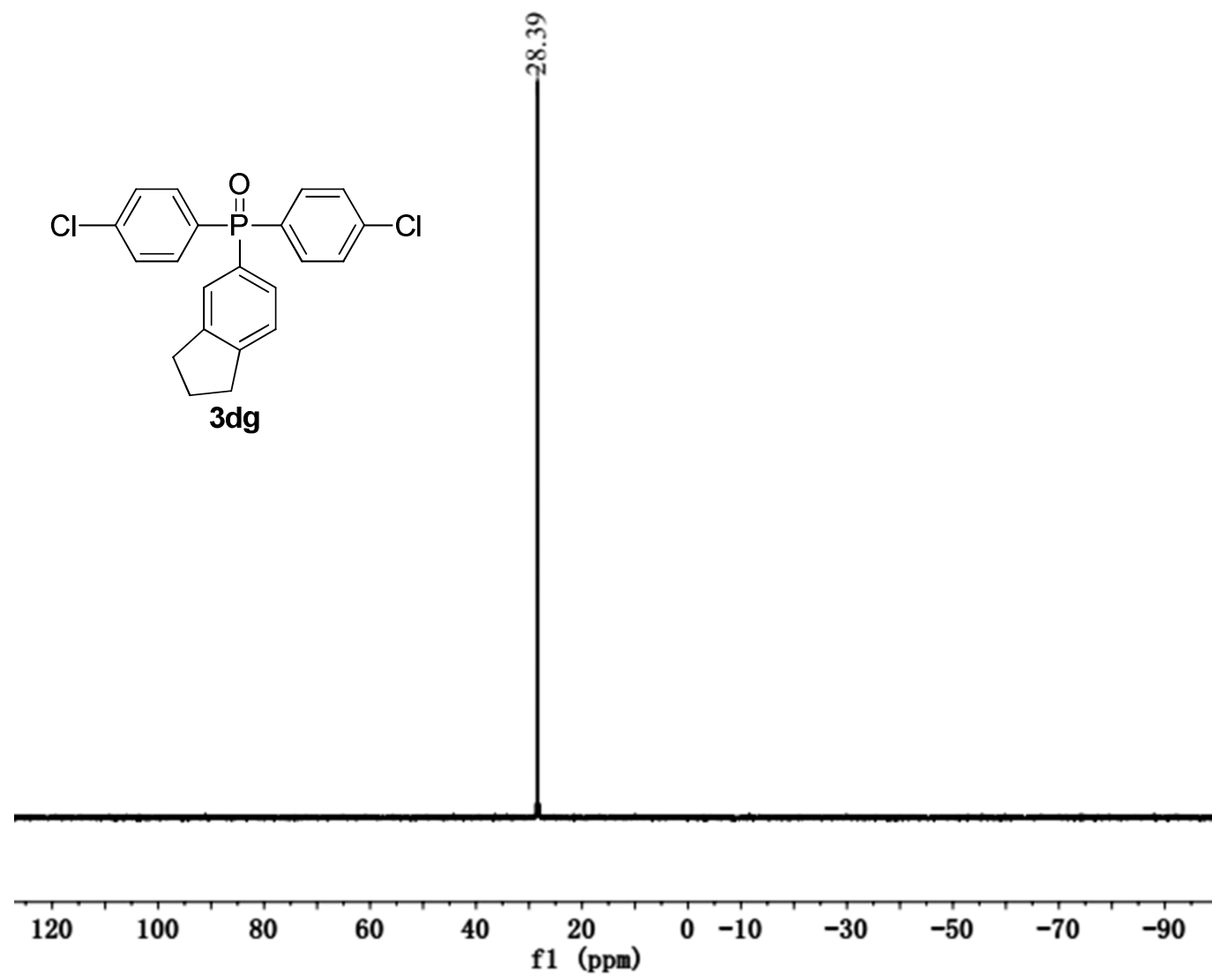

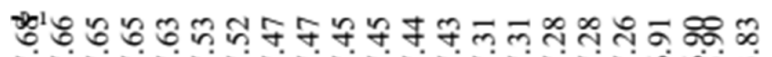

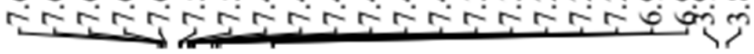

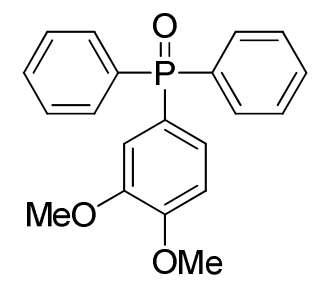

3ea

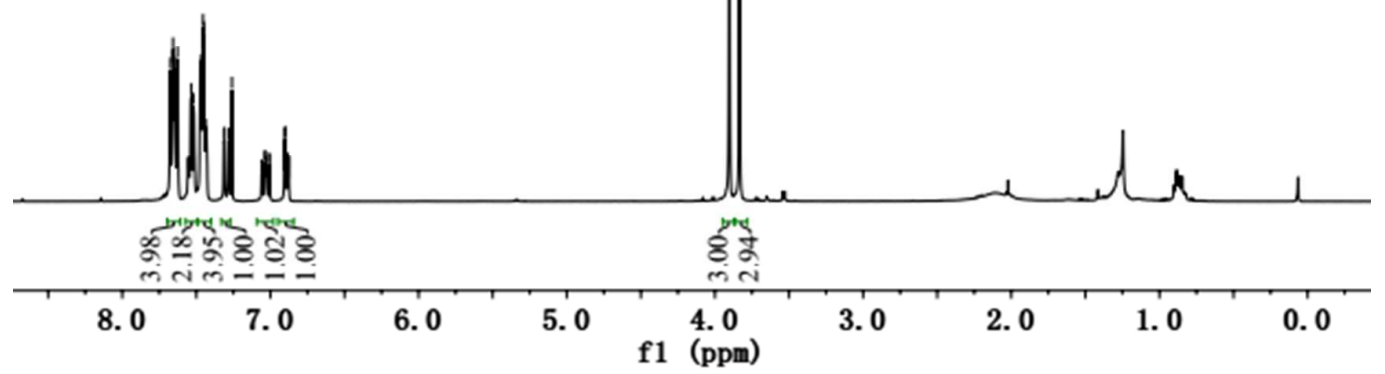



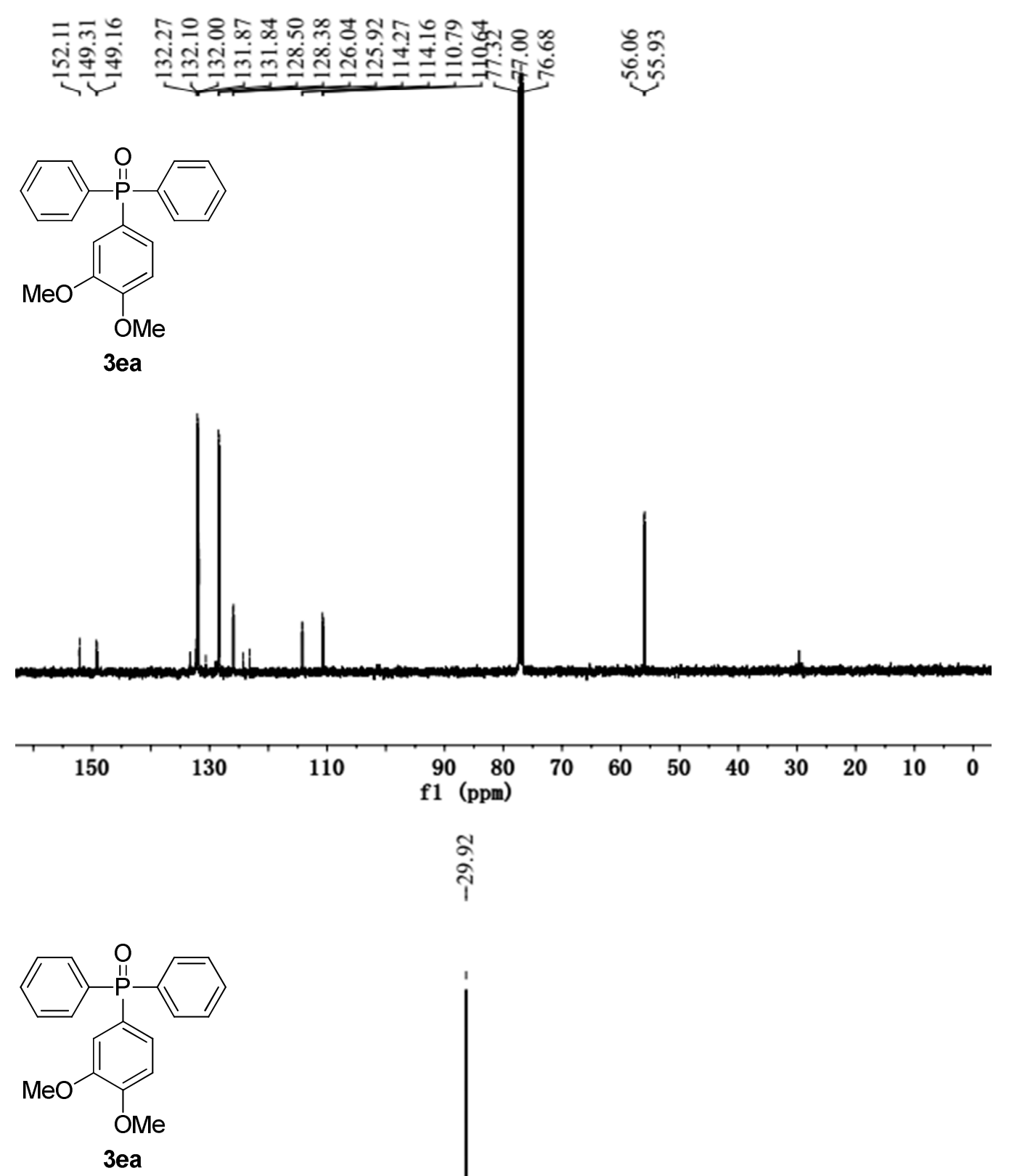

$\begin{array}{lllllllllllll}110 & 90 & 80 & 70 & 60 & 50 & 40 \underset{\mathrm{f} 1}{30} \begin{array}{l}30 \\ (\mathrm{ppm})\end{array} & 10 & 0 & -20 & -40 & -60\end{array}$




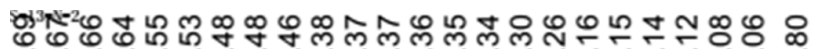

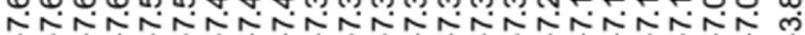<smiles>COc1cccc(P(=O)(c2ccccc2)c2ccccc2)c1</smiles>

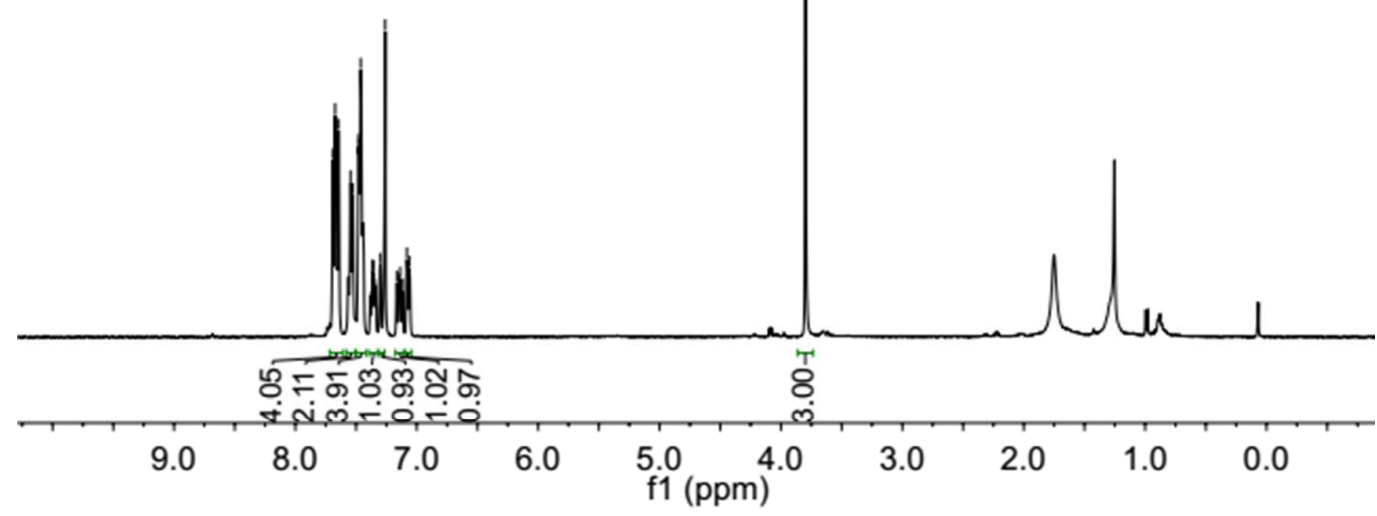

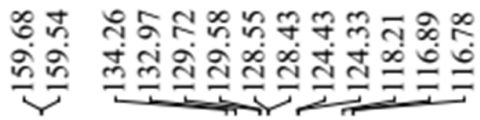<smiles>COc1cccc(P(=O)(c2ccccc2)c2ccccc2)c1</smiles>
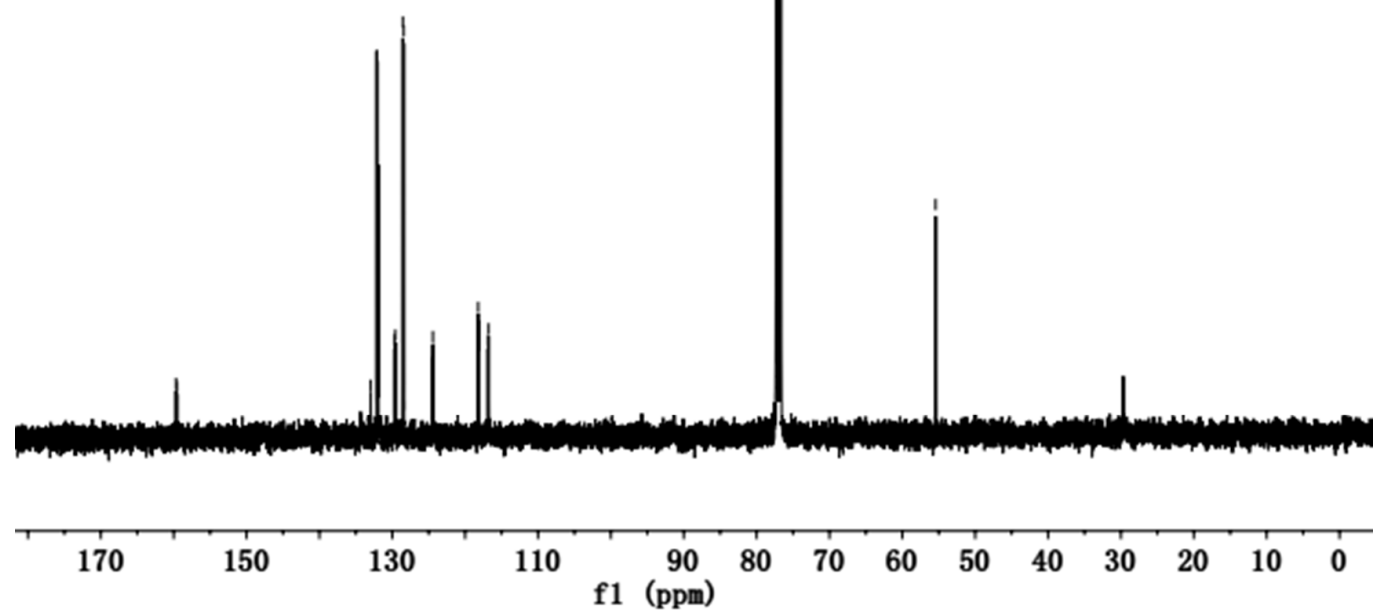
2<smiles>COc1cccc(P(=O)(c2ccccc2)c2ccccc2)c1</smiles>

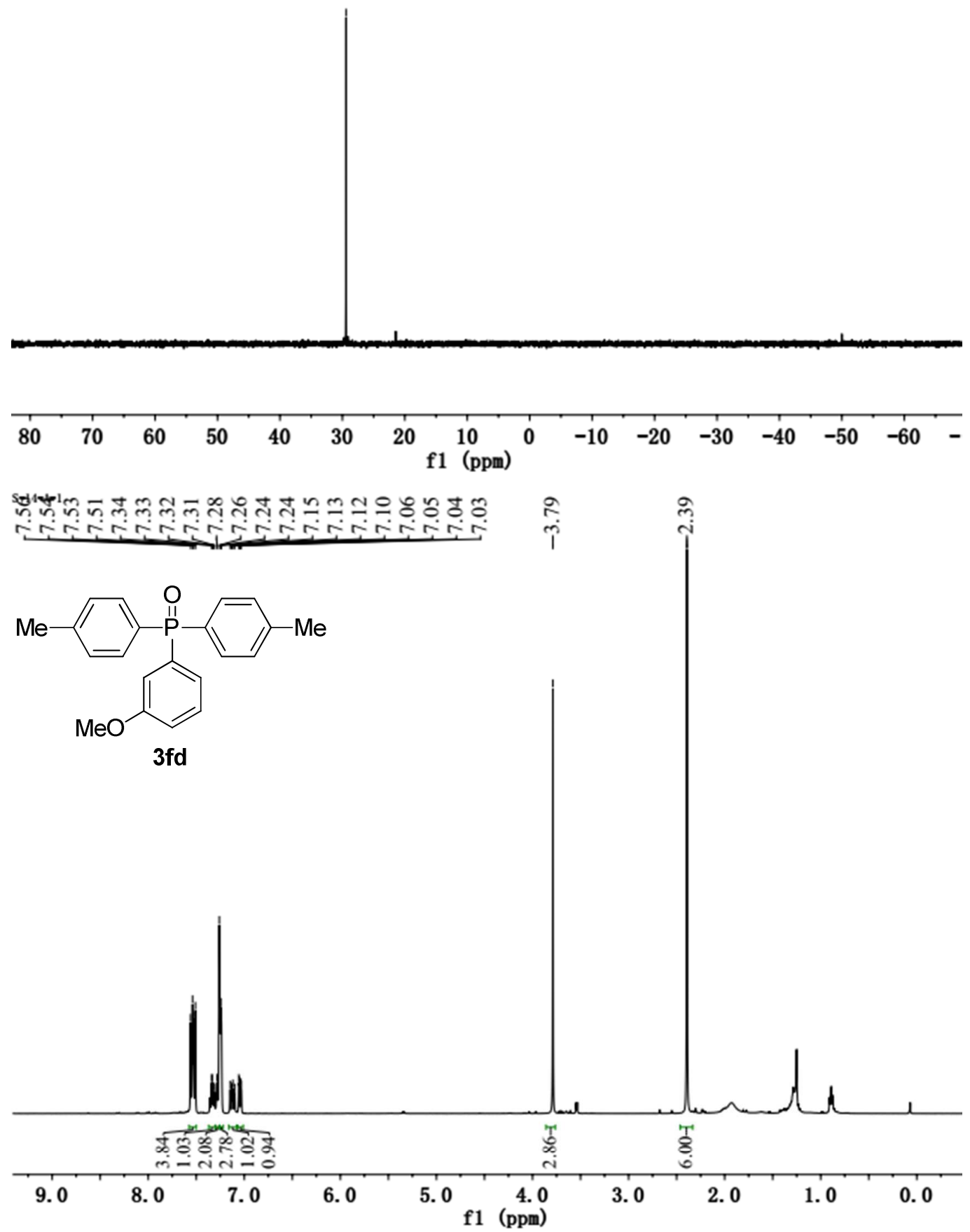



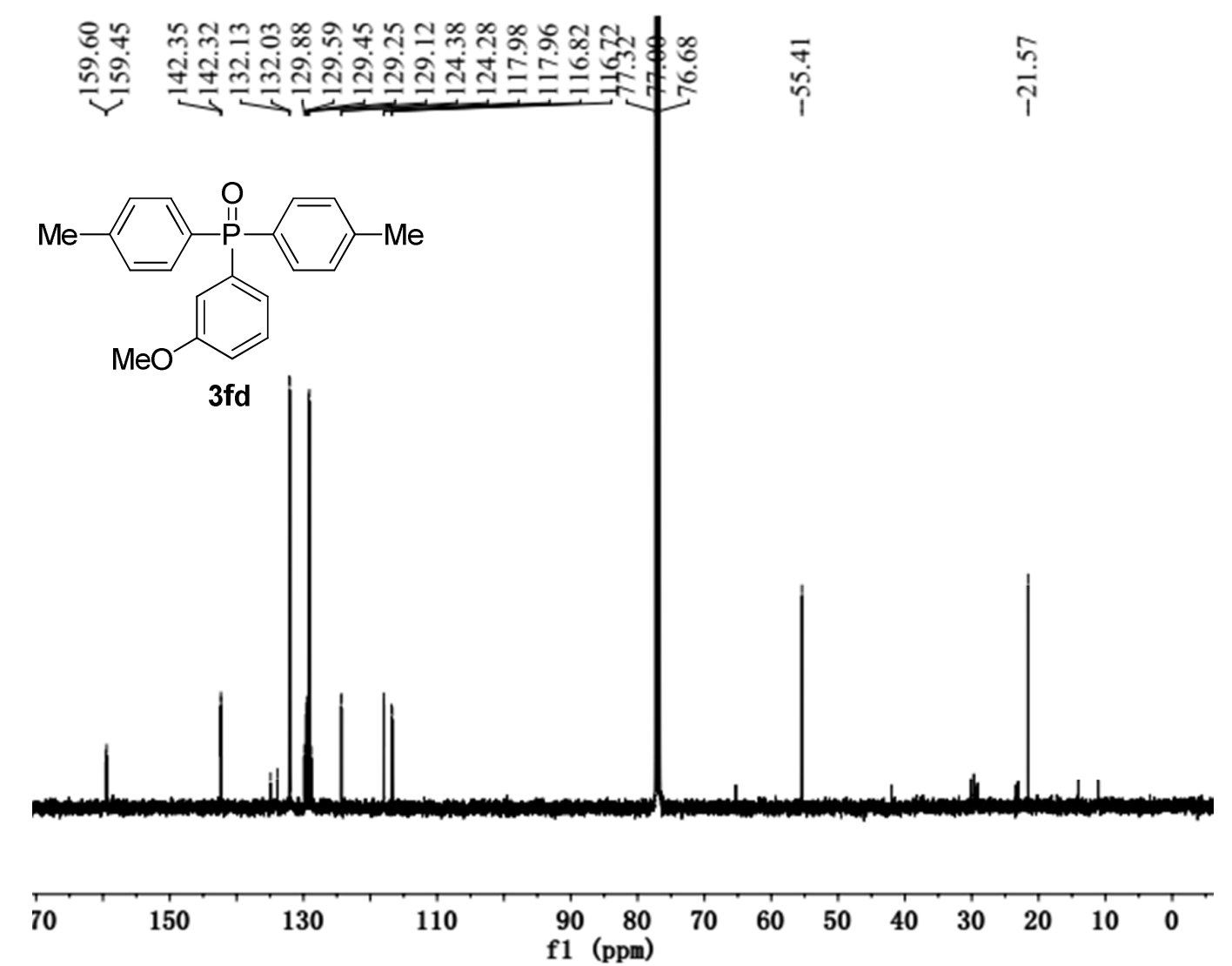

$|-|-1$
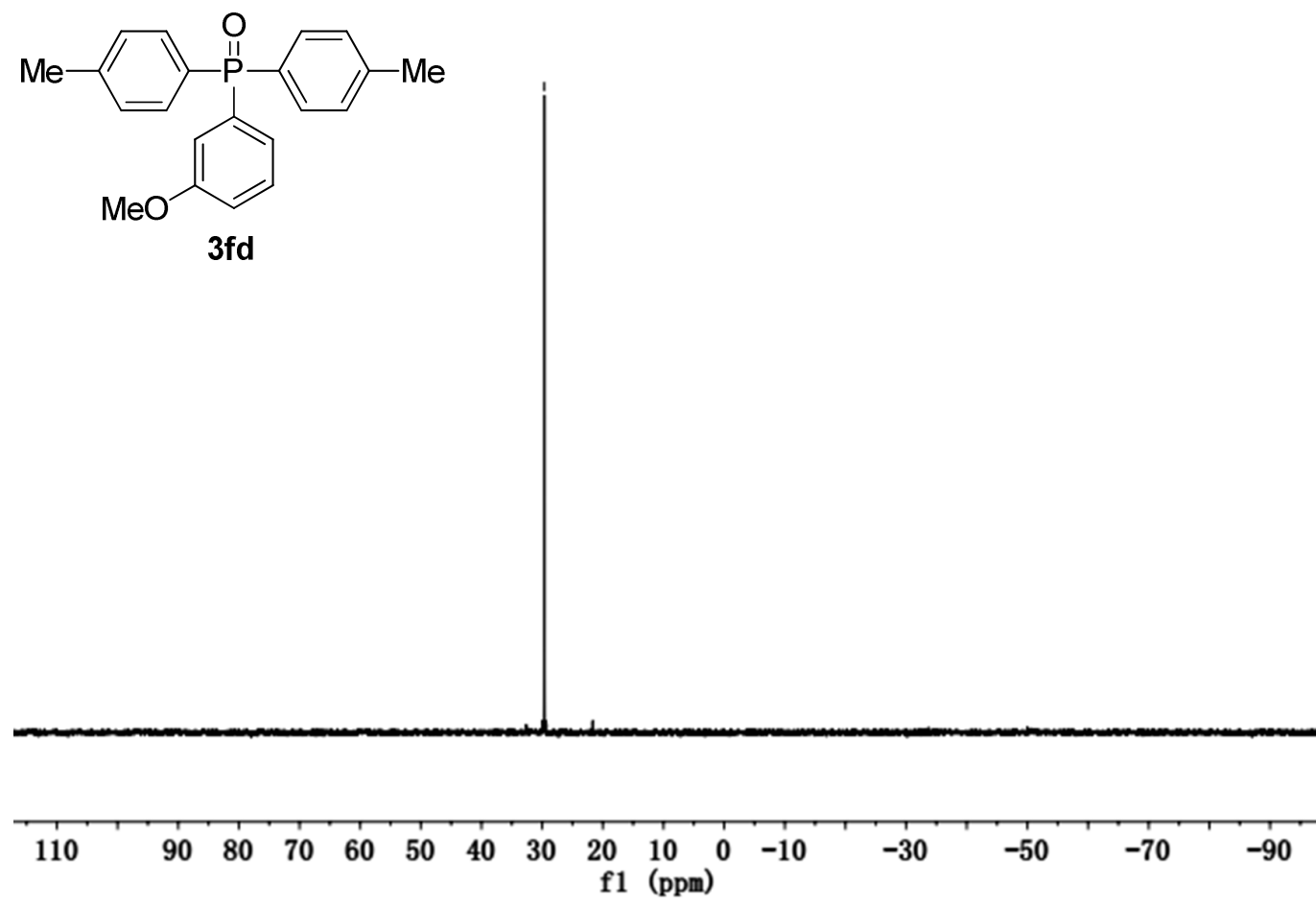

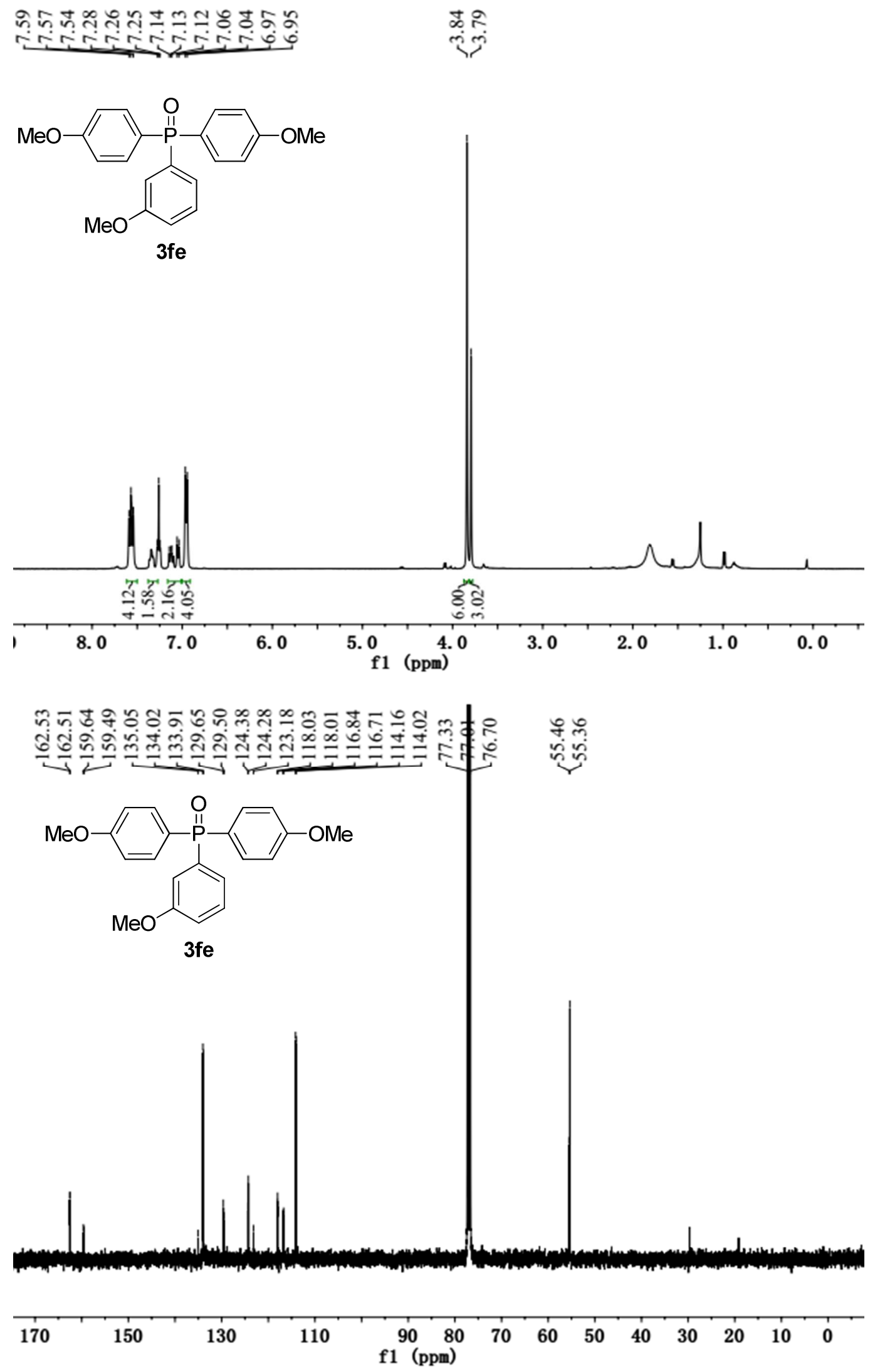

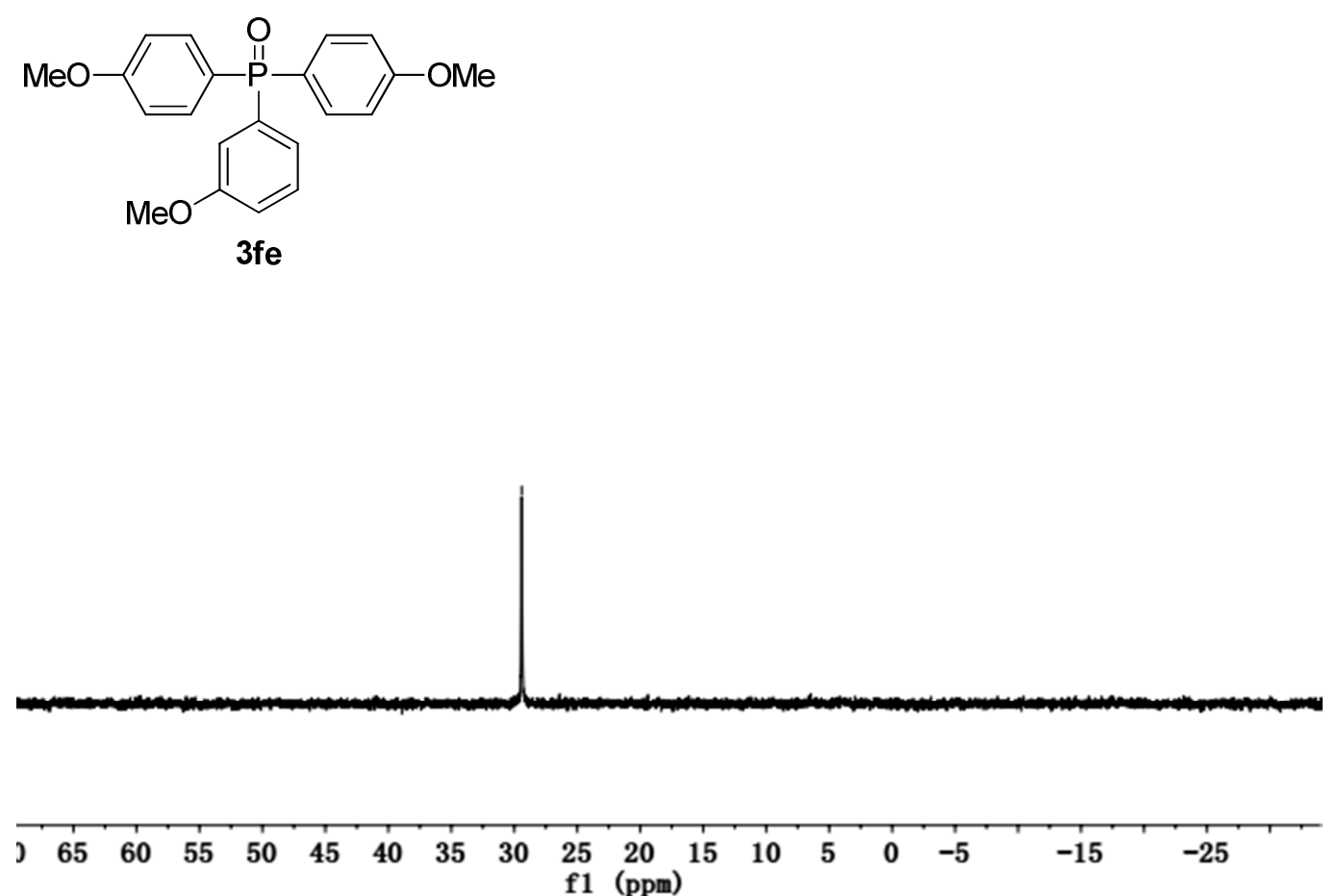

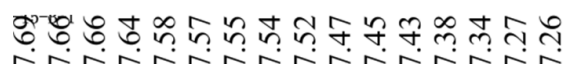

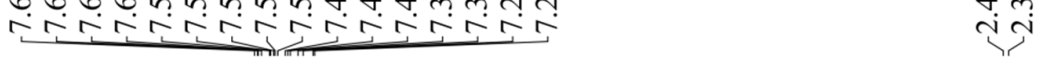<smiles>Cc1ccc(P(=O)(c2ccccc2)c2ccccc2)cc1</smiles>

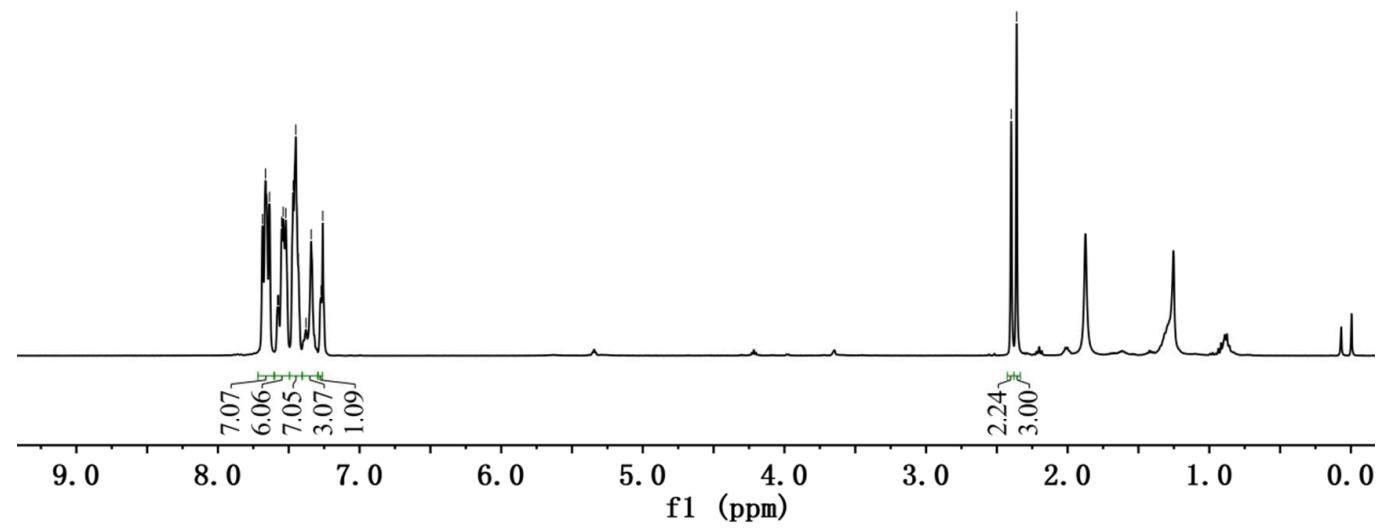



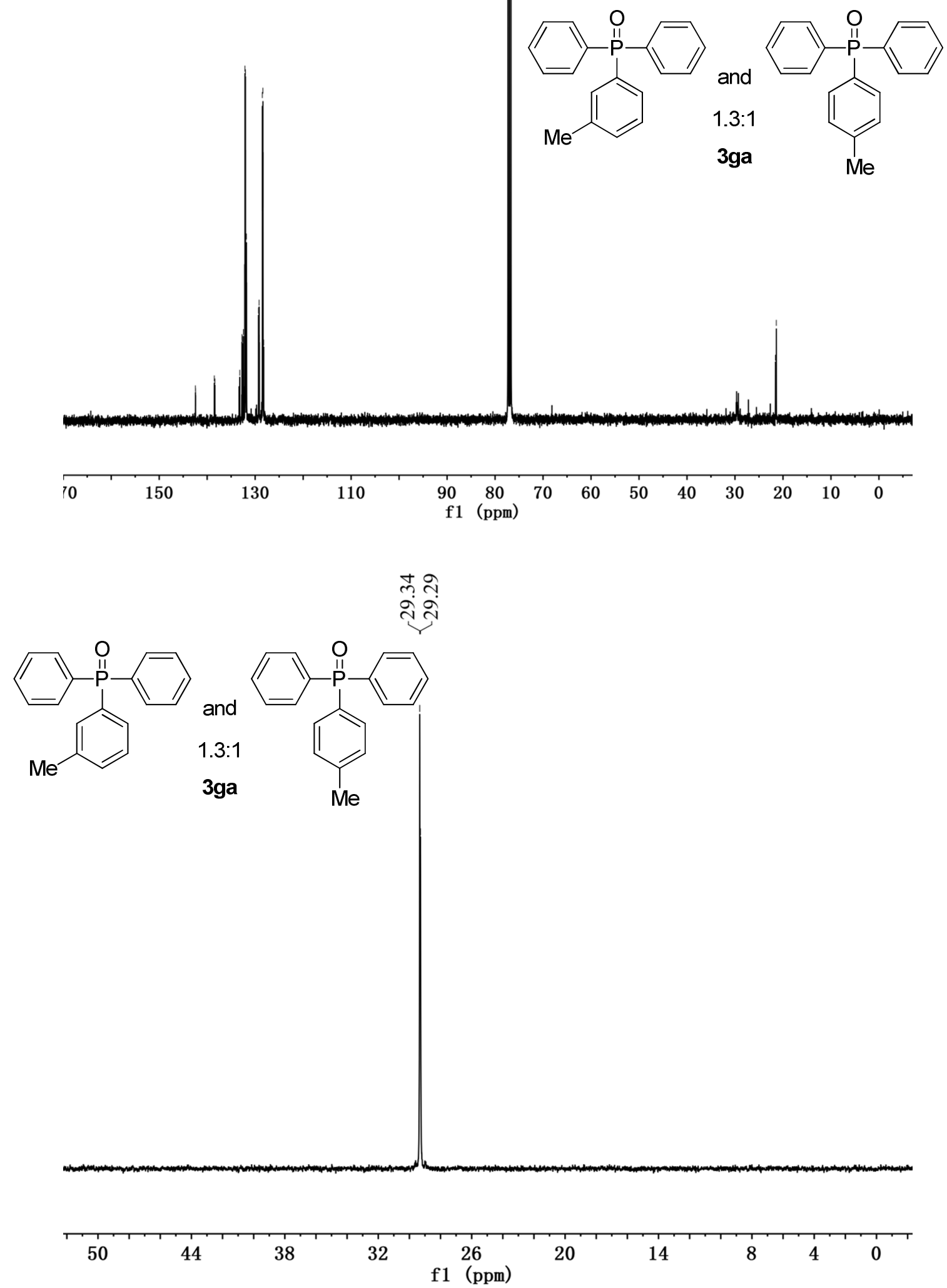